\title{
Revisão de Crenças em Lógicas de Descrição - Um Plug-In para o Protégé
}

Fillipe Manoel Xavier Resina

\author{
DisSERTAÇÃO APRESENTADA \\ $A O$ \\ Instituto De Matemática e Estatística \\ DA \\ Universidade De SÃo Paulo \\ PARA \\ OBTENÇÃO DO TÍTULO \\ $\mathrm{DE}$ \\ Mestre em CiÊnCIAS
}

Programa: Pós-Graduação em Ciência da Computação

Orientadora: Profa. Dra. Renata Wassermann

Durante o desenvolvimento deste trabalho o autor recebeu auxílio financeiro da FAPESP

São Paulo, abril de 2014 


\section{Revisão de Crenças em Lógicas de Descrição - Um Plug-In para o Protégé}

Esta versão da dissertação contém as correções e alterações sugeridas pela Comissão Julgadora durante a defesa da versão original do trabalho, realizada em 07/04/2014. Uma cópia da versão original está disponível no

Instituto de Matemática e Estatística da Universidade de São Paulo.

Comissão Julgadora:

- Profa. Dra. Renata Wassermann (orientadora) - IME-USP

- Prof. Dr. Marcelo Finger - IME-USP

- Prof. Dr. Eduardo Fermé - UMa-Portugal 


\section{Agradecimentos}

O trabalho de pesquisa em Pós-graduação não é uma caminhada simples, mas certamente pode ser gratificante. Sem sobra de dúvida, considero que, entre os fatores do sucesso, está o apoio, o auxílio e o carinho de pessoas especiais, sem as quais o labor seria muito mais difícil, talvez impossível.

Em primeiro lugar, agradeço a Deus, o Doador da vida e de toda sabedoria. Sem Sua graça, amizade, paz, alegria, amor e condução, eu jamais teria chegado até aqui.

Agradeço também aos meus pais, que por toda a vida me encorajaram a buscar uma formação e nunca me acomodar. Sustentaram-me não apenas financeiramente, mas com amor, cuidado, conselhos e com suas orações. Obrigado por me apoiarem nessa decisão de continuar os estudos acadêmicos.

Outra peça fundamental neste trabalho é, com certeza, o trabalho da minha orientadora. Obrigado, professora, por me mostrar que a vida acadêmica não precisa ser, como muitos pensam e sentem, enfadonha e sufocante, mas pode ser prazerosa e extremamente construtiva. Cada reunião de orientação foi um momento importante e motivador, pois sempre saí delas motivado e cheio de ideias. Juntamente com ela, o Prof. Dr. Márcio Ribeiro acompanhou este trabalho desde o início, dando também ideias, fazendo críticas construtivas, auxiliando a pensar nos algoritmos e a ter uma visão maior da área. Obrigado a vocês pela paciência de sempre e por saberem me encorajar e me ajudar a melhorar.

Agradeço, também, aos meus irmãos e a todos meus amigos, que sempre torceram pelo meu sucesso e me apoiaram. Entre eles, não poderia deixar de citar meus amigos e colegas do laboratório LIAMF, os quais diariamente estavam ali comigo nesta empreitada acadêmica. Obrigado pelo apoio, pelos conselhos, pelo auxílio mútuo e por naturalmente me ajudarem a encontrar o equilíbrio entre o trabalho e o descanso.

A todos vocês dedico meus sinceros agradecimentos. 


\section{Resumo}

As Lógicas de Descrição são usadas como base para a linguagem OWL, padrão para representação de ontologias na web. No entanto, conhecimento não é estático e, com tal dinamismo, o estudo de revisão de crenças e sua correta e adequada aplicação tornam-se muito importantes. Neste trabalho, pretendemos desenvolver uma ferramenta para revisão de ontologias como um plug-in para o Protégé, o editor de ontologias mais utilizado atualmente.

Palavras-chave: Lógicas de Descrição, ontologia, revisão de crenças, contração múltipla, Protégé, OWL, depuração de ontologias 


\section{Abstract}

Description Logics are the basis for OWL language, which is the standard to represent ontologies on the web. However, knowledge is usually not satic and its dynamics brings the importance of belief revision and its correct and proper application. In this work, we intend to develop a tool for revising ontologies as a plug-in for Protégé, the most used ontology editor nowadays.

Keywords: Description Logics, ontology, belief revision, multiple contraction, Protégé, OWL, ontology debugging 



\section{Sumário}

1 Introdução $\quad \mathbf{1 3}$

1.1 Motivação e contribuição . . . . . . . . . . . . . . . . . 13

1.2 Organização do trabalho . . . . . . . . . . . . . . . . . 13

1.3 Notação . . . . . . . . . . . . . . . . . . . . . . . . . . . . . . . 14

2 Revisão de Crenças $\quad 15$

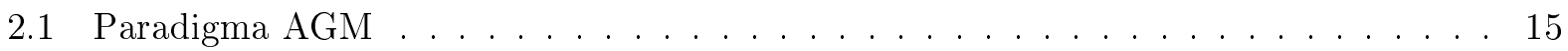

2.1.1 Suposições AGM e Conjuntos de Crenças . . . . . . . . . . . . . . . . 15

2.1.2 Mudanças Epistêmicas . . . . . . . . . . . . . . . . . 16

2.2 Bases de crença . . . . . . . . . . . . . . . . . . . . . 17

2.2 .1 Postulados para Contração . . . . . . . . . . . . . . . . . . 17

2.3 Contração Partial Meet . . . . . . . . . . . . . . . . . . . . 18

2.4 Contração Kernel . . . . . . . . . . . . . . . . . . . . . . . . . . . . . 19

2.5 Algoritmo para Kernel . . . . . . . . . . . . . . . . . . . . . 20

2.6 Revisão de bases de crenças . . . . . . . . . . . . . . . . . . 21

3 Contração Múltipla $\quad 23$

3.1 Extensão de contração simples para múltipla . . . . . . . . . . . . . . . . . . 23

3.2 Motivações . . . . . . . . . . . . . . . . . . . . . 23

3.3 Postulados e propriedades básicas de contração múltipla . . . . . . . . . . . . . . 24

3.4 Contração Múltipla Partial Meet . . . . . . . . . . . . . . . . . . 26

3.5 Contração Múltipla Kernel . . . . . . . . . . . . . . . . . . . . . . . 27

4 Revisão de Ontologias $\quad 29$

4.1 Ontologias . . . . . . . . . . . . . . . . . . . . . . . 29

4.2 Lógicas de Descrição . . . . . . . . . . . . . . . . . . . . 30

4.2 .1 Representação . . . . . . . . . . . . . . . . . . . . . 30

4.2 .2 Serviços de Inferência . . . . . . . . . . . . . . . . . . . . . 33

4.3 Revisão em Lógicas de Descrição e Depuração de Ontologias . . . . . . . . . . . . . . 35

5 Revisor de Ontologias para o Protégé $\quad 37$

5.1 O programa e a motivação do plug-in . . . . . . . . . . . . . . . . . . 37

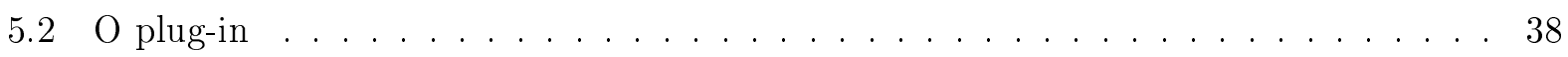

5.2 .1 Instruções de uso . . . . . . . . . . . . . . . . . . . . . . 38

5.2 .2 Organização do código-fonte . . . . . . . . . . . . . . . . . . 41 
5.3 Revisão . . . . . . . . . . . . . . . . . . . . . 43

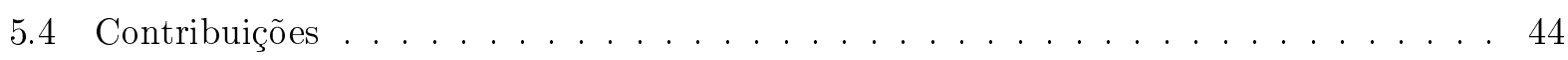

6 Partial Meet e Contração Múltipla $\quad 47$

6.1 Operações por Partial Meet . . . . . . . . . . . . . . . . . . . . . . . 47

6.1.1 Algoritmo, correção e completude . . . . . . . . . . . . . . . . . 47

6.1 .2 Implementação . . . . . . . . . . . . . . . . . . . . . . . . . . . . . . 49

6.2 Algoritmos para contração múltipla . . . . . . . . . . . . . . . . . . . . 49

6.2 .1 Kernel Package . . . . . . . . . . . . . . . . . . . . . . . . 51

6.2 .2 Kernel Choice . . . . . . . . . . . . . . . . . . . . . 58

$6.2 .3 \quad$ Partial Meet Package . . . . . . . . . . . . . . . . . . . . . . . 62

6.2 .4 Partial Meet Choice . . . . . . . . . . . . . . . . . . . . . 64

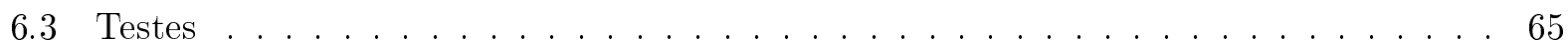

6.3.1 Kernel pequeno e Resíduo grande . . . . . . . . . . . . . . . . . 65

6.3.2 Resíduo pequeno e Kernel grande . . . . . . . . . . . . . . . . . . . 67

6.3 .3 Comparação entre implementações . . . . . . . . . . . . . . . . 68

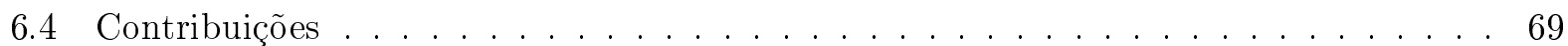

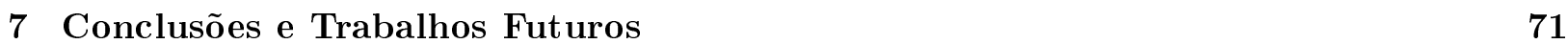

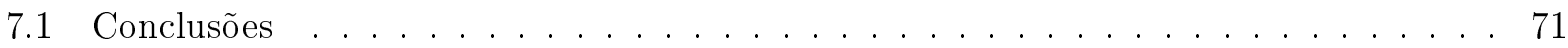

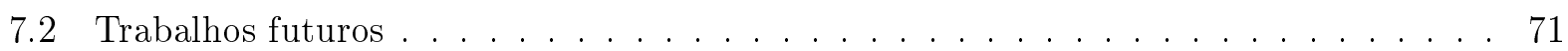




\section{Lista de Figuras}

4.1 Diagrama de uma ontologia que representa conhecimento sobre pessoas e parentescos 30

5.1 Localização do plug-in nos menus do Protégé . . . . . . . . . . . . . . . . . . . . . 38

5.2 Ontologia sobre aves e pinguins representada no Protégé . . . . . . . . . . . . . . . . 39

5.3 Tela inicial do plug-in para contração . . . . . . . . . . . . . . . . . . . . . . 39

5.4 Plug-in recebendo textualmente a sentença pela qual operará contração . . . . . . . . 40

5.5 Kernel resultante da contração da ontologia pela sentença pedida . . . . . . . . . . . 41

5.6 Resultado da ontologia contraída de acordo com a escolha do usuário . . . . . . . . . 42

5.7 Tela inicial do plug-in para revisão . . . . . . . . . . . . . . . . . . . . . . . . 43

5.8 Plug-in recebendo textualmente a sentença pela qual operará revisão . . . . . . . . . . 43

5.9 Kernel resultante da revisão da ontologia pela sentença pedida . . . . . . . . . . . . . 44

5.10 Modo de visualização dos axiomas dos $\alpha$-kernels nas versões anteriores do plug-in 45

5.11 Modo de visualização dos axiomas dos $\alpha$ - kernels na versão atual do plug-in . . . . 46

6.1 Plug-in recebendo textualmente a sentença pela qual operará contração . . . . . . . . 50

6.2 Conjunto resíduo resultante da contração da ontologia pela sentença pedida . . . . . . 50

6.3 Seleção dos elementos do conjunto resíduo sobre os quais se deseja que seja operada a intersecção . . . . . . . . . . . . . . . . . . . . . . . . . . . . 51

6.4 Ontologia das pizzas modelada a partir do tutorial do Protégé . . . . . . . . . . . . . 53

6.5 Tela inicial do plug-in com funcionalidade para contração múltipla . . . . . . . . . . 53

6.6 Exemplo de adição de 2 axiomas ao conjunto pelo qual queremos contrair . . . . . . . 54

6.7 Exemplo de remoção de um axioma antes de dar prosseguimento à operação de contração ................................ 55

6.8 Exemplificação de como adicionar sentenças e finalizar para dar prosseguimento à contração . . . . . . . . . . . . . . . . . . . . . . . . . . . . . 56

6.9 Conjunto Kernel resultante da contração múltipla package pelas sentenças selecionadas 56

6.10 Ontologia após ser aplicada contração Kernel package . . . . . . . . . . . . . . . . 57

6.11 Exemplo de contração múltipla usando união de conceitos . . . . . . . . . . . . . . . 57

6.12 Conjunto Kernel resultante da contração múltipla package pelas sentenças selecionadas 58

6.13 Ontologia após ser aplicada contração Kernel package . . . . . . . . . . . . . . . . . . 59

6.14 Inserção de sentenças para executar uma contração múltipla choice . . . . . . . . . . 60

6.15 Kernel resultante da operação de contração múltipla choice pelas sentenças escolhidas 61

6.16 Ontologia modelada para testar a execução de contração múltipla choice. . . . . . . . 61

6.17 Kernel resultante da operação de contração múltipla choice pelas sentenças escolhidas 62

6.18 Estado final da ontologia após a execução da contração . . . . . . . . . . . . . . . . . 62 


\section{Capítulo 1}

\section{Introdução}

O problema de representação de conhecimento é uma área na intersecção entre as pesquisas atuais em Filosofia, Inteligência Artificial e Ciência Cognitiva. Nesse contexto, encontramos as ontologias como grandes aliadas, pois são elas que nos fornecem uma representação formal do conhecimento ao descreverem conceitos e relacionamentos que são importantes em um domínio particular. Existem softwares para edição de ontologias e o principal tem sido o Protégé ${ }^{1}$, software livre que permite criar e editar ontologias. Além de oferecer uma interface gráfica, é possível exportar em diversos formatos a base de conhecimento criada.

A lógica é a base para a maioria dos formalismos de representação de conhecimento. Nesse campo, as Lógicas de Descrição ganharam muita importância. Elas são um subconjunto estruturado e decidível da Lógica de Primeira Ordem e, apesar de serem menos expressivas que esta última, possuem grande capacidade de representação para sistemas baseados em conhecimento. Ainda associados a elas, também encontramos métodos eficientes de raciocínio e inferência. As Lógicas de Descrição tornaram-se um dos principais formalismos de representação, tendo sido adotadas como base para a linguagem OWL (Web Ontology Language), a linguagem padrão para representação de ontologias na web.

Muito se discute também sobre o dinamismo do conhecimento, seja na web ou em outros campos. Para essa questão, encontramos o estudo de revisão de crenças [AGM85]. Em um âmbito mais geral, a teoria de revisão de crenças é desenvolvida e estudada a fim de descrever como um agente, baseado em procedimentos racionais e munido de um conjunto de crenças, deve mudá-lo, quando confrontado com novas informações, sejam esses agentes seres humanos, programas de computador ou sistemas. Segundo Gärdenfors [Gar88, p. ix], solucionar o problema de encontrar uma representação de conhecimento apropriada é de pouca ajuda se não se souber como evoluir os estados epistêmicos à luz de novas informações. Para as ontologias, aplicar um método eficiente de revisão de crenças, ou seja, que elimine inconsistências e provoque mudanças mínimas, é essencial. Portanto, faz-se necessário que ferramentas tais como o Protégé tenham essa capacidade, interagindo com o usuário na revisão de sua ontologia.

\subsection{Motivação e contribuição}

Os objetivos do nosso trabalho são dar continuidade ao estudo de revisão de crenças em Lógicas de Descrição iniciado em [Rib10] e aplicá-lo no desenvolvimento de uma ferramenta para revisão de ontologias como um plug-in para o Protégé.

\subsection{Organização do trabalho}

Este trabalho está dividido da forma descrita a seguir. O Capítulo 2 contém um resumo da fundamentação teórica de Revisão de Crenças e o Capítulo 3, de contração múltipla. O Capítulo

\footnotetext{
${ }^{1}$ http://protege.stanford.edu/doc/owl/getting-started.html
} 
4 foi dedicado às Lógicas de Descrição e Revisão de Ontologias. No Capítulo 5, apresentamos o programa Protégé e detalhes do desenvolvimento do plug-in, bem como instruções acerca do uso do mesmo e um exemplo. No Capítulo 6, expusemos os algoritmos desenvolvidos para as operações de Partial Meet e também de contração múltipla, junto com a demonstração destas novas funcionalidades no plug-in. Apresentamos, também, alguns testes realizados. Por fim, no Capítulo 7, apresentamos as conclusões e possíveis trabalhos futuros.

\subsection{Notação}

Definiremos aqui os símbolos que usaremos ao longo deste trabalho. Para conjuntos e bases, usaremos letras maiúsculas A, B, C...; para fórmulas e sentenças, usaremos letras gregas minúsculas $\alpha, \beta$, etc.

Nos propósitos desta dissertação, uma lógica é um par $\langle\mathcal{L}, C n\rangle$ em que $\mathcal{L}$ é a linguagem da lógica e $C n$ o seu operador de consequência. Assim, se $\mathcal{L}$ é o conjunto de todas as sentenças aceitas na lógica, $C n$ é uma função que leva um conjunto de sentenças $A \in 2^{\mathcal{L}}$ ao conjunto de suas consequências lógicas $C n(A)$. Para consequência lógica, podemos definir dois operadores. Para conjuntos de sentenças $A$ e $B$ quaisquer:

1. $A \vdash B \Longleftrightarrow B \cap C n(A) \neq \emptyset$

2. $A \Vdash B \Longleftrightarrow B \subseteq C n(A)$

Para sentenças unitárias no lado direito, as duas relações coincidem:

$$
A \vdash \alpha \Longleftrightarrow A \Vdash \alpha(\Longleftrightarrow \alpha \in C n(A))
$$




\section{Capítulo 2}

\section{Revisão de Crenças}

\subsection{Paradigma AGM}

A maior parte da bibliografia sobre Revisão de Crenças está baseada no paradigma AGM, teoria que se tornou célebre no famoso artigo [AGM85] e cujo nome deriva das iniciais dos sobrenomes de seus autores. O objeto de estudo dessa teoria é a dinâmica das crenças, ou seja, como um agente deve acomodar novas informações de maneira consistente ou então remover alguma informação de uma base de conhecimento.

O estado epistêmico de um agente pode ser representado de várias formas. Em $A G M$, ele é representado como um conjunto de crenças (conjunto logicamente fechado de sentenças), forma de representação detalhada a seguir.

\subsubsection{Suposições AGM e Conjuntos de Crenças}

Supomos definida uma lógica $\mathcal{L}$ com as ideias de consequência lógica e consistência definidas. Boa parte da literatura de revisão de crenças assume que essa lógica satisfaz algumas propriedades conhecidas como suposições $A G M$. Assume-se que $\mathcal{L}$ é fechada pelos conectivos lógicos convencionais $(\wedge, \vee, \rightarrow$ e $\neg)$ e que $\langle\mathcal{L}, C n\rangle$ é:

- tarskiana: a lógica é monotônica ${ }^{1}$, idempotente $(C n(A)=C n(C n(A)))$ e satisfaz inclusão $(A \subseteq C n(A))$;

- compacta: uma lógica $\langle\mathcal{L}, C n\rangle$ é dita compacta se e somente se para todo $B \in 2^{\mathcal{L}}$ se $\alpha \in C n(B)$ então existe $B^{\prime} \subseteq B$ finito tal que $\alpha \in C n\left(B^{\prime}\right)$

- supra-clássica: toda consequência da lógica proposicional clássica é consequência de $\langle\mathcal{L}, C n\rangle$ Além disso, também se assume que essa lógica satisfaz o teorema da dedução, no qual $\alpha \in$ $C n(K \cup\{\beta\})$ se e somente se $\beta \rightarrow \alpha \in C n(K)$.

Alguns critérios de racionalidade são desejados para conjuntos de crenças. Por exemplo, que as consequências lógicas do que é aceito também devem ser aceitas, ou seja, as crenças implícitas.

Definição 1 Um conjunto de sentenças $K$ é um conjunto de crenças se e somente se $K$ for logicamente fechado, ou seja, se $K \vdash \beta$, então $\beta \in K$.

A definição acima implica que todos os conjuntos de crenças satisfazem a condição que expressa a ideia de equilíbrio dos estados epistêmicos, ou seja, para um conjunto de crenças $K, K=C n(K)$.

As atitudes epistêmicas ligadas a conjuntos de crenças definem que, dado um conjunto $K$ e para qualquer sentença $\alpha$, existem 3 tipos de atitude:

\footnotetext{
${ }^{1}$ Sendo $A, B \in 2^{\mathcal{L}}$ e $C n$ um operador de consequência, o operador de consequência satisfaz monotonicidade se vale a propriedade: se $A \subseteq B$ então $C n(A) \subseteq C n(B))$.
} 
- $\alpha$ é aceita $(\alpha \in K)$

- $\alpha$ é rejeitada $(\neg \alpha \in K)$

- $\alpha$ é indeterminada, ou seja, nem aceita nem rejeitada $(\alpha \in K$ e $\neg \alpha \in K)$

\subsubsection{Mudanças Epistêmicas}

Os três tipos básicos de mudança epistêmica são expansão, revisão e contração. Nesta subseção e nas próximas, trataremos dessa dinâmica das crenças, expondo suas propriedades e definindo operadores para as mesmas.

As operações de mudança de crença são definidas por meio de construções matemáticas. Para delimitar as propriedades às quais os operadores devem obedecer, a teoria AGM define os chamados postulados de racionalidade, tanto para as operações de contração quanto de revisão, além de fornecer construções para elas. A conexão entre os postulados e as construções, demonstrando suas equivalências, é dada pelos teoremas de representação.

Considerando as atitudes epistêmicas definidas na subseção anterior, uma mudança de crença em relação a uma sentença $\alpha$ pode ser definida como uma mudança de uma das atitudes epistêmicas para uma das outras duas, ou seja:

Expansão: $\alpha$ era indeterminada e agora $\alpha$ é aceita

Contração: $\alpha$ era aceita e agora $\alpha$ é indeterminada

Revisão: $\alpha$ era rejeitada e passa a ser aceita

A expansão é a forma de representar, entre as possíveis mudanças epistêmicas, como aprender algo novo, ou seja, passar a aceitar uma crença antes considerada indeterminada, mas sem retirar nenhuma outra anteriormente já presente. Ainda, além de adicionar ao conjunto de crenças a nova sentença, adicionam-se também suas consequências junto às sentenças previamente aceitas.

Seja $K$ um conjunto de crenças e $\alpha$ uma nova sentença a ser adicionada ao conjunto. A expansão é representada pela função + e é definida como:

$$
K+\alpha=C n(K \cup\{\alpha\})
$$

Ao contrário da expansão, contração e revisão não são definidas de modo único e mais à frente veremos suas variantes.

Seja a contração representada pela função -. Apresentaremos a seguir os postulados básicos para essa operação.

Seja $K$ um conjunto de crenças e $\alpha$ a sentença que desejamos extrair do mesmo. É desejável que a operação seja bem sucedida, ou seja, a menos que $\alpha$ seja uma tautologia, não queremos que ela seja uma consequência lógica das sentenças que permanecerem em $K-\alpha$ :

(sucesso) $\nvdash \alpha \Rightarrow \alpha \notin K-\alpha$

Como a proposta da contração é desistir de alguma crença, não deve haver novas sentenças no conjunto resultante da operação:

(inclusão) $K-\alpha \subseteq K$

O postulado do fecho determina que, para qualquer sentença $\alpha$ e qualquer conjunto de crenças $K, K-\alpha$ é um conjunto de crenças.

(fecho) $K-\alpha=C n(K-\alpha)$

Se a sentença que desejamos contrair não está no conjunto, então a operação é nula:

(vacuidade) $\alpha \notin K \Rightarrow K-\alpha=K$ 
O próximo postulado estabelece que todas as crenças de $K$ são recuperadas quando o contraímos por $\alpha$ e, em seguida, fazemos a expansão do conjunto contraído também por $\alpha$ :

(recuperação) $K \subseteq(K-\alpha)+\alpha$

Se duas sentenças são logicamente equivalentes, o resultado da contração por uma ou por outra deve ser o mesmo:

(extensionalidade) Se $C n(\alpha)=C n(\beta)$ então $K-\alpha=K-\beta$

Isaac Levi [Lev77] apresentou um processo pelo qual a revisão pode ser obtida por meio de uma contração seguida de uma expansão, processo este conhecido como a identidade de Levi. Considerando que a função * representa a revisão, formalmente temos:

$$
K * \alpha=(K-\neg \alpha)+\alpha
$$

Assim, por meio dessa identidade, a operação de revisão pode ser obtida a partir da contração. Portanto, vamos apresentar aqui apenas uma construção, a de contração. Para mais detalhes sobre as relações entre contração e revisão, veja [Gar88]. As construções para essa operação serão apresentadas, em outra seção, para bases de crença, sobre as quais discorreremos a seguir.

\subsection{Bases de crença}

Até o momento, referimo-nos apenas a conjuntos de crenças, em acordo com o paradigma AGM. No entanto, eles não são adequados aos nossos propósitos neste trabalho. Um desses propósitos é trazer uma abordagem computacional à revisão de crenças em lógicas de descrição. Geralmente, os conjuntos de crenças são infinitos, o que torna impossível sua manipulação computacional. Além disso, em conjuntos de crenças não temos distinção entre conhecimento explícito e implícito, ou seja, não diferenciamos o conhecimento já presente de antemão daquilo que inferimos a partir do mesmo. Ainda em conjuntos, sempre que precisássemos executar operações de revisão ou contração, precisaríamos considerar muitas sentenças que são, na realidade, consequências das sentenças inicialmente presentes no conjunto e que estão nele por serem geradas pelo fecho lógico; logo, precisaríamos considerar sentenças "irrelevantes" para a operação em questão, dada a dimensão atingida pelo conjunto na aplicação do fecho.

Assim, ao invés de trabalhar somente com conjuntos de crenças, alguns autores passaram a trabalhar com bases de crença, que são bases de conhecimento não necessariamente fechadas. Assim, para implementações práticas de operações de revisão, utilizar bases de crenças finitas ou contáveis é mais conveniente.

Neste contexto, nosso principal propósito é estudar e investigar a relação entre a teoria de bases de crenças e a implementação das operações, o que veremos adiante por meio dos algoritmos.

Neste trabalho, consideramos o modelo de bases proposto por Hansson [Han91a].

\subsubsection{Postulados para Contração}

Apresentamos a seguir os postulados básicos para contração em bases de crenças. A contração continuará a ser representada pela função - e $B$ representará uma base de crenças.

Uma contração é realizada quando se deseja retirar alguma informação $\alpha$ da uma base de crença $B$. Então, a menos que $\alpha$ seja uma tautologia, a base resultante da operação não mais implicará $\alpha$, o que é expresso por meio do postulado de sucesso:

(sucesso) $\nvdash \alpha \Rightarrow B-\alpha \nvdash \alpha$

Além disso, é assumido na literatura que a base resultante deve ser um subconjunto da base de crença original, dado que na contração não ocorre adição de nenhuma sentença. Isso nos leva ao postulado da inclusão: 
(inclusão) $B-\alpha \subseteq B$

Uma das características do paradigma AGM é o Princípio da Mudança Mínima, ou seja, ao remover $\alpha$ de sua base, não queremos remover sentenças desnecessariamente, mas sim provocar o mínimo de mudança possível na mesma. Em AGM, essa propriedade é expressa por meio do postulado de recuperação, abordado na seção anterior. No entanto, usaremos aqui outros postulados de minimalidade já apresentados [Han99], uma vez que na literatura há controvérsias na discussão de recuperação como um princípio geral para contração. Além disso, esse postulado também foi considerado não adequado para bases de crença [Han91b, Mak87]. Apresentamos, então, os dois postulados a seguir:

(relevância) Se $\beta \in B$ e $\beta \notin B-\alpha$, então existe $B^{\prime}$ tal que $B-\alpha \subseteq B^{\prime} \subseteq B$ e $B^{\prime} \nvdash \alpha$, mas $B^{\prime} \cup\{\beta\} \vdash \alpha$

(core-retainment) Se $\beta \in B$ e $\beta \notin B-\alpha$, então existe $B^{\prime}$ tal que $B^{\prime} \subseteq B$ e $B^{\prime} \nvdash \alpha$, mas $B^{\prime} \cup\{\beta\} \vdash \alpha$

Esses postulados estabelecem que só serão removidas de $B$ as sentenças $\beta$ que são relevantes para implicar $\alpha$. Core-retainment é uma versão mais fraca (e, portanto, mais geral) de relevância, visto que, ao invés de requerer $B^{\prime}$ alocado entre $B-\alpha$ e $B$, requeremo-lo apenas como subconjunto de $B$.

Outra propriedade tida como desejável na teoria AGM é que sentenças logicamente equivalentes sejam tratadas da mesma forma, como vimos no postulado de extensionalidade. No entanto, quando olhamos para bases de crença, vemos que a propriedade de extensionalidade não é suficiente pois pode gerar resultados não intuitivos (para um exemplo, veja [RW09]). Para servir, então, a esse propósito das sentenças equivalentes, o postulado de uniformidade garante um tratamento mais coerente das mesmas:

(uniformidade) Se para todos os subconjuntos $B^{\prime}$ de $B, B^{\prime} \vdash \alpha \Leftrightarrow B^{\prime} \vdash \beta$, então $B-\alpha=B-\beta$

A seguir, serão apresentadas duas construções para a operação de contração, já utilizando bases. $\mathrm{Na}$ literatura, podemos encontrar a discussão dessas operações em [Han99].

\subsection{Contração Partial Meet}

A contração Partial Meet foi primeiramente sugerida em [AM82], sendo aprofundada em [AGM85] e posteriormente generalizada para bases. Uma contração partial meet de uma base $B$ por $\alpha$ busca encontrar os subconjuntos maximais de $B$ que não implicam $\alpha$ e realizar a intersecção de alguns deles. Para isso, utiliza-se o conceito de conjunto resíduo:

Definição 2 Sendo $B$ uma base de crenças, um conjunto $B^{\prime}$ é um subconjunto maximal de $B$ que não implica $\alpha$ se e somente se:

- $B^{\prime}$ é um subconjunto de $B\left(B^{\prime} \subseteq B\right)$

- $B^{\prime} \nvdash \alpha$

- Se $B^{\prime} \subset B^{\prime \prime} \subseteq B$, então $B^{\prime \prime} \vdash \alpha$

$O$ conjunto de todos os subconjuntos maximais de $B$ que não implicam $\alpha$ (conjunto resíduo) é denotado por $B \perp \alpha$ e cada elemento desse conjunto é chamado de $\alpha$-resíduo de $B$.

Encontrados todos os $\alpha$-resíduos, precisamos escolher alguns deles. Para isso, usamos a definição de função de seleção: 
Definição 3 Seja $\mathcal{L}$ uma linguagem e $B$ uma base de crenças nesta linguagem. Tem-se que, para qualquer sentença $\alpha$, uma função de seleção para $B$ é uma função $\gamma$ tal que para qualquer sentença $\alpha \in \mathcal{L}:$

- se $B \perp \alpha \neq \emptyset$, então $\gamma(B \perp \alpha) \neq \emptyset$ e $\gamma(B \perp \alpha) \subseteq B \perp \alpha$

- se $B \perp \alpha=\emptyset, \gamma(B \perp \alpha)=\{K\}$

Informalmente dizendo, podemos obter o resultado da contração escolhendo alguns elementos de $B \perp \alpha$ e tomando sua interseç̧ão. Formalizando a definição:

Definição 4 Seja $B$ uma base de crenças, $\alpha$ uma sentença qualquer e $\gamma$ uma função de seleção. Definimos a função de contração Partial Meet como $B-\alpha=\bigcap \gamma(B \perp \alpha)$.

Teorema de Representação 1 [Han92] Uma operação - satisfaz sucesso, inclusão, relevância e uniformidade se e somente se é uma contração Partial Meet para alguma $\gamma$.

\subsection{Contração Kernel}

Essa operação foi definida em [Han94] e aborda o problema de uma forma diferente. A ideia é encontrar os subconjuntos minimais de $B$ que implicam $\alpha$ e, então, retirar pelo menos um elemento de cada subconjunto encontrado. O conceito utilizado aqui é de conjunto kernel:

Definição 5 Sendo B uma base de crenças, um conjunto $B$ 'é um subconjunto minimal de $B$ que implica $\alpha$ se e somente se:

- $B^{\prime}$ é um subconjunto de $B\left(B^{\prime} \subseteq B\right)$

- $B^{\prime} \vdash \alpha$

- se $B^{\prime \prime} \subset B^{\prime}$ então $B^{\prime \prime} \nvdash \alpha$

$O$ conjunto de todos os subconjuntos minimais de $B$ que implicam $\alpha$ (chamado de conjunto kernel) é denotado por $B \Perp \alpha$ e cada elemento desse conjunto é chamado de $\alpha$-kernel de $B$.

A ação de retirar pelo menos um elemento de cada $\alpha$-kernel vem por meio da função de incisão:

Definição 6 Seja $\mathcal{L}$ uma linguagem e $B$ uma base de crenças nesta linguagem. Tem-se que, para qualquer sentença $\alpha$, uma função de incisão para $B$ é uma função $\sigma$ tal que, para qualquer sentença $\alpha \in \mathcal{L}$, satisfaz:

- $\sigma(B \Perp \alpha) \subseteq \bigcup(B \Perp \alpha) e$

- se $\emptyset \neq X \in B \Perp \alpha$ então $X \cap \sigma(B \Perp \alpha) \neq \emptyset$

Assim, podemos definir a operação:

Definição 7 Seja $B$ uma base de crenças, $\alpha$ uma sentença qualquer e $\sigma$ uma função de incisão. Definimos a função de contração Kernel como $B-{ }_{\sigma} \alpha=B \backslash \sigma(B \Perp \alpha)$

Teorema de Representação 2 [Han94] O operador - é uma contração Kernel se e somente se satisfaz os seguintes postulados para contração: sucesso, inclusão, core-retainment e uniformidade. 


\subsection{Algoritmo para Kernel}

Nesta seção, descreveremos como encontrar o conjunto kernel e, a partir dele, o conjunto resíduo.

O Kernel pode ser computado usando uma técnica conhecida na literatura como Black-Box [Kal06, Rib10]. O algoritmo Black-Box não depende do motor de inferências, isto é, chama-o como subrotina mas sem alterar sua estrutura interna, o que justifica o nome do algoritmo. Por isso, o método Black-Box independe da lógica subjacente. A estratégia aplicada nesse método é conhecida como Expande-Encolhe.

Seja $B$ uma base de crenças. Para a operação de contração, são adicionados, na parte expansão do algoritmo, axiomas (sentenças de $B$ ) a um conjunto $B^{\prime}$ inicialmente vazio até que esse conjunto implique $\alpha$. Depois, ao encolher, remove-se cada elemento de $B^{\prime}$ separadamente e verifica-se, a cada remoção, se o novo conjunto continua implicando $\alpha$. Em caso afirmativo, aquele axioma não era crucial para inferir $\alpha$ e realmente deve ser removido. Em caso negativo, o axioma retirado deve fazer parte do Kernel e volta ao conjunto. Dessa forma, o conjunto devolvido é um conjunto minimal de $B$ que implica $\alpha$ e, consequentemente, um elemento do Kernel.

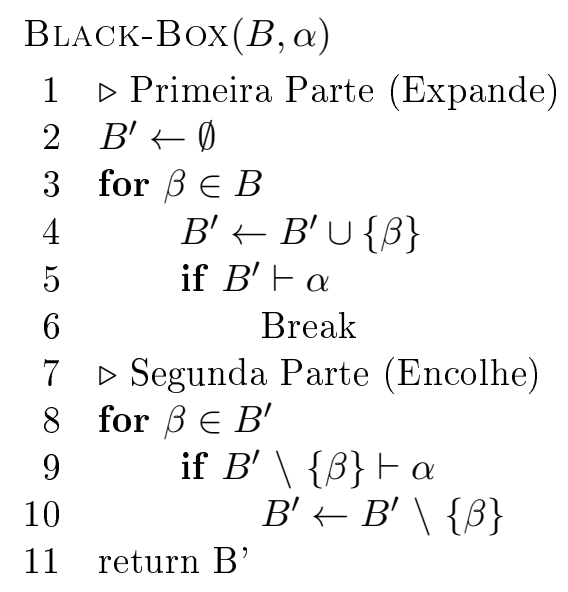

O que garante a correção do algoritmo (conjuntos realmente minimais) é a segunda parte, isto é, o "Encolhe". Esta parte poderia ser aplicada diretamente na base $B$, mas o tamanho de $B$ poderia tornar esta tarefa inviável e é nesse ponto que entra a importância da primeira parte.

Então, o que temos até aqui é um elemento do Kernel, obtido com o algoritmo BlAcK-Box. No entanto, precisamos de todos os elementos. Para isso, usaremos uma aplicação do algoritmo de Reiter [Rei87]. Tal algoritmo calcula os os cortes mínimos de uma classe de conjuntos (conjunto de conjuntos).

Definição 8 Um corte em uma classe $\mathfrak{S}$ de conjuntos é um conjunto $C$ cuja intersecção com cada conjunto da classe $\mathfrak{S}$ não é vazia. Um corte $C$ é minimo se e somente se não existe nenhum corte $C^{\prime}$ propriamente contido em $C$.

Em [Was00] foi apresentada uma adaptação do algoritmo de Reiter, ideia esta aplicada em Lógica de Descrição e depuração de ontologias por outros autores. Utilizaremos, aqui, a adaptação apresentada em [Rib10], na forma de um algoritmo iterativo equivalente ao algoritmo recursivo apresentado em [RW08] e [RW09]. No caso específico de contração: 


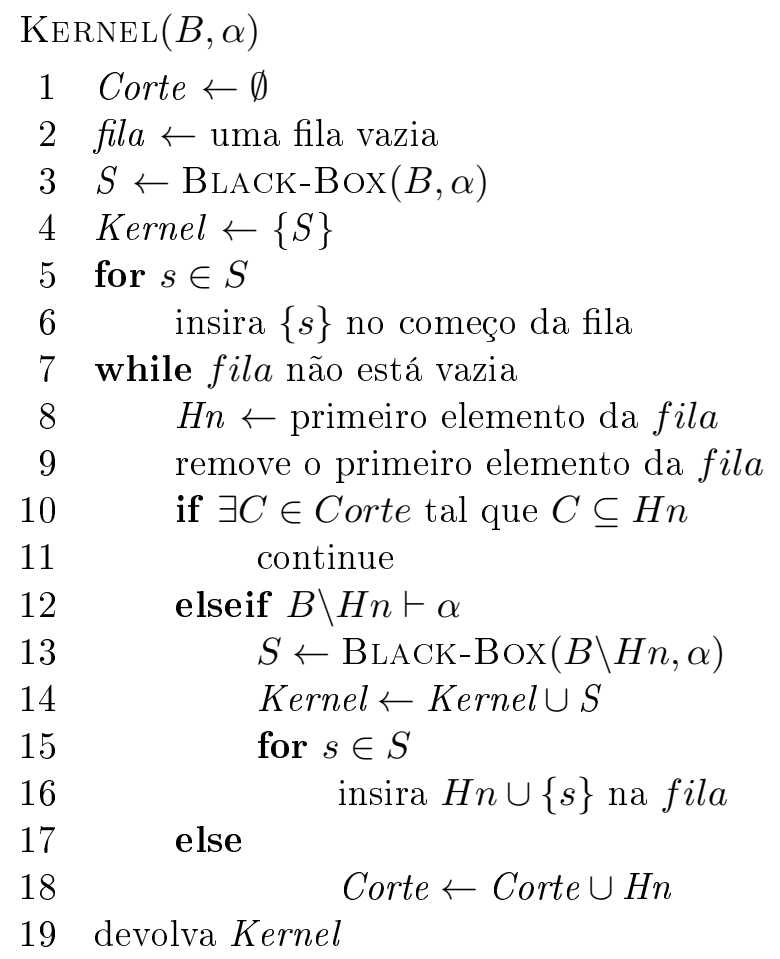

Como apresentado acima, iniciamos com um elemento do Kernel. Hn recebe um provável corte minimal mas, se algum corte está inteiramente contido em $H n$, este último ou não é minimal ou já havia sido encontrado, o que nos permite desconsiderá-lo e partir para o próximo elemento da fila. Caso contrário, se $B \backslash H n$ não implicar $\alpha, H n$ é um corte minimal no Kernel. Porém, se $B \backslash H n$ implicar $\alpha$, computa-se o menor subconjunto $S$ de $B \backslash H n$ que implica $\alpha$ e temos em $S$ um novo elemento do Kernel; ainda nesse caso, sendo $s$ cada elemento de $S$, temos $H n \cup\{s\}$ um corte mínimo em potencial e por isso o adicionamos à fila.

Observamos que este algoritmo não é determinístico. O não-determinismo do mesmo está nas linhas 3 e 8 do BlACK-Box e nas linhas 5 e 15 do KERNEL, pontos em que são feitas escolhas nas iterações sobre um conjunto. Os resultados do BLACK-Box dependem diretamente das escolhas feitas. No entanto, como no algoritmo KeRnel calculamos todos os $\alpha$-kernels, as escolhas em questão não alteram o resultado, influenciando apenas na ordem de execução do algoritmo.

Outro ponto a ressaltar é que, com o Kernel em mãos, o conjunto resíduo pode ser obtido calculando os cortes mínimos do Kernel, também conforme a ideia da adaptação do algoritmo de Reiter apresentada em [Was00].

\subsection{Revisão de bases de crenças}

Apesar do foco deste capítulo estar nas contrações, nesta seção faremos considerações acerca das operações de revisão. Em [Han99], vemos que construções para revisão podem ser obtidas a partir das construções para contração que já temos. Sendo $B$ uma base de crenças e $\alpha$ a sentença pela qual queremos revisar a base, por revisão externa define-se a operação de expandir a base por $\alpha$ e, em seguida, contraí-la por $\neg \alpha(B+\alpha-\neg \alpha)$. Já a revisão interna é o processo inverso: primeiramente, contrai-se por $\neg \alpha$ e, então, expande-se por $\alpha(B-\neg \alpha+\alpha)$.

No entanto, conforme exposto em [RW09], essas construções dependem da definição de negação na lógica à qual $\alpha$ pertence e a definição de negação de uma sentença em algumas Lógicas de Descrição é ainda um problema em aberto. Isso inviabiliza a utilização de revisão como na forma apresentada no parágrafo anterior. Assim, também em [RW09], são apresentadas construções alternativas para revisão que podem ser usadas para qualquer lógica compacta e monotônica. Na Seção 5.3, mostraremos uma implementação de uma das construções. 


\section{Capítulo 3}

\section{Contração Múltipla}

No capítulo anterior, a contração via Kernel foi abordada envolvendo uma base de crenças e uma sentença. Mas há a possiblidade de generalizar as construções para que sejam aceitos conjuntos de sentenças como entrada, ao invés de apenas uma sentença. Sendo $B$ e $A$ conjuntos de sentenças, o conjunto resíduo generalizado de $B$ por $A$ é o conjunto de subconjuntos maximais de $B$ que não implicam nenhum elemento de $A$. Assim, a contração por uma única sentença torna-se um caso particular desta ideia proposta [RW09]. Neste capítulo, as operações de contração múltipla serão discutidas em maior detalhe.

\subsection{Extensão de contração simples para múltipla}

Após a publicação e difusão do modelo AGM, ele começou a ser estendido para servir outras necessidades de revisão de crenças. Ao se propor uma extensão, além da ideia da mesma estar clara, é necessário prover os meios de construir as funções que realizarão as operações e também definir postulados, os quais irão ditar o comportamento das funções construídas.

Uma das extensões propostas foi a de realizar a contração de uma base de crenças por um conjunto e não apenas por uma sentença [Fuh88, Nie91, FH94, FSS03]. Assim, a contração por uma sentença torna-se apenas um caso particular da contração múltipla em que o conjunto pelo qual se quer contrair é unitário. O termo "contração múltipla" foi proposto por Fuhrmann [Fuh88] com o intuito de indicar essa operação de contração simultânea por mais de uma sentença. É importante, também, dizer que contração múltipla é diferente de contração iterada ou repetida [DP97], isto é, a execução de duas ou mais contrações em sequência. Veremos isso com mais detalhes um pouco adiante.

Nessa extensão proposta para a contração, há duas variantes principais: package e choice. Na contração package de um conjunto $A$ por um conjunto $B$, todas as sentenças de $B$ devem ser removidas de $A$, enquanto que em uma contração choice é suficiente que pelo menos um elemento de $B$ seja removido.

\subsection{Motivações}

Entre as dúvidas levantadas em relação à contração múltipla, buscou-se investigar se ela realmente ocorre e se é necessária, o que nos leva a avaliar se ela pode ser substituída por contrações simples. No entanto, a constatação é que não há maneiras alternativas de se atingir os mesmos efeitos, o que justifica classificá-las como sui generis.

Algumas outras operações podem parecer ter efeitos semelhantes aos da contração múltipla. No entanto, assim como exposto em [FH94], se temos um conjunto de crenças e desejamos remover dele por completo um conjunto de sentenças $\{\alpha, \beta\}$, temos que diferenciar isso de outras operações tais como:

1. contrair por $\alpha \vee \beta$ 
2. realizar a interseção dos resultados de contrair por $\alpha$ e contrair por $\beta$

3. primeiro contrair por $\alpha$ e então por $\beta$ ou vice-versa

4. contrair por $\alpha \wedge \beta$

Para contrair uma disjunção de um conjunto, precisamos remover ambos os elementos que a compõem. Em contrapartida, o contrário não é verdade, isto é, contrair pelo conjunto $\{\alpha, \beta\}$ não implica em remover $\alpha \vee \beta$. Além disso, no caso específico que desejamos tratar nesse trabalho, ou seja, o caso das Lógicas de Descrição, o operador de disjunção não está definido, ou seja, não seria possível reduzir contração múltipla a um caso de disjunção.

A segunda operação, apesar de parecer coerente, pode gerar um conjunto pequeno demais para configurar o resultado de uma contração múltipla.

Já foi mostrado em publicações da literatura, tal como [Han93], que a ordem de execução de contrações pode fazer diferença no resultado final. Assim, a terceira operação envolveria uma assimetria não desejável, uma vez que, em contração múltipla, todas as sentenças a serem contraídas são consideradas como tendo igual prioridade. Logo, contração sequencial não pode ser considerada igual à multipla.

Já a quarta operação traz uma opção inviável dado que, para remover uma conjunção de um conjunto, basta remover um dos elementos que a compõem. No caso de uma contração package, por exemplo, esse não é o resultado final almejado. Porém, numa contração choice em Lógica Proposicional, por exemplo, a conjunção poderia ser uma forma de redução:

Observação 1 [FH94] Para todos os conjuntos finitos $B$ e qualquer conjunto de crenças $A, A^{\exists} B=$ $A-\wedge B$.

No entanto, assim como para o operador de disjunção, o operador de conjunção também não está definido para as Lógicas de Descrição, o que inviabiliza essa redução no âmbito deste trabalho.

Para considerações acerca de reduções de contração múltipla em contrações simples no âmbito das contrações baseadas em epistemic entrechment[Gar88, GM88], veja [FR13].

\subsection{Postulados e propriedades básicas de contração múltipla}

Dedicaremos esta subseção para a generalização dos postulados anteriormente estabelecidos para contrações por conjuntos unitários, generalização esta definida em [FH94, FSS03]. Assim, este capítulo configura-se como um resumo de ambos os artigos. Seguindo a notação de Fuhrmann e Hansson, utilizaremos a letra $P$ para indicar a contração package e a letra $C$ para a choice.

O primeiro postulado que queremos abordar é o de sucesso. Esse postulado na teoria AGM visa garantir que a sentença pela qual se quer contrair não seja mais implicada pelo conjunto. No caso de múltiplas sentenças, na contração package de $A$ por $B$ queremos que nenhum elemento de $B$ seja inferido por $A$ e na choice, que pelo menos um elemento de B não seja inferido por $A$. Além disso, precisamos considerar as situações em que $B$ contém tautologias. Se $B$ contém pelo menos uma tautologia, então esse conjunto não pode ser completamente removido de $A$ (package) e, se $B$ contém apenas tautologias, então ele não pode ser parcialmente removido de $A$ (choice). Assim, sendo $\stackrel{\forall}{\forall}$ um operador de contração package e $\exists^{\exists}$ um operador de contração choice, podemos ter:

$$
\begin{aligned}
& \text { (sucesso-P) } \nvdash B \Longrightarrow A^{\forall} B \nvdash B \\
& \text { (sucesso-C) } \nVdash B \Longrightarrow A^{\exists} B \nVdash B
\end{aligned}
$$

No entanto, essa condição pode limitar alguns casos em que uma operação mais intuitiva resolveria a questão. Uma variação mais satisfatória de contração package é uma que contrai o máximo possível, removendo de $A$ tudo que pode ser removido a partir de $B$. Seja $\smile$ essa operação de

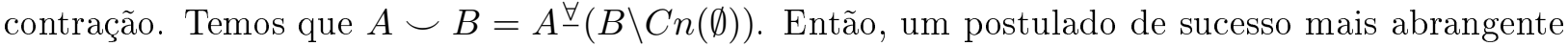
seria: 


$$
A \smile B \nvdash B \backslash C n(\emptyset)
$$

A condição de inclusão tem a mesma ideia originalmente proposta em AGM, ou seja, que o resultado da contração deve ser um subconjunto do conjunto original:

(inclusão-P) $A \stackrel{\forall}{-} B \subset A$

(inclusão-C) $A^{\exists} B \subset A$

O postulado AGM de vacuidade estabelece a condição na qual a operação é nula, ou seja, quando o resultado que se deseja obter já foi alcançado. No caso de contração package, isso ocorre quando $B$ é completamente disjunto de $A$ e, no caso de choice, quando pelo menos um elemento de $B$ não está implicado por $A$. Assim:

(vacuidade-P) $A \nvdash B \Longrightarrow A \subseteq A^{\forall} B$

(vacuidade-C) $A \nVdash B \Longrightarrow A \subseteq A^{\exists} B$

Como já citado neste trabalho, o postulado de recuperação é considerado, em muitos contextos, controverso. No entanto, em vista do Princípio de Mudança Mínima, não podemos desconsiderá-lo sem ter uma condição substituta que garanta que sentenças não serão excluídas sem terem envolvimento direto na implicação da(s) sentença(s) pela(s) qual(is) se quer contrair. A generalização dos postulados de relevância e core-retainment garante essa propriedade:

(relevância-P) Se $\alpha \in A \backslash\left(A^{\forall} B\right)$, então existe algum $A^{\prime}$ tal que $A^{\forall} B \subseteq A^{\prime} \subseteq A$ e $A^{\prime} \nvdash B$, mas $A^{\prime} \cup\{\alpha\} \vdash B$.

(relevância-C) Se $\alpha \in A \backslash\left(A^{\exists} B\right)$, então existe algum $A^{\prime}$ tal que $A^{\exists} B \subseteq A^{\prime} \subseteq A$ e $A^{\prime} \nVdash B$, mas $A^{\prime} \cup\{\alpha\} \Vdash B$.

(core-retainment-P) Se $\alpha \in A$ e $\alpha \notin A^{\forall} B$, então existe algum $A^{\prime}$ tal que $A^{\prime} \subseteq A$ e $A^{\prime} \nvdash B$, mas $A^{\prime} \cup\{\alpha\} \vdash B$

(core-retainment-C) Se $\alpha \in A$ e $\alpha \notin A^{\exists} B$, então existe algum $A^{\prime}$ tal que $A^{\prime} \subseteq A$ e $A^{\prime} \nVdash B$, $\operatorname{mas} C \cup\{\alpha\} \Vdash B$

Retomando a questão sobre quando $B$ contém tautologias, pode-se estabelecer condições sob as quais se espera que as contrações sejam vazias:

(falha-P) $\vdash B \Longrightarrow A \subseteq A \stackrel{\forall}{ } B$

(falha-C) $\Vdash B \Longrightarrow A \subseteq A^{\exists} B$

Resta, também, generalizar a condição de uniformidade, expressa anteriormente pelo postulado de extensionalidade. No caso de contração múltipla, querendo que a contrações por conjuntos logicamente equivalentes produzam o mesmo resultado. Assim:

(uniformidade-P) Se, para qualquer $A^{\prime} \subseteq A, A^{\prime} \vdash B \Leftrightarrow A^{\prime} \vdash C$, então $A^{\sharp} B=A^{\forall} C$

(uniformidade-C) Se, para qualquer $A^{\prime} \subseteq A, A^{\prime} \Vdash B \Leftrightarrow A^{\prime} \Vdash C$, então $A^{\exists} B=A^{\exists} C$

Nas próximas subseções, dedicaremo-nos a expor a construção das operações múltiplas. 


\subsection{Contração Múltipla Partial Meet}

A contração múltipla Partial Meet foi proposta em [FH94]. Para o conjunto resíduo em package usaremos a notação $A \perp_{P} B$, enquanto que para choice usaremos $A \perp_{C} B$.

Definição 9 [FH94] (Resíduo package) $X \in A \perp_{P} B$ se e somente se:

- $X \subseteq A$

- $X \nvdash B$

- $\forall Y: X \subset Y \subseteq A \Longrightarrow Y \vdash B$

Assim, $A \perp_{P} B$ é o conjunto de todos os subconjuntos maximais de $A$ que não tem interseção com $B$. Em choice, a abordagem é diferente, uma vez que precisamos encontrar os subconjuntos maximais de $A$ que não contêm o conjunto $B$ :

Definição 10 [FH94] (Resíduo choice) $X \in A \perp_{C} B$ se e somente se:

- $X \subseteq A$

- $X \nVdash B$

- $\forall Y: X \subset Y \subseteq A \Longrightarrow Y \Vdash B$

Lema 1 [FH94] Para todos os conjuntos $A$ e $B$ de sentenças da linguagem:

1. $A \perp_{P} B=\emptyset$ se e somente se $\vdash B$

2. $A \perp_{C} B=\emptyset$ se e somente se $\Vdash B$

Tendo o conjunto resíduo em mãos, precisamos escolher alguns de seus elementos e, para isso, lançaremos mão da função de seleção. Tendo os elementos selecionados, obteremos o resultado por meio da interseção dos mesmos, como definido a seguir:

Definição 11 [FH94] $\gamma$ é uma função de seleção package para A se e somente se para todos os conjuntos B:

1. Se $A \perp_{P} B$ é não-vazio, então $\gamma\left(A \perp_{P} B\right)$ é um subconjunto não-vazio de $A \perp_{P} B$.

2. Se $A \perp_{P} B$ é vazio, então $\gamma\left(A \perp_{P} B\right)=\{A\}$.

Definição 12 [FH94] Um operador $\underline{\forall}$ é um operador de contração partial meet package se e somente se existe uma função de seleção package $\gamma$ tal que $A \stackrel{\forall}{B}=\bigcap \gamma\left(A \perp_{P} B\right)$ para todo conjunto $B$.

Definição 13 [FH94] $\gamma$ é uma função de seleção choice para A se e somente se para todos os conjuntos B:

1. Se $A \perp_{C} B$ é não-vazio, então $\gamma\left(A \perp_{C} B\right)$ é um subconjunto não-vazio de $A \perp_{C} B$.

2. Se $A \perp_{C} B$ é vazio, então $\gamma\left(A \perp_{C} B\right)=\{A\}$.

Definição 14 [FH94] Um operador $\exists^{\exists}$ é um operador de contração partial meet choice se e somente se existe uma função de seleção choice $\gamma$ tal que $A^{\exists} B=\bigcap \gamma\left(A \perp_{C} B\right)$ para todo conjunto $B$.

Para demonstrar a validade das operações apresentadas, referimo-nos aos teoremas de representação:

Teorema 1 [FH94] Para todo conjunto de crenças $A$, uma operação $\underline{\forall}$ é uma contração partial meet package sobre $A$ se e somente se ela satisfaz sucesso- $P$, inclusão- $P$, uniformidade- $P$ e relevância- $P$.

Teorema 2 [FH94] Para todo conjunto de crenças A, uma operação $\exists$ é uma contração partial meet choice sobre $A$ se e somente se satisfaz sucesso- $C$, inclusão- $C$, uniformidade- $C$ e relevância- $C$. 


\subsection{Contração Múltipla Kernel}

Agora, passaremos às definições para contrair uma base de crenças por um conjunto de sentenças utilizando a operação Kernel, ou seja, investigaremos os elementos de $A$ envolvidos na implicação de $B$. O processo é semelhante ao da contração por uma sentença.

O conjunto kernel em package denotaremos por $\Perp_{P}$ e em choice por $\Perp_{C}$.

Definição 15 [FSS03] (Kernel Package) Sejam $A, B$ conjuntos em $\mathcal{L}$. Então $A \Perp_{P} B$ é o conjunto tal que $X \in A \Perp_{P} B$ se e somente se:

- $X \subseteq A$

- $X \vdash B$

- Se $Y \subset X$ então $Y \nvdash B$

Definição 16 [FSS03] (Kernel Choice) Sejam $A, B$ conjuntos em $\mathcal{L}$. Então $A \Perp_{C} B$ é o conjunto tal que $X \in A \Perp_{C} B$ se e somente se:

- $X \subseteq A$

- $X \Vdash B$

- Se $Y \subset X$ então $Y \nVdash B$

Tendo o conjunto kernel, precisamos eliminar pelo menos uma sentença de cada elemento do conjunto, o que nos leva à função de incisão:

Definição 17 [FSS03] Uma função $\sigma$ é uma função de incisão para A se e somente se ela satisfaz para todo $B$ :

1. $\sigma\left(A \Perp_{i} B\right) \subseteq \bigcup\left(A \Perp_{i} B\right)$

2. $S e \emptyset \neq X \in A \Perp_{i} B$, então $X \bigcap \sigma\left(A \Perp_{i} B\right) \neq \emptyset$

em que $i$ é $P$ ou $C$.

Definição 18 [FSS03] Seja $\sigma$ uma função de incisão para A. A Contração Múltipla Kernel $\approx_{\sigma}$ para A é definida da forma:

$$
A \approx_{\sigma} B=A \backslash \sigma\left(A \Perp_{i} B\right)
$$

em que $i$ é $P$ ou $C$.

Com relação à caracterização axiomática da operação:

Teorema 3 [FSS03] Um operador $\div$ para um conjunto $A$ é um operador de contração Kernel package se e somente se satisfaz sucesso- $P$, inclusão- $P$, core-retainment- $P$ e uniformidade- $P$.

Teorema 4 [FSS03] Um operador $\div$ para um conjunto A é um operador de contração Kernel choice se e somente se satisfaz sucesso- $C$, inclusão- $C$, core-retainment- $C$ e uniformidade- $C$.

Neste capítulo, vimos a generalização dos postulados e operações $A G M$ para o caso da contração múltipla, ou seja, contração não apenas por sentenças unitárias mas por um conjunto delas. Veremos, no Capítulo 6, a aplicação da teoria exposta aqui no desenvolvimento e aplicação de algoritmos. 


\section{Capítulo 4}

\section{Revisão de Ontologias}

\subsection{Ontologias}

O conceito de ontologia já era estudado desde a Grécia Antiga, sendo que o termo ontologia originou-se na Filosofia em referência a um campo da Metafísica que estuda e trata da existência dos entes. Esse primeiro uso delas explica a origem do vocábulo, o qual é derivado de duas palavras gregas: ontos ("ente") e logoi ("ciência do ser").

No entanto, as ontologias são objetos de estudo em várias áreas e, neste trabalho, estamos interessados em seu significado para Ciência da Computação e da Informação. Alguns pesquisadores de Inteligência Artificial viram nas ontologias da Filosofia uma possibilidade de aplicação e começaram a propor a criação de novos tipos delas, isto é, olhá-las como modelos computacionais, visando, também, o uso de raciocínio automatizado [Hay85].

Segundo Tom Gruber [Gru95], uma definição curta para ontologia seria dizer que é uma "especificação explícita de uma conceitualização ${ }^{1}$." De forma mais abrangente, "uma ontologia é uma descrição (como uma especificação formal de um programa) dos conceitos e relacionamentos que podem existir formalmente para um agente ou uma comunidade de agentes. Essa definição é consistente com o uso de ontologia como um conjunto de definições de conceitos, mas de forma geral. E certamente é um sentido diferente da palavra usada na Filosofia." Assim, as ontologias são usadas para capturar conhecimento sobre algum domínio de interesse, seja ele real ou imaginário. A descrição fornecida por elas forma um modelo de dados que é utilizado também para realizar inferência sobre os objetos do domínio.

Essa especificação de conceitualização envolve a descrição de indivíduos, classes, atributos (propriedades) dessas classes e relacionamentos entre elas. Veremos um exemplo logo a seguir.

As linguagens utilizadas para especificar ontologias são tais que possibilitam a criação de uma abstração sem referências a estruturas de dados ou estratégias de implementação. Esse é um dos motivos por que as ontologias são classificadas como pertencentes ao nível semântico e não ao lógico ou físico. Como a linguagem mais utilizada, tanto na academia quanto na indústria [KV11], podemos citar a $\mathrm{OWL}^{2}$ (Web Ontology Language), a qual é recomendada como padrão pela W3C desde 2004 para representar (definir e instanciar) ontologias na web.

Podemos citar como áreas de aplicação das ontologias a Web Semântica, Inteligência Artificial, processamento de linguagens naturais, Engenharia de Software, Medicina, Biomedicina e outras áreas da Saúde. Também são usadas na integração de bancos de dados heterogêneos, justamente devido ao fato supracitado de que elas funcionam no nível semântico, o que proporciona a criação de interfaces para interoperabilidade de sistemas independentes. Vale ressaltar que o propósito do uso de ontologias não está apenas na representação do conhecimento mas na possibilidade de compartilhá-lo e reutilizá-lo.

Como exemplo, veja a figura abaixo:

\footnotetext{
${ }^{1}$ Conceitualização é uma visão abstrata e simplificada do domínio de interesse que se deseja representar. Toda base de conhecimento ou sistema baseado em conhecimento está ligado a alguma conceitualização.

${ }^{2}$ http://www.w3.org/TR/owl-guide/
} 


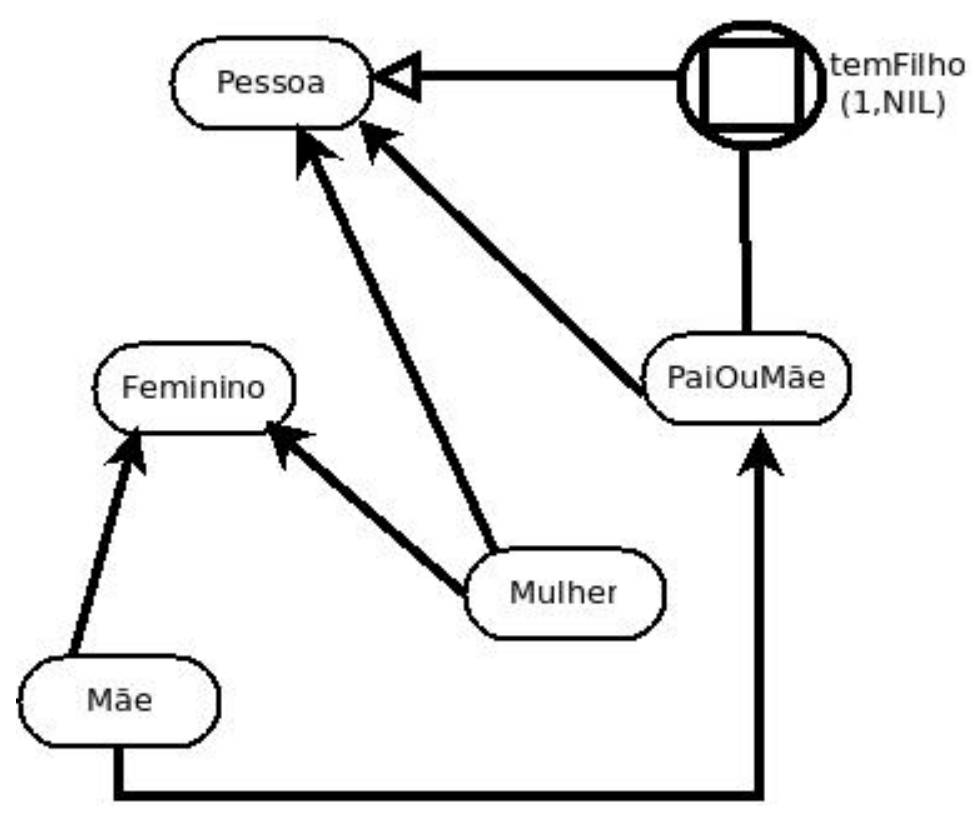

Figura 4.1: Diagrama de uma ontologia que representa conhecimento sobre pessoas e parentescos

$\mathrm{Na}$ figura acima, as elipses representam conceitos, cujos nomes estão no interior das mesmas. Temos, então, cinco conceitos. As setas com ponta cheia representam conceitos que estão contidos em outros, isto é, subconceitos. Por exemplo, Mulher é subconceito de Pessoa e de Feminino. Também vemos, representado pelo quadrado dentro do círculo e pela seta com ponta vazada, um relacionamento entre os conceitos PaiOuMãe e Pessoa nomeado como temFilho. Ele indica que todo PaiOuMãe tem um Filho, sendo este último pertencente ao conceito Pessoa. Além disso, a restrição de valor $(1, \mathrm{NIL})$ indica que todo PaiOuMãe tem pelo menos um Filho e não há limite superior.

\subsection{Lógicas de Descrição}

Os estudos e pesquisas nas áreas de Lógica e Inteligência Artificial buscam definições de linguagens formais para representação de conhecimento e também desenvolver métodos de raciocínio e inferência associados às mesmas. Assim, é de grande interesse que os sistemas desenvolvidos com esse propósito sejam capazes não só de representar conhecimento mas de extrair informações implícitas da base de conhecimento.

Nesse âmbito, as Lógicas de Descrição têm sido um dos principais formalismos para representar conhecimento, em especial conhecimento terminológico. Como subconjuntos estruturados da Lógica de Primeira Ordem, elas detêm uma semântica formal bem definida e baseada na lógica. Em termos de raciocínio, são decidíveis, ao contrário da inferência em Lógica de Primeira Ordem. Além disso, a linguagem OWL citada anteriormente é baseada nas Lógicas de Descrição, as quais formam a base teórica tanto da OWL quanto dos perfis associados e ela ${ }^{3}$.

Assim, as Lógicas de Descrição são uma família de formalismos aplicada para representar conhecimento sobre um domínio, isso por meio da definição dos conceitos relevantes do mesmo e também pela especificação de propriedades de objetos e indivíduos, propósitos esses que condizem com a conexão dessas lógicas com ontologias.

Para mais detalhes sobre as Lógicas de Descrição, veja $\left[\mathrm{BCM}^{+} 03\right]$.

\subsubsection{Representação}

Denotemos, daqui em diante, Lógicas de Descrição por LD. Em LD, o conhecimento é dividido em duas partes: TBox e ABox. Uma TBox refere-se às terminologias, ou seja, o conhecimento

\footnotetext{
${ }^{3}$ http://www.w3.org/TR/owl2-overview/
} 
"intensional" sobre um determinado domínio, definindo conceitos e suas propriedades (o vocabulário do domínio de aplicação). Uma ABox refere-se às asserções, ou seja, o conhecimento "extensional" do domínio, especificando indivíduos de um ou mais conceitos.

Nas terminologias, os conceitos são conjuntos de indivíduos com alguma característica em comum e as propriedades (chamadas de papéis) são relacionamentos binários entre indivíduos. As LDs também permitem que os usuários construam descrições complexas de conceitos e papéis a partir dos conceitos e papéis atômicos já definidos. Essas descrições são formadas por meio da utilização de construtores de conceitos e a os construtores disponíveis na linguagem são o que diferencia uma lógica de descrição da outra.

Para fins de notação, nesta subseção utilizaremos as letras $A, B$ para conceitos atômicos, a letra $R$ para papéis atômicos e as letras $C, D$ para descrições complexas.

A linguagem mininal definida é a $\mathcal{A L}$ (do inglês, abreviação para linguagem atributiva), sendo que as demais linguagens são derivadas dela. As regras de sintaxe de $\mathcal{A L}$ para construção de conceitos são:

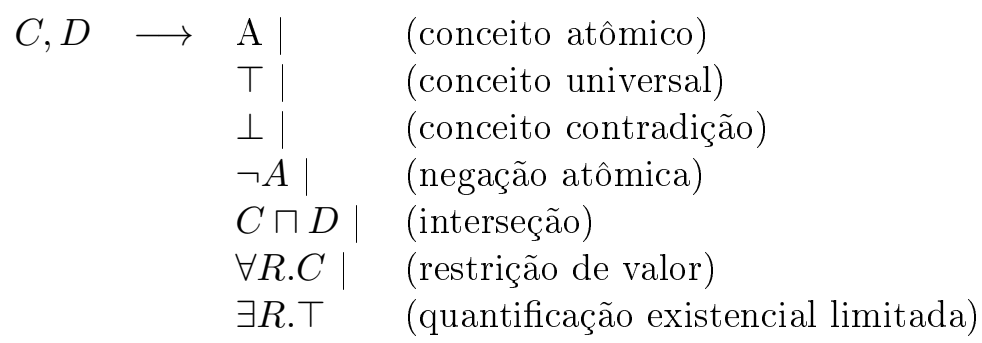

Note que em $\mathcal{A L}$ a negação só é aplicada em conceitos atômicos. Sendo Mulher, Pessoa e Feminino conceitos atômicos e temFilho um papel atômico, algumas coisas que podemos representar no domínio pessoas, com os construtores fornecidos até o momento, são:

- Pessoa $\sqcap$ Feminino

- Mulher $\sqcap \exists$ temfilho. $\top$

- Pessoa $\sqcap \forall$ temFilho.Pessoa

Pode-se facilmente deduzir que esses conceitos indicam, respectivamente, as pessoas que são do sexo feminino, as mulheres que têm filho e as pessoas cujos filhos são também pessoas.

Visando a definição de uma semântica formal dos conceitos em $\mathcal{A L}$, utilizaremos interpretações. Uma interpretaçẫo $\mathcal{I}$ é formada por um conjunto não-vazio $\Delta^{\mathcal{I}}$ (domínio da interpretação) e uma função de interpretação, a qual atribuirá para cada conceito atômico $A$ um conjunto $A^{\mathcal{I}} \subseteq \Delta^{\mathcal{I}}$ e, para cada papel atômico $R$, uma relação binária $R^{\mathcal{I}} \subseteq \Delta^{\mathcal{I}} \times \Delta^{\mathcal{I}}$. A função indica as descrições dos conceitos conforme as definições a seguir:

$$
\begin{aligned}
\top^{\mathcal{I}} & =\Delta^{\mathcal{I}} \\
\perp^{\mathcal{I}} & =\emptyset \\
(\neg A)^{\mathcal{I}} & =\Delta^{\mathcal{I}} \backslash A^{\mathcal{I}} \\
(C \sqcap D)^{\mathcal{I}} & =C^{\mathcal{I}} \cap D^{\mathcal{I}} \\
(\exists R . \top)^{\mathcal{I}} & =\left\{a \in \Delta^{\mathcal{I}} \mid \exists b .(a, b) \in R^{\mathcal{I}}\right\} \\
(\forall R . C)^{\mathcal{I}} & =\left\{a \in \Delta^{\mathcal{I}} \mid \forall b .(a, b) \in R^{\mathcal{I}} \rightarrow b \in C^{\mathcal{I}}\right\}
\end{aligned}
$$


Dizemos que dois conceitos $C, D$ são equivalentes, isto é, $C \equiv D$, se $C^{\mathcal{I}}=D^{\mathcal{I}}$ para qualquer interpretação $\mathcal{I}$.

A adição de novos construtores de conceitos à linguagem torna-a mais expressiva. Listamos abaixo, juntamente com suas interpretações e letras correspondentes, alguns construtores que podem ser adicionados à linguagem $\mathcal{A L}$. Consideramos ".|" como a cardinalidade de um conjunto. Como letras representativas das linguagens, $\mathcal{U}$ representa união, $\mathcal{E}$ o quantificador existencial total, $\mathcal{N}$ as restrições de cardinalidade, $\mathcal{Q}$ a restrição numérica qualificada e $\mathcal{C}$ a negação de conceitos arbitrários.

$$
\begin{aligned}
(\mathcal{U}) \rightarrow \quad(C \sqcup D)^{\mathcal{I}} & =C^{\mathcal{I} \cup D^{\mathcal{I}}} \\
(\mathcal{E}) \rightarrow \quad(\exists R . C)^{\mathcal{I}} & =\left\{a \in \Delta^{\mathcal{I}} \mid \exists b .(a, b) \in R^{\mathcal{I}} \wedge b \in C^{\mathcal{I}}\right\} \\
(\mathcal{N}) \rightarrow \quad(\geq n R)^{\mathcal{I}} & =\left\{a \in \Delta^{\mathcal{I}}||\left\{b \mid(a, b) \in R^{\mathcal{I}}\right\} \mid \geq n\right\} \\
(\leq n R)^{\mathcal{I}} & =\left\{a \in \Delta^{\mathcal{I}}||\left\{b \mid(a, b) \in R^{\mathcal{I}}\right\} \mid \leq n\right\} \\
(\mathcal{Q}) \rightarrow \quad(\geq n R . C)^{\mathcal{I}} & =\left\{a \in \Delta^{\mathcal{I}}||\left\{b \mid(a, b) \in R^{\mathcal{I}} \text { e } b \in C^{\mathcal{I}}\right\} \mid \geq n\right\} \\
(\leq n R . C)^{\mathcal{I}} & =\left\{a \in \Delta^{\mathcal{I}}||\left\{b \mid(a, b) \in R^{\mathcal{I}} \mathrm{e} b \in C^{\mathcal{I}}\right\} \mid \leq n\right\} \\
(\mathcal{C}) \rightarrow \quad(\neg C)^{\mathcal{I}} & =\Delta^{\mathcal{I}} \backslash C^{\mathcal{I}}
\end{aligned}
$$

Nomeamos as linguagens derivadas pela inclusão desses construtores adicionando a $\mathcal{A L}$ as letras correspondentes a eles. Como exemplo, a linguagem $\mathcal{A L U C}$ é formada pela extensão de $\mathcal{A} \mathcal{L}$ por meio da adição de união de conceitos e também da negação dos mesmos.

Duas lógicas muito difundidas são as lógicas $\mathcal{S H \mathcal { F }}(\mathcal{D})$ e $\mathcal{S H O} \mathcal{H} \mathcal{N}(\mathcal{D})$, em que $\mathcal{S}$ é uma abre-

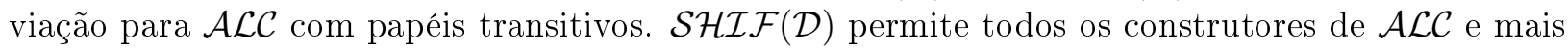
hierarquia de papéis $(\mathcal{H}: R \sqsubseteq S)$, papéis transitivos, papéis inversos $(\mathcal{I})$, papéis funcionais $(\mathcal{F})$ e tipos de dados com suas propriedades $((\mathcal{D}))$. Algo possível de se expressar em $\mathcal{S H} \mathcal{I} \mathcal{F}(\mathcal{D})$, por

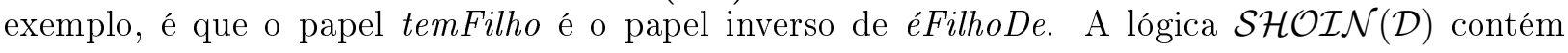

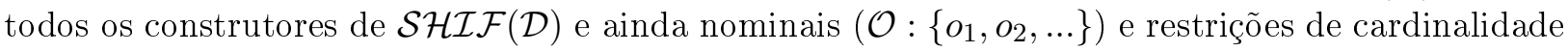
em papéis. Para uma definição completa de conceitos e sentenças em $\mathcal{S H \mathcal { H }} \mathcal{F}(\mathcal{D})$ e $\mathcal{S H O} \mathcal{H} \mathcal{N}(\mathcal{D})$,

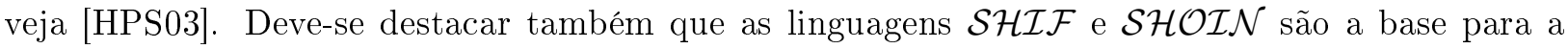

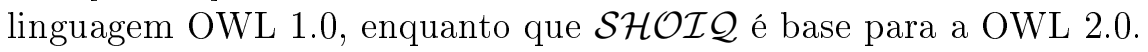

Nessas condições, alguns outros aspectos do domínio pessoas que podemos representar são:

- Homem $\sqcup$ Mulher

- Mãe $\sqcap \geq_{3}$ temfilho.Pessoa

Representamos aqui, respectivamente, os indivíduos que são homem ou mulher e as mães que têm pelo menos 3 filhos.

A partir dos recursos de representação que foram apresentados aqui, é possível formar os axiomas terminológicos, os quais são declarações acerca da relação entre conceitos e também papéis. Tais axiomas podem ser de inclusão () ou de igualdade (三). Se o lado esquerdo de uma inclusão é um conceito atômico, então essa inclusão representa uma especialização. Sendo $C, D$ conceitos, são exemplos de declarações:

- $C \sqsubseteq D$

- $C \equiv D$

Cosiderando os axiomas fora dos parêntesis, uma interpretação $\mathcal{I}$ satisfaz a inclusão se $C^{\mathcal{I}} \subseteq D^{\mathcal{I}}$ e satisfaz a a igualdade se $C^{\mathcal{I}}=D^{\mathcal{I}}$. Se $\mathcal{P}$ é um conjunto de axiomas, $\mathcal{I}$ satisfaz $\mathcal{P}$ se e somente se $\mathcal{I}$ satisfaz cada elemento de $\mathcal{P}$. Se $\mathcal{I}$ satisfaz um axioma, então dizemos que essa interpretação é 
um modelo para este axioma. A relação para modelos de conjuntos de axiomas é análoga. Por fim, dois axiomas ou dois conjuntos de axiomas são equivalentes se eles têm os mesmos modelos.

Se o lado esquerdo de uma igualdade é composto por um conceito atômico, então essa igualdade é uma definição. Definindo alguns conceitos expressos até aqui e acrescentando uma inclusão, podemos ter:

- Mulher $\equiv$ Pessoa $\sqcap$ Feminino

- Mãe $\equiv$ Mulher $\sqcap \exists$ temfilho. $\top$

- PaiOuMãe $\equiv$ Pessoa $\sqcap \forall$ temFilho.Pessoa

- Pessoa $\equiv$ Homem $\sqcup$ Mulher

- SuperMãe $\equiv$ Mãe $\sqcap \geq \geq_{3}$ temfilho.Pessoa

- Aluno $\sqsubseteq$ Pessoa

Em uma ABox, temos sentenças sobre indivíduos específicos expressos de duas formas: declaração de um indivíduo como pertencente a um determinado conceito (definindo o nome desse indivíduo) ou da relação entre ele e outro(s) indivíduo(s) por meio de um papel. Como exemplos:

- Aluno(FILLIPE)

- temFilho(ELOISA, FILLIPE)

Aqui, representamos que o indivíduo FILLIPE é um aluno e que FILLIPE é filho do indivíduo ELOISA.

A semântica também é estendida aos indivíduos. Uma interpretação $\mathcal{I}$ mapeia um indivíduo $a$ a um elemento $a^{\mathcal{I}} \in \Delta^{\mathcal{I}}$. Uma interpretação $\mathcal{I}$ satisfaz a asserção de conceito $C(a)$ se $a^{\mathcal{I}} \in C^{\mathcal{I}}$ e satisfaz uma asserção de papel $R(a, b)$ se $\left(a^{\mathcal{I}}, b^{\mathcal{I}}\right) \in R^{\mathcal{I}}$. Uma interpretação satisfaz a ABox $\mathcal{A}$ se ela satisfaz cada asserção em $\mathcal{A}$. Então, dizemos que $\mathcal{I}$ é um modelo da asserção ou da ABox.

Mais recentemente, surgiu o interesse pela lógica $\mathcal{E} \mathcal{L}$ [BBL05], LD minimal e dual a $\mathcal{A L}$ em que ao invés de $\exists R . \top$ e $\forall R$.C temos $\exists R . C$ e $\forall R$. T. Esta lógica é suficiente para descrever diversos domínios médicos (como o SNOWMED ${ }^{4}$, por exemplo) e é mais eficiente do ponto de vista computacional. Além disso, ela está por trás de um dos perfis da OWL $2.0\left(\right.$ OWL-EL $\left.^{5}\right)$. Na próxima subseção, mostraremos a complexidade das diversas LDs citadas aqui.

\subsubsection{Serviços de Inferência}

Uma das principais características das LDs é a ênfase no raciocínio como um serviço central, o qual permite, a partir do que está explicitamente expresso na base de conhecimento, inferir o conhecimento implícito. O padrão de inferência que utilizamos é a classificação de conceitos e indivíduos.

Antes de expor os tipos de inferência, uma questão importante a ser levada em conta é a complexidade computacional da inferência em uma dada LD. A decidibilidade e complexidade desses problemas depende da expressividade da LD que se está utilizando. LDs muito expressivas tendem a ter problemas de inferência muito complexos ou mesmo indecidíveis. No entanto, LDs mais simples, apesar dos raciocínios serem mais eficientes, podem não ser suficientes para expressar o domínio que se quer representar. Portanto, lidar com esse trade-off entre complexidade e expressividade é um aspecto muito relevante a ser levado em conta por quem deseja utilizar LDs.

Um tipo primordial de inferência é o teste de satisfatibilidade. Seja $\mathcal{P}$ uma terminologia. Um conceito é satisfatível se há uma interpretação que satisfaz os axiomas de $\mathcal{P}$ tal que esse conceito é não-vazio nessa interpretação.

\footnotetext{
${ }^{4}$ http://www.ihtsdo.org/snomed-ct

${ }^{5}$ https://www.w3.org/2007/OWL/wiki/EL
} 
Outra forma de inferência sobre uma TBox é a verificação de subsunção ("concept subsumption"), isto é, verificar se um conceito é mais geral que outro, alcançando inferências da forma $C \sqsubseteq D$. Um conceito $C$ é um subconceito de um conceito $D$ se em todo modelo de $\mathcal{P}$ o conjunto que representa $C$ é um subconjunto do conjunto que representa $D$.

Todo sistema gerenciador de conceitos em LD deve ser capaz de realizar esses tipos de inferência e elas são baseadas nos relacionamentos definidos na terminologia.

Como exemplo, pode-se inferir que, baseado na terminologia definida na subseção anterior:

- Homem $\sqsubseteq$ Pessoa

- Mãe $\sqsubseteq$ Mulher

Essa definição de subconceitos e superconceitos forma uma hierarquia de subsunção, a qual é útil para determinar a relação entre diferentes conceitos e também para acelerar outros serviços de inferência que dependem dessa informação.

Ainda sobre os conceitos e sentenças de um TBox, a permissão ou não de algumas restrições influencia diretamente na complexidade computacional da LD envolvida. Para abordar isso, usaremos o conceito de GCI (general concept inclusion). Uma GCI tem a forma $C \sqsubseteq D$ e escrevemos $\mathrm{C}$ $\equiv \mathrm{D}$ quando $C \sqsubseteq D$ e $D \sqsubseteq C$. Assim, uma lógica que admite axiomas GCI permite essas inclusões e, também, definições cíclicas. Porém, há um grande salto de complexidade nos problemas de inferência, conforme podemos constatar nas tabelas a seguir ${ }^{6}$.

\begin{tabular}{|c|c|}
\hline Complexidade & Lógicas \\
\hline PSPACE-completo & $\mathcal{A L ~ e ~} \mathcal{A L U C}$ \\
\hline ExpTime-completo & $\mathcal{S H \mathcal { H }}(\mathcal{D})$ \\
\hline NExpTime-completo & $\mathcal{S H O \mathcal { N }}(\mathcal{D})$ e $\mathcal{S H O I} \mathcal{Q}$ \\
\hline
\end{tabular}

Tabela 4.1: Complexidade das LDs sem axiomas GCI

\begin{tabular}{|c|c|}
\hline Complexidade & Lógicas \\
\hline ExpTime-completo & $\mathcal{A L}, \mathcal{A L U C}$ e $\mathcal{S H \mathcal { I }}(\mathcal{D})$ \\
\hline NExpTime-completo & $\mathcal{S H O I N}(\mathcal{D})$ e $\mathcal{S H O I} \mathcal{Q}$ \\
\hline
\end{tabular}

Tabela 4.2: Complexidade das LDs com axiomas GCI

Já em relação a uma $\mathrm{ABox} \mathcal{A}$, dizemos que ela é consistente em relação a uma TBox $\mathcal{T}$ se há uma interpretação que é modelo tanto de $\mathcal{A}$ quanto de $\mathcal{T}$.

Uma forma muito utilizada de inferência sobre uma ABox denomina-se instanciação (instantiation), isto é, verificar se um indivíduo é ou não instância de um conceito, ou seja, verificar se uma ABox implica uma asserção. Uma asserção $\alpha$ é implicada por $\mathcal{A}(\mathcal{A} \vDash \alpha)$ se toda interpretação que satisfaz $\mathcal{A}$ também satisfaz $\alpha$.

Como exemplo, considere o seguinte domínio:

- Mãe $\sqsubseteq$ Pessoa

- PaiOuMãe $\equiv$ Pessoa $\sqcap$ $\exists$ temFilho.Pessoa

- Mãe(ELOISA)

- Pessoa(FILLIPE)

- temFilho(ELOISA,FILLIPE)

Como resultado da instanciação, temos:

\footnotetext{
${ }^{6}$ As informações usadas para construir essas tabelas foram tiradas de http://www.cs.man.ac.uk/ ezolin/dl
} 
- Pessoa(ELOISA)

- PaiOuMãe(ELOISA)

Também existe o problema da recuperação, que consiste em, dada uma ABox $\mathcal{A}$ e um conceito $C$, encontrar todos os indivíduos $a$ tal que $\mathcal{A} \vDash C(a)$, ou seja, todos os indivíduos que são instâncias de uma dada descrição de conceito.

Retomando a questão da consistência, frisamos aqui que este é um conceito que necessita de uma definição precisa. Em LD, uma base é inconsistente se e somente se implica $\top \sqsubseteq \perp$. Outra definição cabível em LD é a de coerência: dada uma base qualquer, se para qualquer conceito $C$ explicitamente dado no TBox a base implica $C \sqsubseteq \emptyset$, a base é incoerente.

Apesar de úteis e aplicáveis, os serviços apresentados aqui não são suficientes; isso porque, em muitos casos, a base de conhecimento não é estática. Portanto, torna-se necessário lidar com o dinamismo do conhecimento.

Ainda a respeito dos serviços de inferência apresentados nesta seção mas no âmbito computacional, vários motores de inferência foram desenvolvidos para oferecer estes serviços ao usuário. Entre eles, podemos citar: Pellet ${ }^{7}$, Racer $^{8}$, Hermi $^{9}$ e FaCT $++^{10}$.

\subsection{Revisão em Lógicas de Descrição e Depuração de Ontologias}

Vimos que a Revisão de Crenças lida com o problema da exclusão de uma sentença de uma base de conhecimento ou com a chegada de novas informações à mesma, possibilitando o surgimento de inconsistências. Com exceção das ontologias estáticas [JMY04], esse dinamismo é normal, uma vez que conhecimento não é estático e as ontologias, especialmente na web, estão sempre evoluindo. Nesse meio, o objetivo da depuração de ontologias é encontrar os axiomas da base que levaram à inconsistência.

Como exposto em [RW09], os operadores de revisão não podem ser aplicados diretamente às Lógicas de Descrição por dependerem de algumas propriedades da lógica. Retomando as suposições AGM indicadas na Seção 2.1.1, muitas construções para revisão de bases assumem que a lógica é fechada sob a negação de sentenças, o que não acontece com muitas LDs, além de, nas LDs, não se trabalhar com o fecho lógico de sentenças, mas com bases de crenças. Assim, apesar de muitas LDs serem monotônicas e compactas, as construções usuais não podem ser aplicadas e, por isso, queremos aproveitar os serviços de depuração para encontrar formas de implementar técnicas de revisão de crenças em Lógicas de Descrição.

Na literatura, existem alguns trabalhos sobre o tópico, tais como [Kal06, Flo06, BP07, Rib10].

\footnotetext{
${ }^{7}$ http://clarkparsia.com/pellet/

${ }^{8}$ http://www.racer-systems.com/

${ }^{9}$ http://hermit-reasoner.com/

${ }^{10}$ http://owl.man.ac.uk/factplusplus/
} 


\section{Capítulo 5}

\section{Revisor de Ontologias para o Protégé}

Neste capítulo, apresentaremos o editor de ontologias Protégé ${ }^{1}$ e sua importância no meio acadêmico e corporativo e a motivação para a execução do projeto exposto neste trabalho. Em seguida, serão descritos detalhes acerca do desenvolvimento do plug-in antes da implementação das operações Partial Meet e de contração múltipla.

\subsection{O programa e a motivação do plug-in}

Editores de ontologias são aplicações desenvolvidas para auxiliar na criação e manipulação das mesmas. Geralmente, criam ontologias em uma ou mais das várias linguagens disponíveis, podendo também, de acordo com a especificação de cada um, exportar em outra linguagem.

Entre esses editores, temos o Protégé, aplicação gratuita e de código-aberto, sendo um arcabouço para bases de conhecimento e o mais utilizado editor atualmente. Foi desenvolvido pela Universidade de Stanford e tem sido gerenciado pela mesma, recebendo, também, colaboração da Universidade de Manchester. Detalhes acerca da instalação e uso do editor podem ser encontrados em http: //protege.stanford.edu/doc/owl/getting-started.html.

Entre as razões pelas quais sua importância é grande, podemos destacar:

- É o editor mais utilizado atualmente, com mais de 230.000 usuários registrados.

- Tem uma comunidade de usuários ativa e distribuída entre mais de 100 países.

- Mais de 180 projetos registrados em seu domínio (de empresas e universidades) ${ }^{2}$

No entanto, mesmo havendo a integração com o plug-in Explanations [Hor11], este software não oferece uma ferramenta para contrair e revisar ontologias. Quando necessário, ele indica, por meio de um motor de inferências, a presença de inconsistências e, a partir daí, temos que encontrar as crenças que causaram a inconsistência. No entanto, fazer isso manualmente pode ser muito custoso ou, até mesmo, inviável.

Para a ontologia apresentada na Seção 4.1 (sobre pessoas e parentescos), poderia ser fácil encontrar, devido ao pequeno tamanho da mesma (menos de 10 axiomas necessários para representá-la). No entanto, quando temos uma ontologia com dezenas, centenas ou milhares de classes, o trabalho manual torna-se impraticável, além de ser uma tarefa mais facilmente passível de erros.

Vemos, portanto, que o programa carece de uma ferramenta apropriada para auxiliar o usuário nessas operações que geralmente acontecem durante o desenvolvimento.

\footnotetext{
${ }^{1}$ http: //protege.stanford.edu/

${ }^{2}$ http://protege.cim3.net/cgi-bin/wiki.pl?ProjectsThatUseProtege
} 


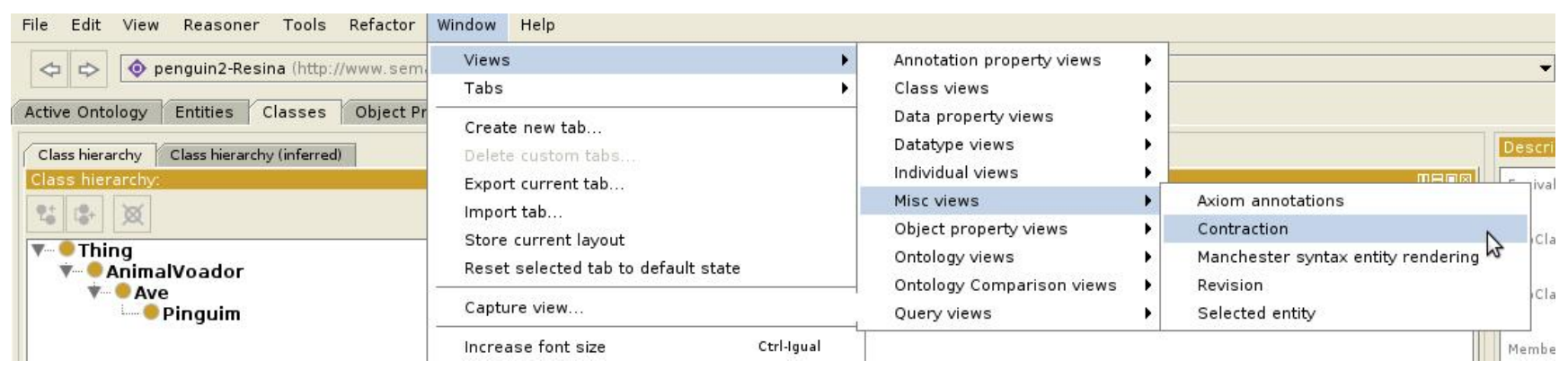

Figura 5.1: Localizaçâo do plug-in nos menus do Protégé

\subsection{O plug-in}

O plug-in está implementado na linguagem Java. Como base de desenvolvimento, utilizamos a OWLAPI $^{3}$, uma Application Programming Interface (ou, em português, Interface de Programação de Aplicativos) em Java implementada para criar, manipular e serializar ontologias em OWL. Outra ferramenta fundamental para o desenvolvimento é o motor de inferências, para o qual utilizamos o Pellet.

Inicialmente, foi criado um protótipo do plug-in revisor para o Protégé, desenvolvido por Márcio Moretto Ribeiro e Renata Wassermann [RW08]. No entanto, ele era compatível apenas com as versões $3{ }^{*}$ do editor, $2{ }^{*}$ da OWLAPI e 2.0* do Pellet, não executava operações por Partial Meet e não envolvia contração múltipla. Em [Res10], demos início à atualização do plug-in para que funcionasse com as novas versões do Protégé, da OWLAPI e do motor de inferências Pellet.

Atualmente, o código fonte do plug-in está disponível em https ://github.com/fillipemanoel/ ontology-change-plugin, sendo compatível com as últimas versões do Protégé (4.3), da OWLAPI (3.4.9) e do Pellet (2.3.1) liberadas até o término da redação desta dissertação.

\subsubsection{Instruções de uso}

Após a instalação do plug-in ${ }^{4}$ e inicialização do editor, o plug-in aparece neste último sob a forma de dois recursos: Contraction e Revision, ambos localizados no submenu Misc Views do menu Window-Views, conforme mostrado na Figura 5.1. Esses recursos foram designados para executarem, respectivamente, as operações de contração e revisão.

Para demonstrar a execução do plug-in, utilizaremos um exemplo simples de base de conhecimento :

- Aves são animais voadores

- Pinguins são aves

- Tweety é um pinguim

Nas Lógicas de Descrição, essa base seria representada da seguinte forma:

- Ave $\sqsubseteq$ AnimalVoador

- Pinguim $\sqsubseteq$ Ave

- Pinguim(Tweety)

Na Figura 5.2, vemos essa base modelada como ontologia no Protégé.

Para executar uma operação de contração, invocamos o aplicativo Contraction no menu Misc Views, o que fará aparecer um ícone redondo de cor preta junto ao cursor do mouse. Basta clicar, 


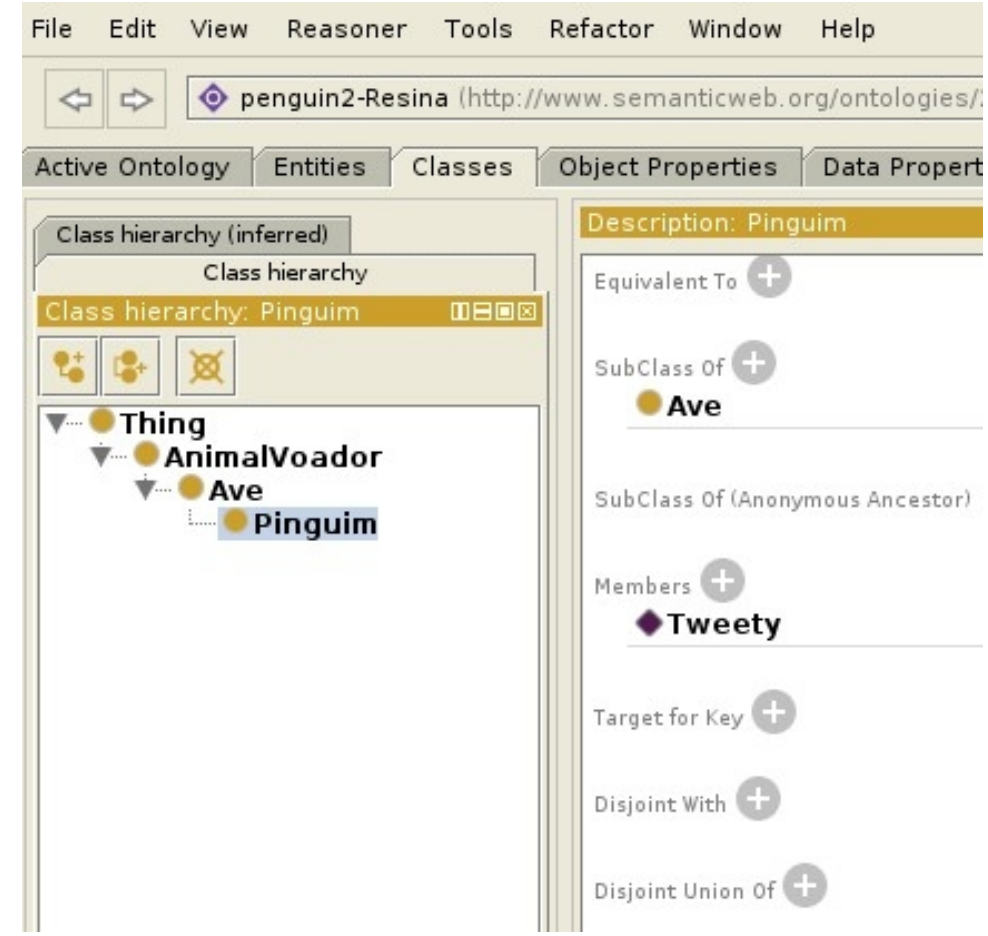

Figura 5.2: Ontologia sobre aves e pinguins representada no Protégé

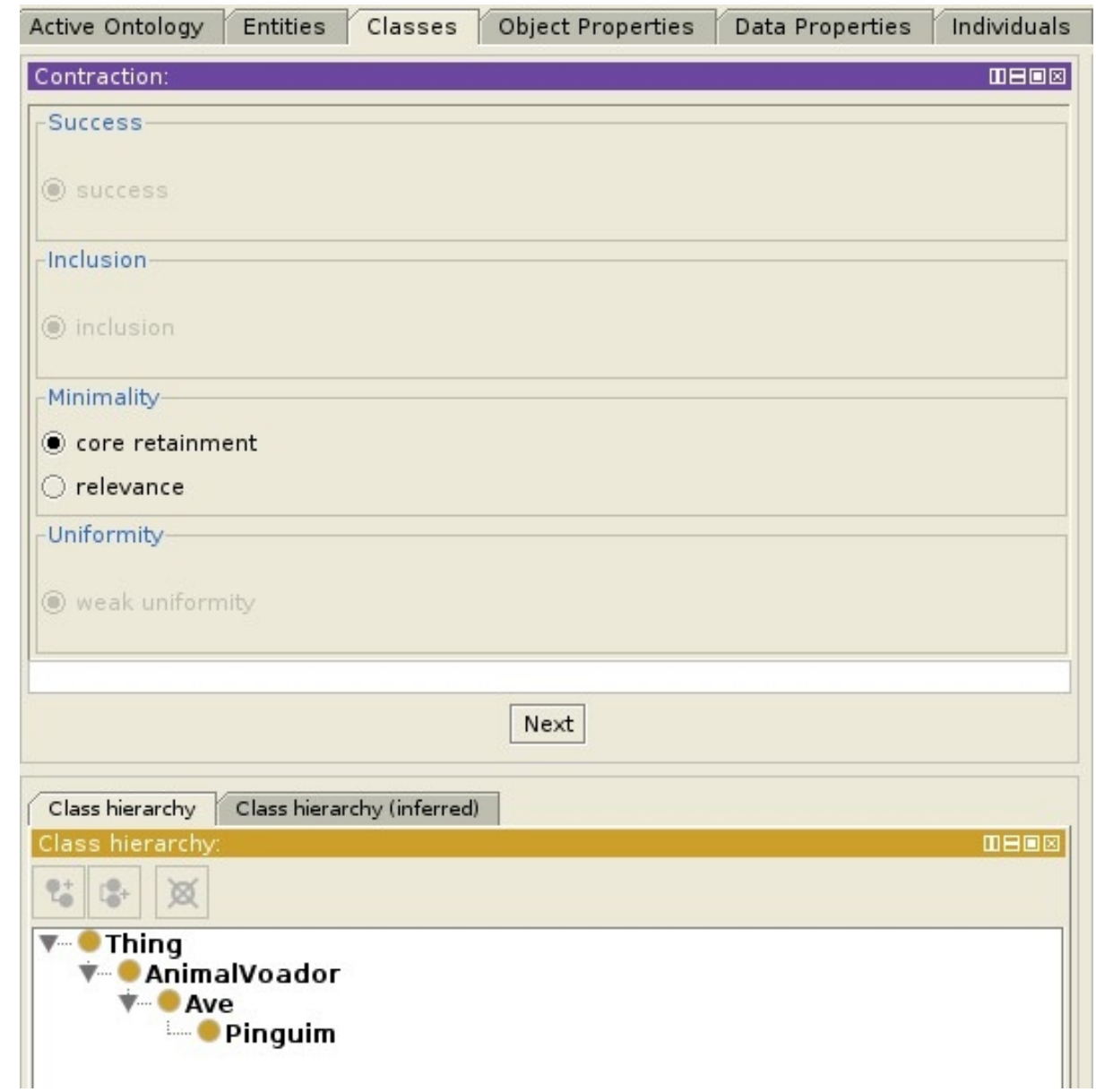

Figura 5.3: Tela inicial do plug-in para contração 


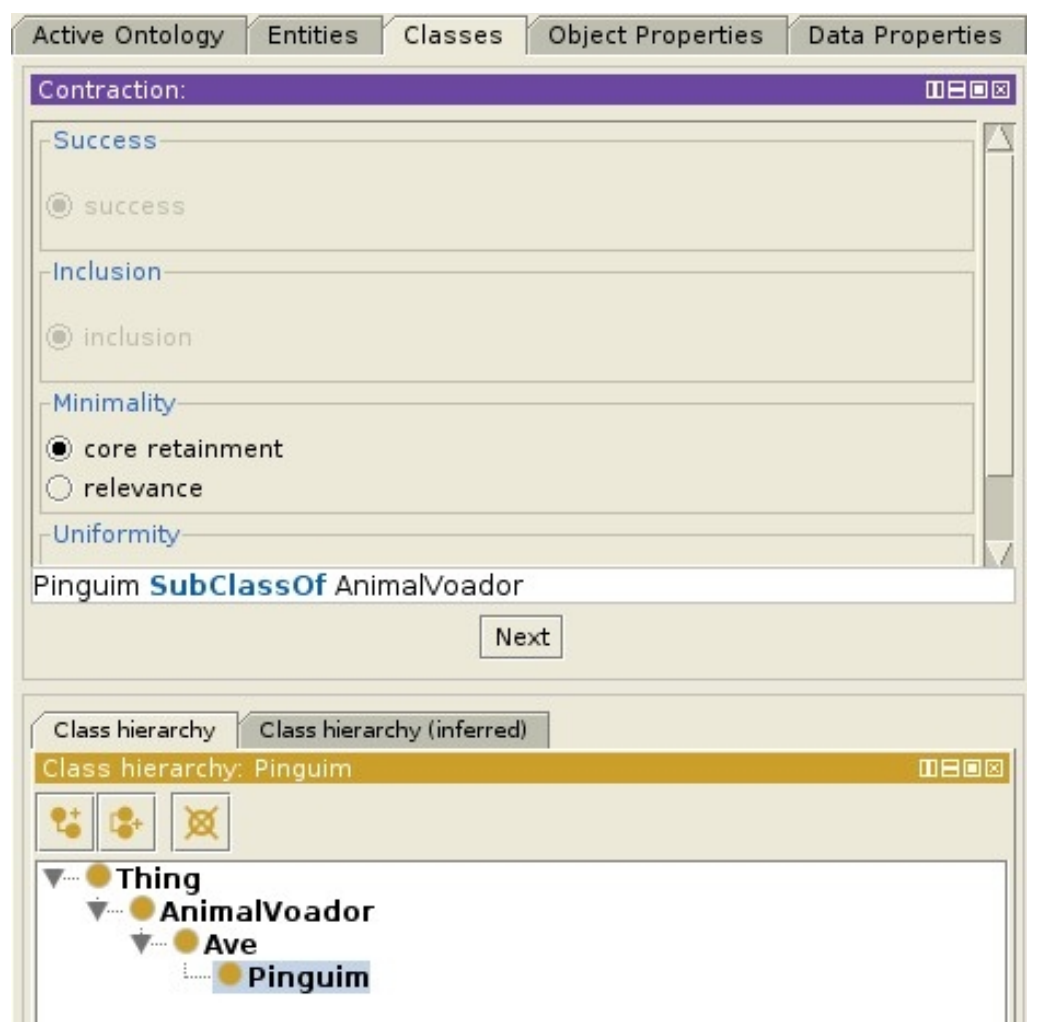

Figura 5.4: Plug-in recebendo textualmente a sentença pela qual operará contração

com esse ícone, na ontologia sobre a qual queremos operar e a interface gráfica da aplicação aparecerá na tela, conforme vemos na Figura 5.3.

A sentença que desejamos contrair da ontologia será inserida no editor de texto presente na parte inferior da interface gráfica, de cor branca. Esse recurso é o Manchester OWL Syntax Editor ${ }^{5}$, por meio do qual podemos expressar axiomas de maneira simplificada usando a Manchester OWL Syntax $\left[\mathrm{HDG}^{+} 06\right]$.

Por meio da ontologia aqui esquematizada, é possível inferir que pinguins são animais voadores. Suponha que não desejamos mais ter essa informação implícita. Assim, queremos contrair da nossa base de conhecimento a sentença Pinguim $\sqsubseteq$ AnimalVoador. Se a contração for feita por meio de uma operação Kernel, temos que só existe um subconjunto minimal da base que implica a sentença em questão. Esse conjunto é:

- Ave $\sqsubseteq$ AnimalVoador

- Pinguim $\sqsubseteq$ Ave

Logo, se desejamos contrair usando conjuntos kernel, esse é o conjunto que a aplicação precisa devolver. A sentença Pinguim $\sqsubseteq$ AnimalVoador na Manchester OWL Syntax é escrita como Pinguim SubClassOf AnimalVoador e é essa última que devemos inserir no editor de texto, conforme mostrado na Figura 5.4.

Antes de clicar no botão Next, é necessário escolher, por meio de um postulado de minimalidade (no plug-in, Minimality), que tipo de operação deseja-se executar. Se for Partial Meet, escolhemos o postulado de relevância (relevance), conforme o Teorema de Representação 1. Se for Kernel, escolhemos core-retainment, conforme o Teorema de Representação 2. Como na versão do plug-in apresentada nesse capítulo só está implementada a operação Kernel, ela será a escolhida.

\footnotetext{
${ }^{3}$ http://owlapi.sourceforge.net/

${ }^{4}$ https://github.com/fillipemanoel/ontology-change-plugin/wiki

${ }^{5}$ http://www.co-ode.org/downloads/manchesterowlsyntaxeditor/
} 


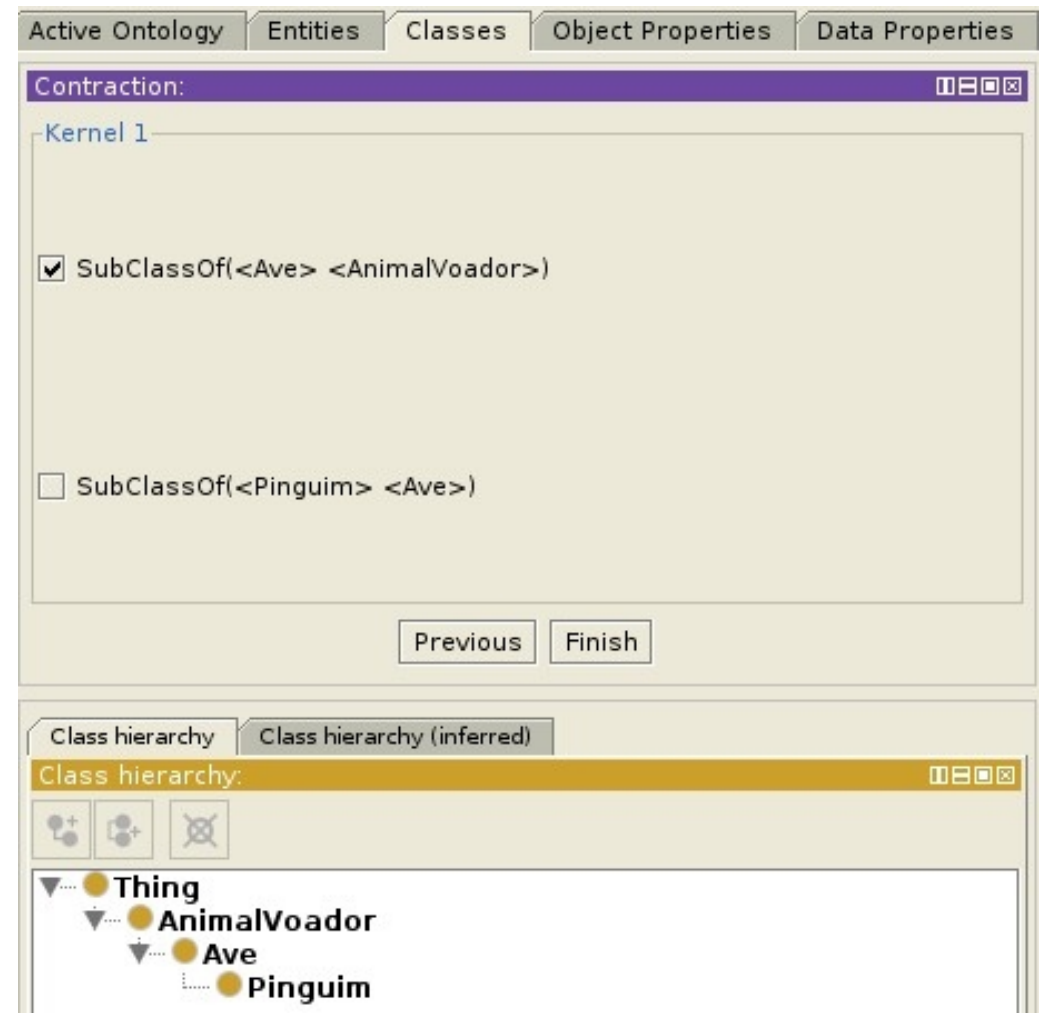

Figura 5.5: Kernel resultante da contração da ontologia pela sentença pedida

Ao clicar em Next, o plug-in calcula os elementos do conjunto Kernel e os exibe na tela, conforme vemos na Figura 5.5, o que está de acordo com o $\alpha-k e r n e l$ calculado acima. De acordo com as definições 6 e 7 do Capítulo 2, vê-se que as sentenças a serem removidas de cada elemento do Kernel são determinadas por meio de uma função de incisão. No caso da aplicação aqui demonstrada, o papel da função da incisão é delegado ao usuário, o qual deve selecionar as sentenças. Isso porque, em geral, o usuário, munido dos $\alpha$-kernels, é quem é capaz de determinar qual(is) delas deve(m) permanecer ou não.

No caso da contração aqui apresentada, é possível que o usuário, ao receber o $\alpha$-kernel, perceba que houve um erro em estabelecer que todas as aves voam (Ave $\sqsubseteq$ AnimalVoador). Ele pode, então, selecionar a sentença Ave SubClass Of AnimalVoador, a qual representa esse conhecimento e, como já exibido na Figura 5.5, está expressa pelo axioma SubClassOf $(\langle$ Ave $\rangle\langle$ AnimalVoador $\rangle)$. Ao clicar em Finish, o plug-in remove da ontologia o que foi selecionado, como pode-se ver na Figura 5.6. O usuário pode, ainda, desistir da operação clicando em Previous, que o leva de volta à tela inicial.

\subsubsection{Organização do código-fonte}

No projeto, todas as classes utilizadas estão no pacote src.revisor.ui. Dentro dele, há um outro pacote chamado algorithms, o qual contém as classes:

- Kernel: definida para realizar operações de contração simples via Kernel.

- Multiple Contraction: contém métodos que implementam os algoritmos de Contração Múltipla.

- PartialMeet: definida para realizar operações de contração simples via Partial Meet.

- Revision: métodos para implementação de revisão simples.

Ainda no pacote src.revisor.ui há 15 classes. Em relação aos recursos da interface do plug-in: 


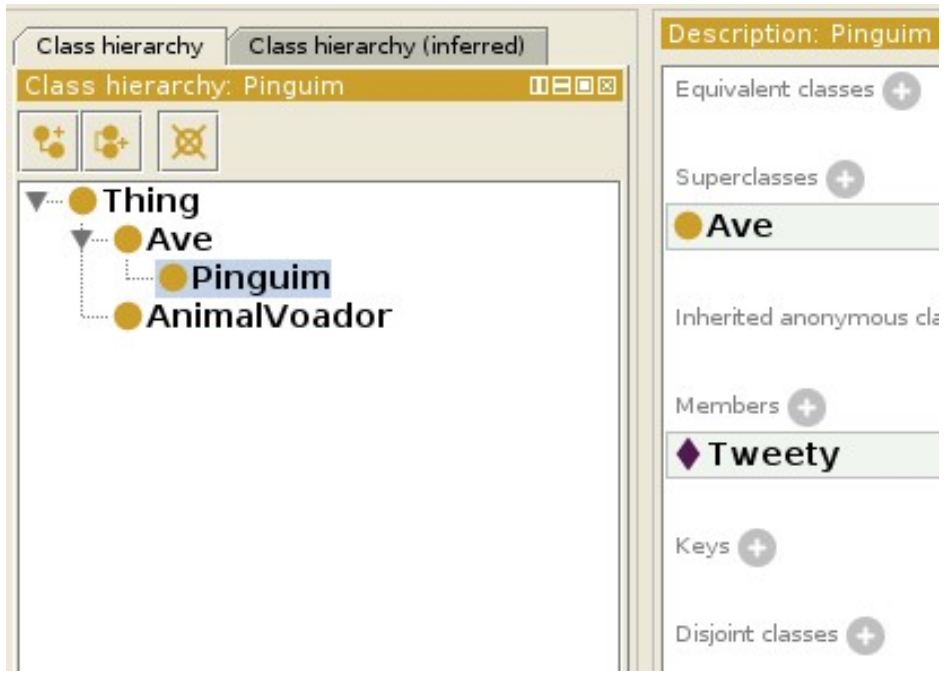

Figura 5.6: Resultado da ontologia contraída de acordo com a escolha do usuário

- AxiomButton: estende JCheckBox (Java) para cada axioma que será representado.

- AxiomGroup: métodos para manipular um conjunto de AxiomButton.

- KernelButton: estende JCheckBox para representar cada um dos axiomas dos $\alpha$-kernels.

- KernelItemListener: implementa a ItemListener do Java para auxiliar na finalização da operação (quando o usuário, no papel da função de incisão, já terminou de selecionar os axiomas).

- PostulateButton: estende JRadioButton (Java) para representar cada postulado que pode ser escolhido na seleção da operação desejada.

- PostulateGroup: métodos para manipular um conjunto de PostulateButton.

- PostulateItemListener: implementa a ItemListener para auxiliar na organização dos postulados que serão considerados na operação.

- RemainderActionListener: implementa ActionListener do Java para lidar com os KernelButton envolvidos de acordo com os postulados escolhidos.

Há também 4 classes Action, sendo que todas implementam ActionListener:

- AxiomAction: quando um usuário entra com um axioma no editor, os métodos desta ação checam se o mesmo está bem formado e, caso sim, adiciona-o à lista de axiomas na interface do plug-in.

- KernelAction: intermediária entre a finalização da entrada de axiomas e o cálculo dos elementos do Kernel.

- PostulatesAction: também trabalha na finalização da entrada de axiomas, mais especificamente para a organização da interface de entrada do plug-in após isso.

- RemoveAction: auxilia na remoção de axiomas quando o usuário deseja retirar algum da lista pela qual ele quer contrair a ontologia.

Por fim, há a RevisorAbstractView, classe abstrata que estende AbstractActiveOntologyViewComponent do Protégé e cuida de toda a inicialização do plug-in. As classes ContractionView e RevisionView são extensões dela e são chamadas conforme a escolha do usuário no menu Misc Views, assim como explicado na seção anterior. A definição da relação entre o menu e essas classes é definida no arquivo plugin.xml, o qual pertence ao jar do plug-in. 


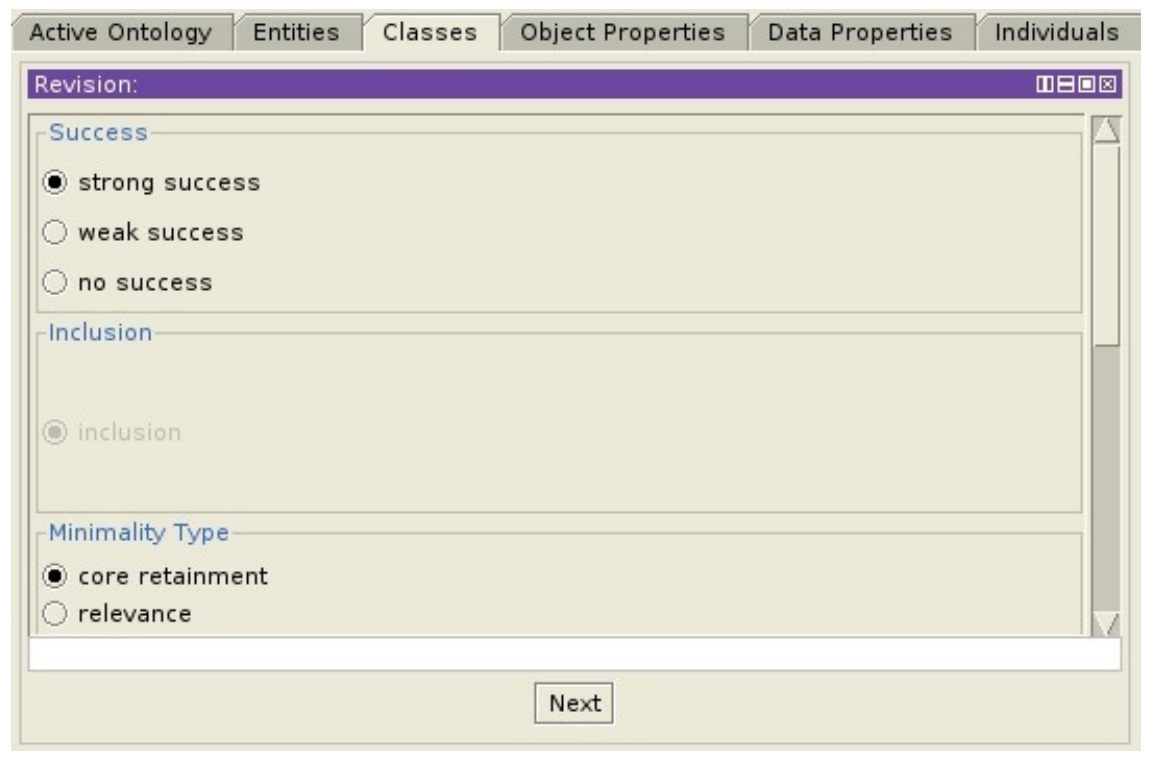

Figura 5.7: Tela inicial do plug-in para revisão

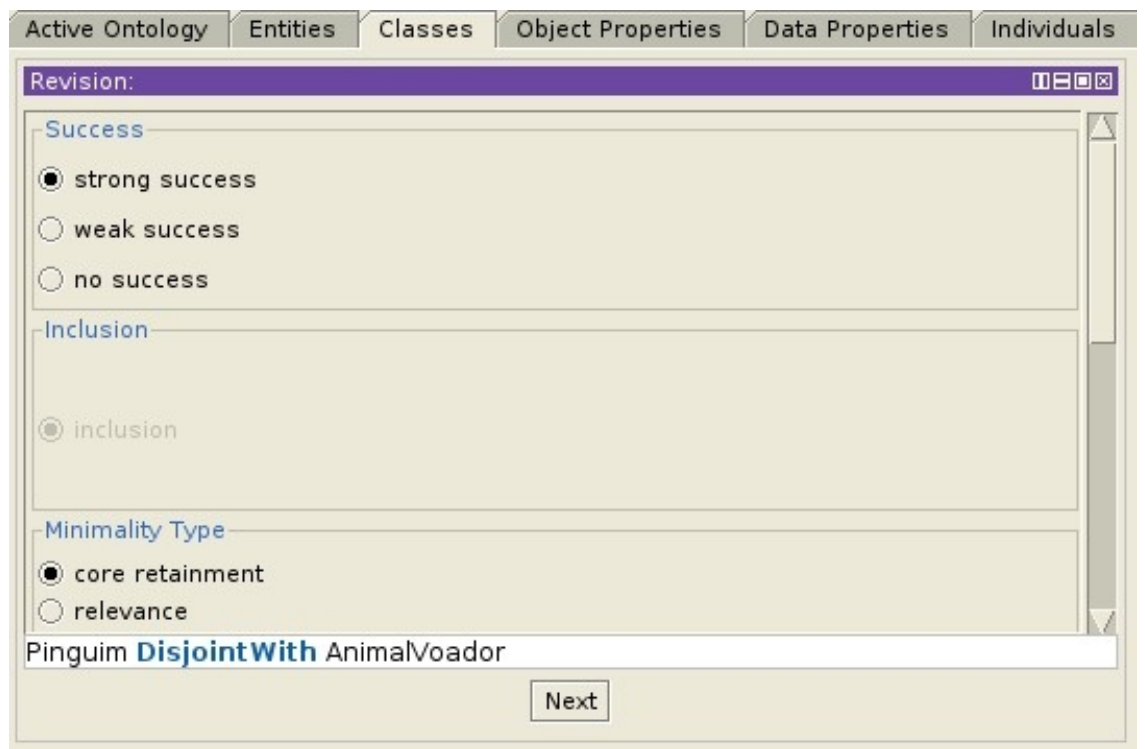

Figura 5.8: Plug-in recebendo textualmente a sentença pela qual operará revisão

\subsection{Revisão}

Assim como referenciado na Seção 2.6, mostraremos aqui o que foi implantado no plug-in em relação à operação de revisão. De modo semelhante à implementação para contração, invocamos o aplicativo Revision no menu Misc Views, o que fará aparecer um ícone redondo de cor preta junto ao cursor do mouse. Basta clicar, com esse ícone, na ontologia sobre a qual queremos operar e a interface gráfica da aplicação aparecerá na tela, conforme vemos na Figura 5.7.

Como exemplo, vamos utilizar a mesma ontologia de aves e pinguins aplicada para contração. A sentença pela qual desejamos revisar a ontologia será inserida no editor de texto presente na parte inferior da interface gráfica. Suponha que queremos acrescentar à base a crença de que Pinguim e AnimalVoador são classes disjuntas. Em LDs que dão suporte à negação, isto é modelado pelo complemento de um dos conceitos em questão. No nosso caso, a sentença seria Pinguim $\sqsubseteq$ not AnimalVoador. Essa sentença na Manchester OWL Syntax é escrita como Pinguim DisjointWith AnimalVoador e é essa última que devemos inserir no editor de texto, conforme mostrado na Figura 5.8 . 


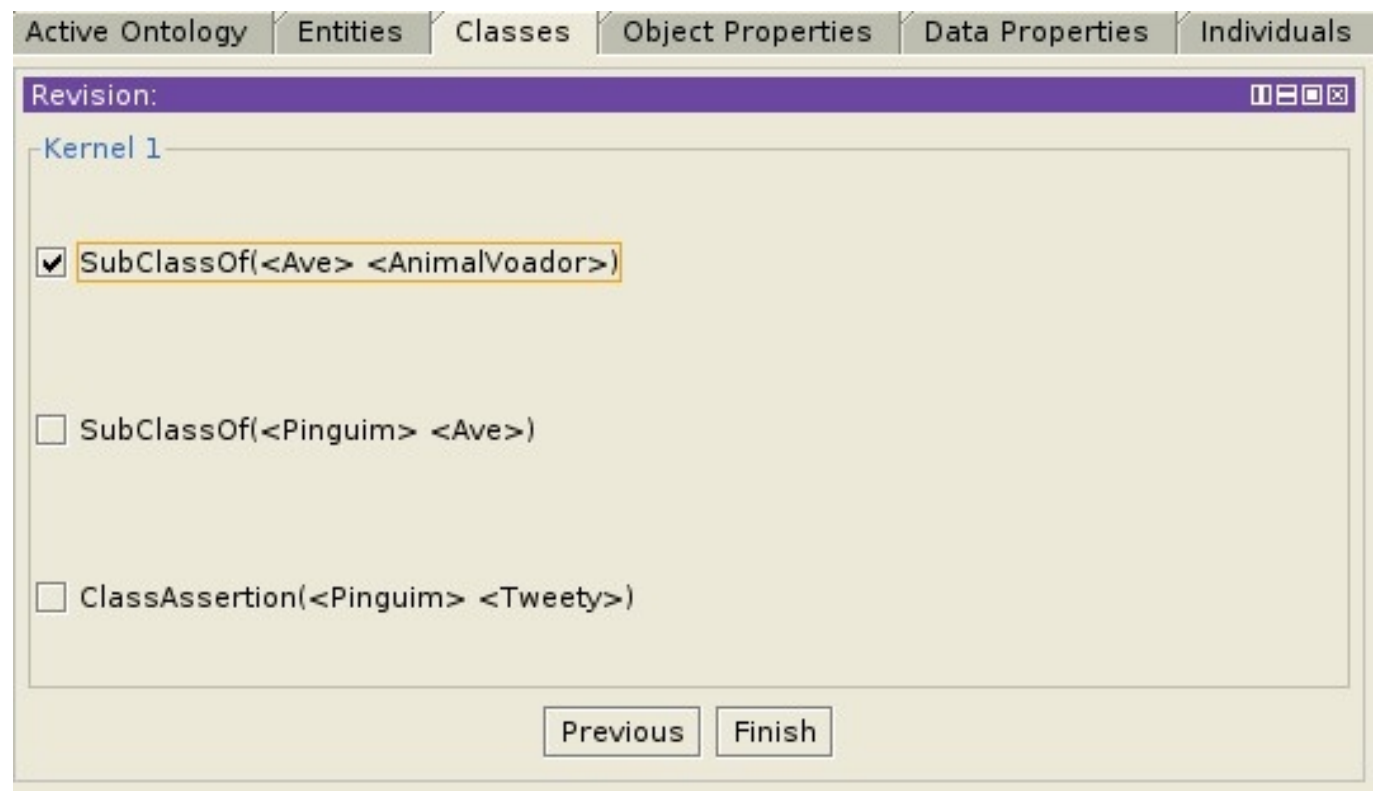

Figura 5.9: Kernel resultante da revisão da ontologia pela sentença pedida

Se a revisão for feita por meio de uma operação Kernel, temos que só existe um subconjunto inconsistente minimal da base. Esse conjunto é:

- Ave $\sqsubseteq$ AnimalVoador

- Pinguim $\sqsubseteq$ Ave

- Pinguim(Tweety)

Vale aqui fazer uma observação quanto ao fato da sentença de asserção na classe Pinguim fazer parte do $\alpha$-kernel acima. Assim como abordado na Subseção 4.2.2, se não houvesse essa asserção do indivíduo Tweety, a expansão da base pela crença da disjunção entre os conceitos Pinguim e AnimalVoador não a tornaria inconsistente mas sim incoerente, já que a base implicaria Pinguim $\sqsubseteq \emptyset$.

Ao clicar em Next, o usuário recebe o conjunto kernel calculado e, no nosso caso, escolhemos novamente excluir a sentença que expressa Ave como subclasse de AnimalVoador, conforme Figura 5.9. E a ontologia é revisada de acordo.

\subsection{Contribuições}

Neste capítulo, nossas contribuições no desenvolvimento do plug-in envolveram a atualização e refatoração do mesmo. Como um dos resultados, ele está compatível com as últimas versões do Protégé, da OWLAPI e do Pellet. O algoritmo Kernel também foi refatorado, antes implementado na sua versão recursiva apresentada em [RW08] mas substituído pela versão iterativa obtida em [Rib10]. Além disso, a visualização dos axiomas nos $\alpha$-kernels foi substituída por uma forma mais legível, uma vez que antes eles eram exibidos junto com o identificador da ontologia, o que é mostrado na Figura 5.10. Se o usuário deseja saber o identificador da ontologia, basta deixar o cursor do mouse sobre um axioma conforme a Figura 5.11.

No capítulo a seguir, apresentaremos uma implementação para Partial Meet e também para operações de contração múltipla. 


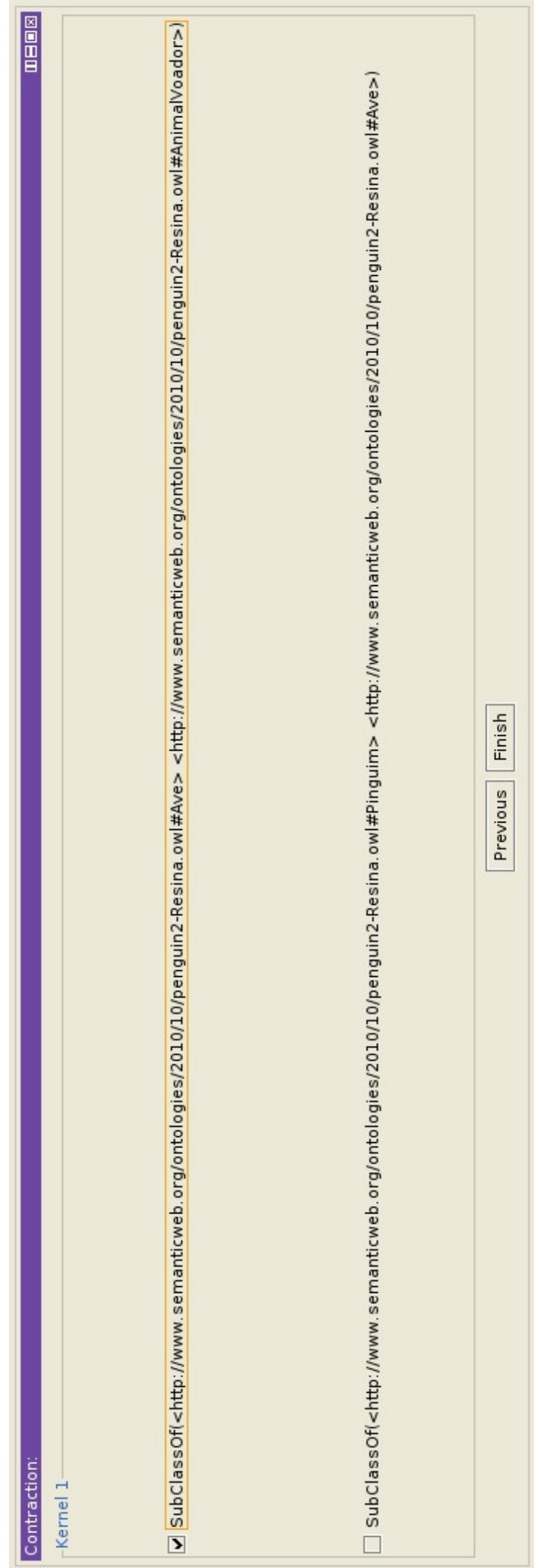

Figura 5.10: Modo de visualizaçẫo dos axiomas dos $\alpha$-kernels nas versões anteriores do plug-in 


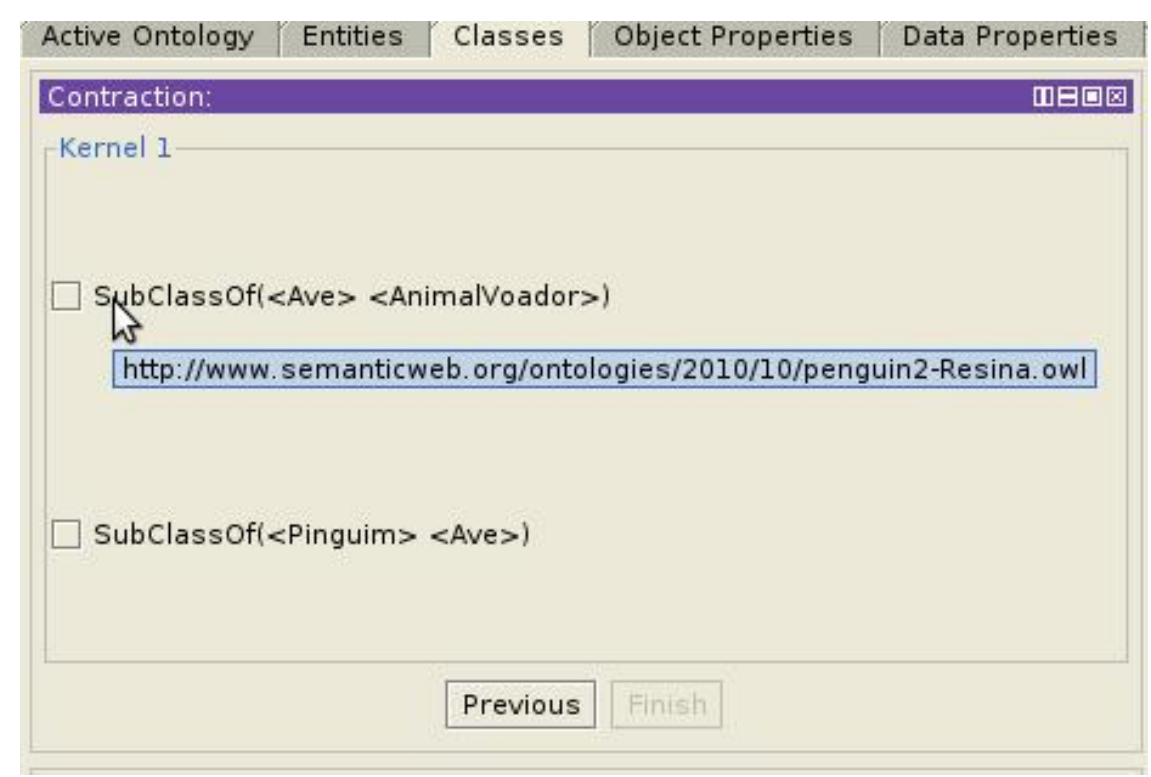

Figura 5.11: Modo de visualização dos axiomas dos $\alpha$-kernels na versão atual do plug-in 


\section{Capítulo 6}

\section{Partial Meet e Contração Múltipla}

Neste capítulo, apresentaremos os algoritmos que desenvolvemos para a implementação das operações Partial Meet e as operações de contração múltipla, além de mostrar como isso foi incorporado ao plug-in. Juntamente, falaremos de alguns testes que realizamos nos algoritmos e no plug-in.

\subsection{Operações por Partial Meet}

No Capítulo 2, foram apresentadas duas operações de contração: Kernel e Partial Meet. Assim como explicado no capítulo anterior, as operações no plug-in foram implementadas, inicialmente, a partir do algoritmo Kernel, buscando os conjuntos minimais que implicam a crença que se deseja remover. A obtenção do conjunto resíduo pode ser feita a partir do conjunto Kernel por meio do algoritmo de Reiter. Porém, tanto para que haja uma aplicação direta de ambos os algoritmos e também para que seja possível compará-los, propomos a implementação das operações por Partial Meet e a comparação de resultados obtidos com operações sobre ontologias submetidas a ambos os algoritmos.

\subsubsection{Algoritmo, correção e completude}

Desenvolvemos o algoritmo apresentado a seguir, juntamente com uma demonstração formal de sua correção e completude:

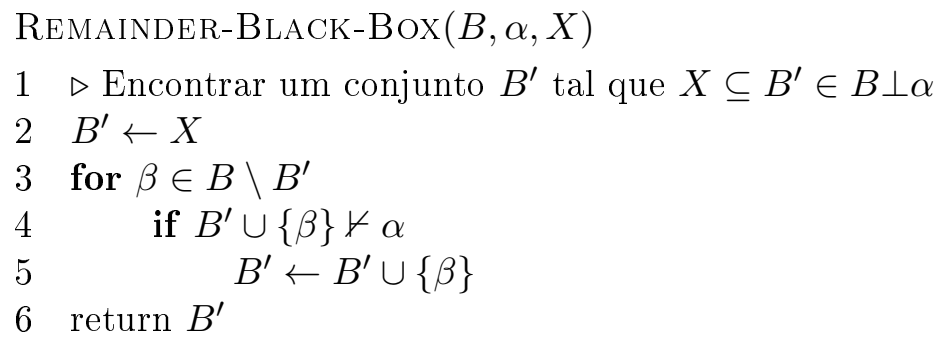

Proposição 1 O algoritmo Remainder-Black-Box devolve um elemento de $B \perp \alpha$.

Prova: Precisamos provar que o $B^{\prime}$ devolvido pelo algoritmo é um $\alpha$-remainder de $B$ (considerando que o $X$ passado como argumento não implica $\alpha$ ).

Suponha, por contradição, que o algoritmo devolve um $B^{\prime}$ tal que $B^{\prime} \notin B \perp \alpha$. Assim, ou $B^{\prime} \vdash \alpha$ ou $\exists Y$ tal que $B^{\prime} \subset Y \subseteq B$ e $Y \nvdash \alpha$ (isto é, $B^{\prime}$ não é maximal).

Suponha que o algoritmo devolveu $B^{\prime}$ tal que $B^{\prime} \vdash \alpha$. No algoritmo, as sentenças de $B$ são adicionadas a $B^{\prime}$ uma a uma (laço entre as linhas 3-5) e, toda vez que algum deles vai implicar $\alpha$, não é adicionado a $B^{\prime}$. Dessa forma, $B^{\prime}$ é composto progressivamente pela linha 4 do algoritmo e apenas se a nova sentença a ser adicionada, junto com as sentenças possivelmente já presentes em $B^{\prime}$, não implica $\alpha$ (condição checada na linha 3 ). Então, há um invariante na linha 3 (início do laço): $B^{\prime} \nvdash \alpha$. Contradição. 
Suponha que $\exists Y$ tal que $B^{\prime} \subset Y \subseteq B$ e $Y \nvdash \alpha$. Então, $\exists \beta \in Y$ tal que $\beta \notin B^{\prime}$. Se $\beta$ não foi adicionado a $B^{\prime}$, ele fez com que a condição da linha 3 falhasse. Assim, $B^{\prime} \cup\{\beta\} \vdash \alpha$. Contradição, porque $\left(B^{\prime} \cup\{\beta\}\right) \subseteq Y$ e $Y \nvdash \alpha$.

Portanto, Remainder-Black-Box devolve um elemento de $B \perp \alpha$.

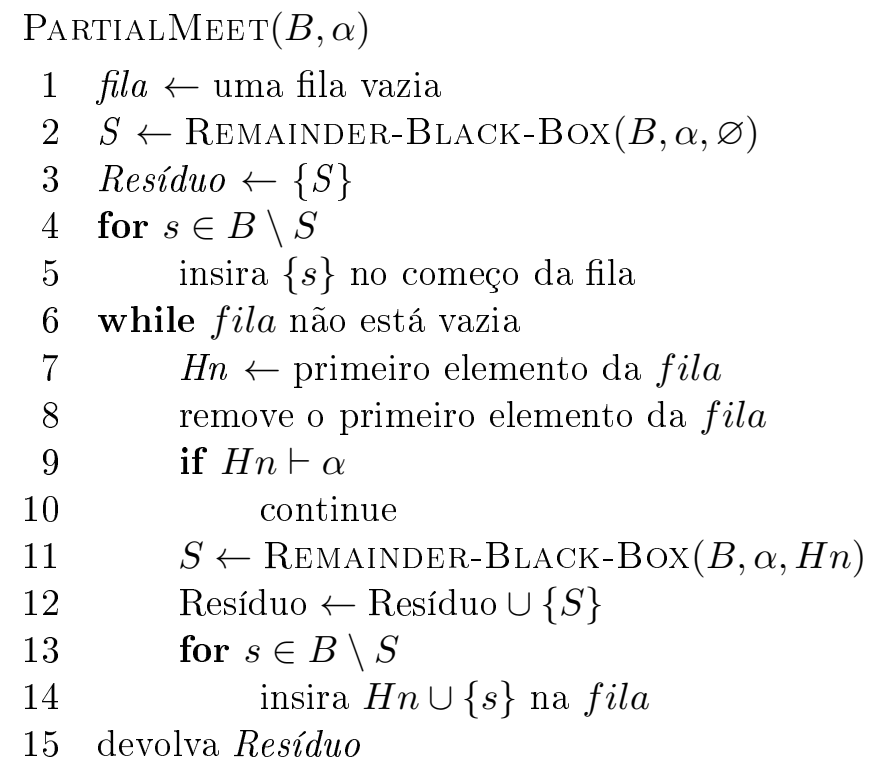

Proposição $2 O$ algoritmo PARTIALMeEt devolve o conjunto resíduo de $B$ em relação a uma sentença $\alpha(B \perp \alpha)$.

Prova: Em relação a esse algoritmo principal que busca encontrar todos os elementos de $B \perp \alpha$, nós precisamos de uma prova em dois passos:

1 - Provar que S na linha 11 é um elemento de $B \perp \alpha$.

2 - Provar que, se $X \in B \perp \alpha$, então $X$ será computado como $S$ na linha 11.

Parte 1:

A primeira parte é mais simples pois, como $H n$ não implica $\alpha$, é uma consequência direta do fato de Remainder-Black-Box devolver um elemento de $B \perp \alpha$. Portanto, $S$ na linha 11 é um elemento de $B \perp \alpha$.

Parte 2:

Para demonstrar essa parte, observaremos o invariante da fila válido na linha 6 do laço entre as linhas 6-14. Temos que, $\forall X \in B \perp \alpha$, ou $X \in$ Resíduo ou então $\exists A \in$ fila tal que $A \subseteq X$. No raciocínio a seguir, verificaremos a validade desse invariante.

Seja $X$ um elemento de $B \perp \alpha$. Se $X$ não for o primeiro elemento de $B \perp \alpha$ obtido na linha 2, então $\exists a \in B \backslash S$ tal que $a \in X$ e, portanto, $\{a\}$ será colocado na fila (linhas 4-5). Vale o invariante.

Agora, vamos considerar o laço entre as linhas 6 e 14. $H n$ recebe os elementos da fila. Toda vez que $H n \subset X$, há a possibilidade de Remainder-Black-Box devolver $X$ (linha 11), já que o $H n$ da iteração em questão é subconjunto do conjunto $S$ obtido na linha 11 naquela mesma iteração. Consideremos o caso quando isso ocorre $(H n \subseteq X)$. Se REMAIndER-Black-BoX devolve $X$, então esse $\alpha$-resíduo é encontrado e computado em Resíduo. Caso contrário, $\exists a \in B \backslash S$ tal que $a \in X$, e $H n \cup\{a\}$ é colocado na fila (linhas 13-14). Assim, o invariante continua valendo.

Como na linha 15 a fila está vazia, temos que Resíduo $=B \perp \alpha$. Logo, se $X \in B \perp \alpha$, então $X$ será computado como $S$ na linha 11.

Observamos que este algoritmo não é determinístico. O não-determinismo do mesmo está na linha 3 do Remainder-Black-Box e nas linhas 4 e 13 do PartialMeEt, pontos em que são feitas 
escolhas nas iterações sobre um conjunto. Os resultados do REMAIndER-Black-Box dependem diretamente das escolhas feitas. No entanto, como no algoritmo PARTialMeEt calculamos todos os $\alpha$-resíduos, as escolhas em questão não alteram o resultado, influenciando apenas na ordem de execução do algoritmo.

Assim como no algoritmo KeRnel apresentado na Seção 2.5, este algoritmo é independente da linguagem, já que o método Black-Box não depende do motor de inferências. Nos testes a seguir, a linguagem utilizada será OWL.

\subsubsection{Implementação}

Ao terminar o desenvolvimento do algoritmo, implementamos uma funcionalidade no plugin para realizar operações de contração por meio de Partial Meet. Para demonstração, retomemos o exemplo utilizado na Seção 5.2.1. Queremos contrair a base pelo axioma Pinguim $\sqsubseteq$ AnimalVoador. Nesse caso, o conjunto resíduo possui dois elementos:

\section{$\alpha$-resíduo 1:}

- Ave $\sqsubseteq$ AnimalVoador

- Pinguim(Tweety)

$\alpha$-resíduo 2:

- Pinguim $\sqsubseteq$ Ave

- Pinguim(Tweety)

Na Figura 6.1, vemos novamente a sentença Pinguim SubClassOf AnimalVoador escrita no editor de Manchester OWL Syntax mas já com o postulado de relevância selecionado (conforme o Teorema de Representação 1).

Após clicar em Next, aparecem ao usuário justamente os dois resíduos calculados acima, o que pode ser conferido na Figura 6.2.

De acordo com as Definições 3 e 4 do Capítulo 2, vê-se que os elementos do resíduo a serem selecionados são determinados por meio de uma função de seleção. No caso da aplicação aqui demonstrada, o procedimento é análogo ao do modo Kernel exibido no capítulo anterior: o papel da função da seleção é delegado ao usuário, o qual deve selecionar os $\alpha$-resíduos desejados. Isso porque, em geral, o usuário, munido dos mesmos, é quem é capaz de determinar qual(is) deles deve $(m)$ entrar na computação da intersecção que será o resultado final da operação.

No caso da interface gráfica do plug-in, isso é feito por meio do botão choose/unchoose presente em cada elemento do resíduo. Choose é usado para escolher aquele elemento e unchoose para desistir da escolha. Para a ontologia e sentença em questão, pode-se escolher apenas um elemento, o primeiro, já que quando a função de seleção devolve um conjunto unitário, ele é o próprio resultado da contração e não se deseja mais que aves sejam classificadas como animais voadores. Vê-se essa escolha na Figura 6.3.

Ao clicar em Finish, o plug-in calcula a intersecção dos $\alpha$-resíduos selecionados e atualiza a ontologia de acordo com esse resultado, como pode-se ver na Figura 5.6. Da mesma forma como no modo Kernel, o usuário pode, ainda, desistir da operação clicando em Previous, que o leva de volta à tela inicial.

\subsection{Algoritmos para contração múltipla}

No Capítulo 3, apresentamos uma revisão bibliográfica em relação às operações de contração múltipla, definidas em package e choice tanto para Kernel quanto para Partial Meet. Para poder aplicar tais operações no plug-in, desenvolvemos algoritmos que sejam capazes de realizá-las de acordo com os postulados e definições dados. 


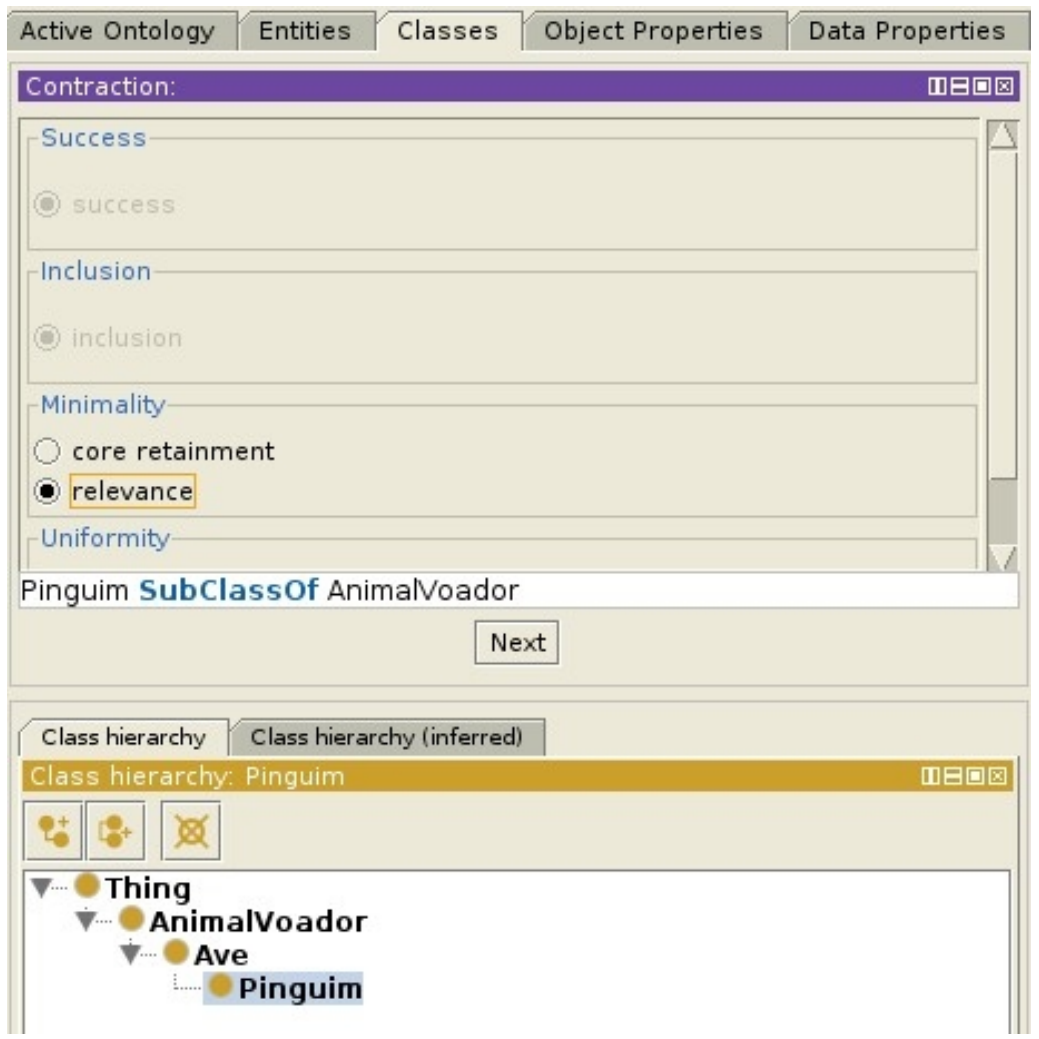

Figura 6.1: Plug-in recebendo textualmente a sentença pela qual operará contração

\begin{tabular}{|c|c|c|c|c|}
\hline Active Ontology & Entities & Classes & Object Properties & Data Properties \\
\hline \multicolumn{4}{|l|}{ Contraction: } & 由日口回 \\
\hline \multicolumn{5}{|c|}{ Remainder 1} \\
\hline \multicolumn{5}{|c|}{$\square$ SubClass of $(<$ Pinguim $><$ Ave $>$ ) } \\
\hline \multicolumn{5}{|c|}{$\square$ classAssertion(<Pinguim $><$ Tweety $>$ ) } \\
\hline & & \multicolumn{2}{|c|}{ choose } & \\
\hline \multicolumn{5}{|l|}{ Remainder 2} \\
\hline \multicolumn{5}{|c|}{$\square$ ClassAssertion(<Pinguim> < Tweety>) } \\
\hline \multicolumn{5}{|c|}{ choose } \\
\hline & & Previous & Finish & \\
\hline
\end{tabular}

Figura 6.2: Conjunto resíduo resultante da contração da ontologia pela sentença pedida 


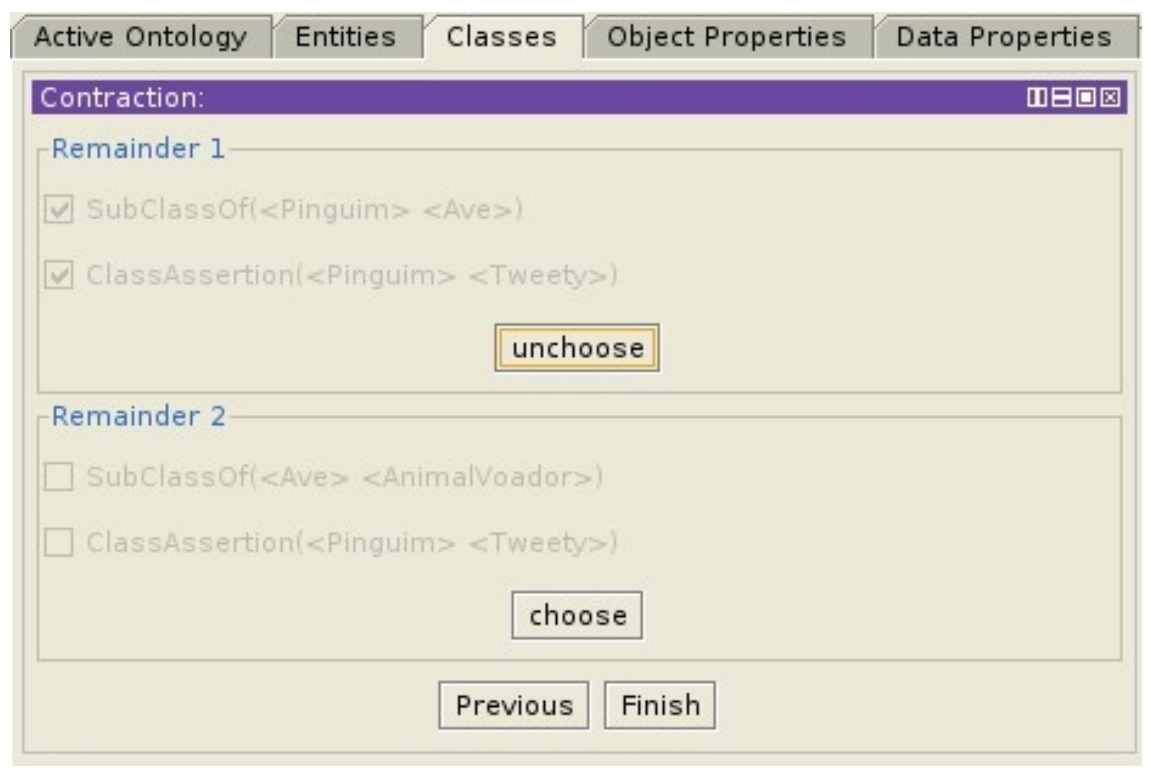

Figura 6.3: Seleção dos elementos do conjunto resíduo sobre os quais se deseja que seja operada a intersecção

\subsubsection{Kernel Package}

Apresentamos, aqui, os algoritmos para contração Kernel package:

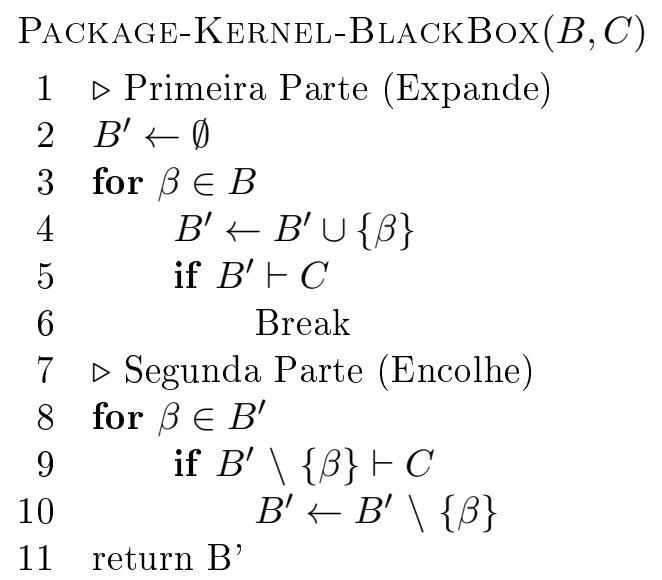

Proposição 3 O algoritmo Package-Kernel-BlackBox devolve um elemento de $B \Perp_{P} C$.

Prova: Precisamos provar que o $B^{\prime}$ devolvido pelo algoritmo é tal que $B^{\prime} \in B \Perp_{P} C$.

Suponha, por contradição, que o algoritmo devolve um $B^{\prime}$ tal que $B^{\prime} \notin B \Perp_{P} C$. Assim, ou $B^{\prime} \nvdash C$ ou $\exists K$ tal que $K \subset B^{\prime} \subseteq B$ e $K \vdash C$ (isto é, $B^{\prime}$ não é minimal).

Suponha que $B^{\prime} \nvdash C$. Como $B^{\prime}$ começa vazio e é construído na linha 4 , a condição da linha 5 junto com o comando de interrupção de laço na linha 6 nos garante um invariante na linha 3 do início laço entre as linhas 3-6: $B^{\prime} \nvdash C$. Assim, esse laço só é interrompido quando $B^{\prime} \vdash C$. No laço entre as linhas 8-10, um elemento $\beta \in B^{\prime}$ só é removido de $B^{\prime}$ se $B^{\prime} \backslash\{\beta\} \vdash C$. Logo, $B^{\prime}$ devolvido pelo algoritmo é tal que $B^{\prime} \vdash C$. Contradição.

Suponha que $\exists K$ tal que $K \subset B^{\prime} \subseteq B$ e $K \vdash C$. Então $\exists \beta \in B^{\prime}$ tal que $B^{\prime} \backslash\{\beta\} \vdash C$. Portanto, $\beta$ foi removido de $B^{\prime}$ devido à condição da linha 9. Assim, $\beta \notin B^{\prime}$ devolvido pelo algoritmo. Contradição.

Portanto, Package-Kernel-BlackBox devolve um elemento de $B \Perp_{P} C$. 


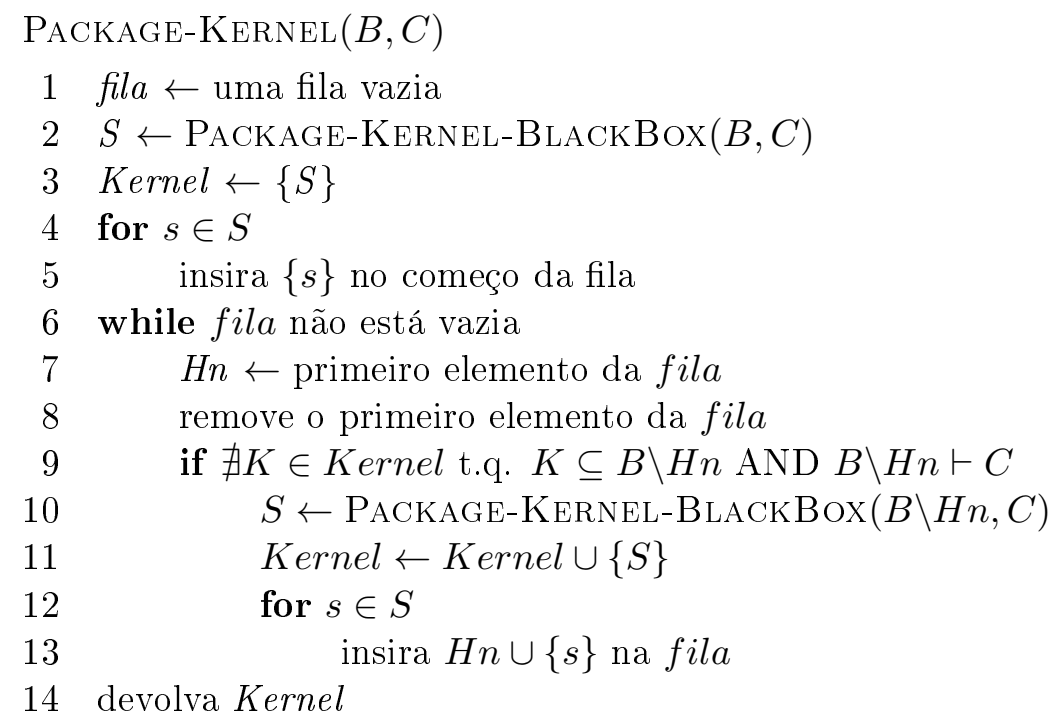

Proposição 4 O algoritmo PACKAGEKERnel devolve o conjunto kernel de $B$ em relação ao conjunto $C$ por meio de contração package $\left(B \Perp_{P} C\right)$.

Prova: Em relação a esse algoritmo principal que busca encontrar todos os elemento do kernel de $B$ em relação a $C$ por meio de contração package, nós precisamos de uma prova em dois passos: 1 - Provar que $\mathrm{S}$ na linha 10 é um elemento de $B \Perp_{P} C$.

2 - Provar que, se $X \in B \Perp_{P} C$, então $X$ será computado como $S$ na linha 10.

Parte 1:

Como o método Package-Kernel-BlackBox na linha 10 só é invocado quando $B \backslash H n \vdash C$, temos que a prova dessa primeira parte decorre diretamente da correção do algoritmo PACKAGEKernel-BlackBox segundo a Proposição 3.

Parte 2: Para demonstrar essa parte, observaremos o invariante da fila válido na linha 6 do laço entre as linhas 6-13. Temos que, $\forall X \in B \Perp_{P} C$, ou $X \in$ Kernel ou $\exists A \in$ fila tal que $X \subseteq B \backslash A$. No raciocínio a seguir, verificaremos a validade desse invariante.

Seja $X$ um elemento de $B \Perp_{P} C$ e $S$ o conjunto obtido na linha 2. Se $X \neq S$, então $\exists a \in S$ tal que $a \notin X$ e $\{a\}$ será colocado na fila. Vale o invariante.

Agora vamos considerar o laço entre as linhas 6-13, sendo $S$ agora o conjunto obtido na linha 10. $H n$ recebe os elementos da fila. Toda vez que $H n \nsubseteq X$, há a possibilidade de PaCKage-KernelBlackBox devolver $X$ (linha 10), já que o conjunto passado como primeiro argumento a esse algoritmo será $B \backslash H n$, sendo que $B \backslash H n \vdash C$, ou seja, o $H n \nsubseteq S$, sendo S o conjunto devolvido na linha 10 na iteração em questão. Se PACKage-Kernel-BlackBox devolve $X$, então esse elemento é encontrado e alocado em Kernel. Caso contrário, $\exists a \in S$ tal que $a \notin X$ e $H n \cup\{a\}$ será colocado na fila (linhas 12-13). Assim, o invariante continua valendo.

Como na linha 14 a fila está vazia, temos que Kernel $=B \Perp_{P} C$. Logo, se $X \in B \Perp_{P} C$ e não for computado como $S$ na linha 2, será computado como $S$ na linha 10.

\section{Implementação}

Apresentaremos, aqui, o funcionamento do plug-in com o desenvolvimento da funcionalidade que permite a operação de contração múltipla. Para tal, usaremos a ontologia das pizzas, conhecida ontologia na literatura por ser o recurso base no tutorial do editor Protégé. Na Figura 6.4, temos uma visão geral da hierarquia de classes dessa ontologia.

Para invocar o plug-in, o procedimento é o mesmo do apresentado no capítulo anterior, ou seja, por meio do menu Window-Views-Misc Views-Contraction. Em seguida, ao clicar sobre a ontologia, temos a tela inicial da aplicação conforme a Figura 6.5. 


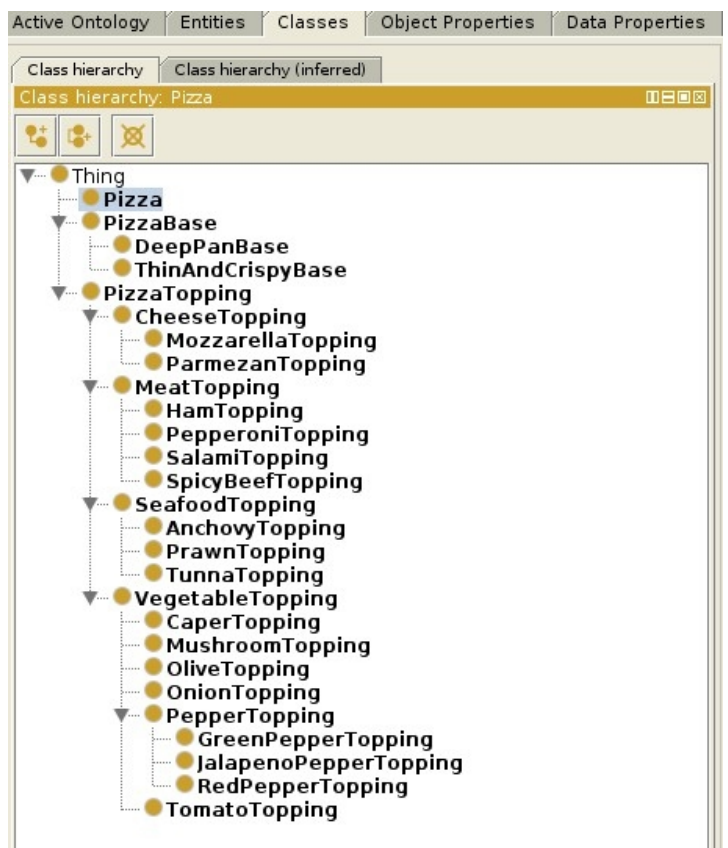

Figura 6.4: Ontologia das pizzas modelada a partir do tutorial do Protégé

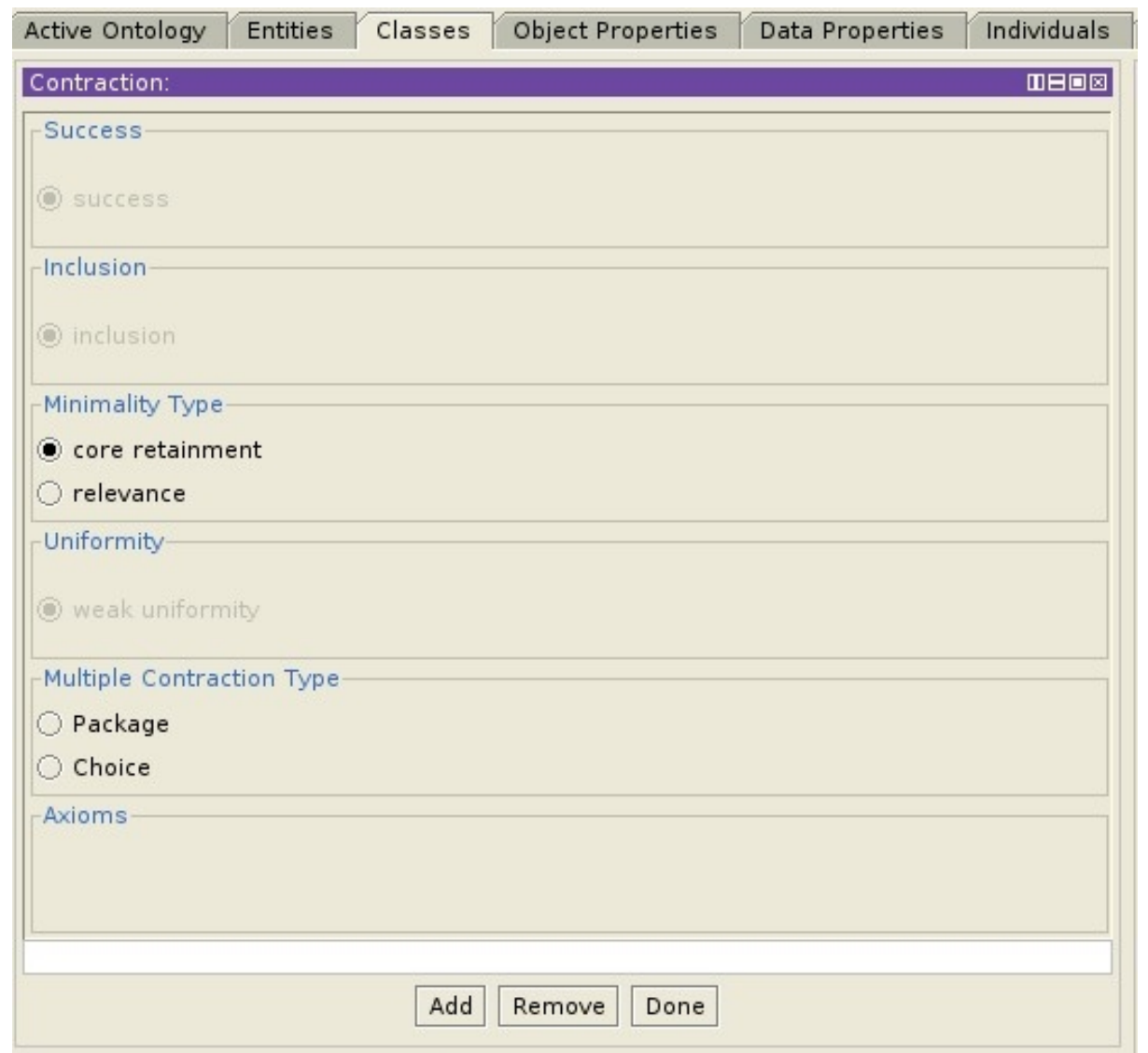

Figura 6.5: Tela inicial do plug-in com funcionalidade para contração múltipla 


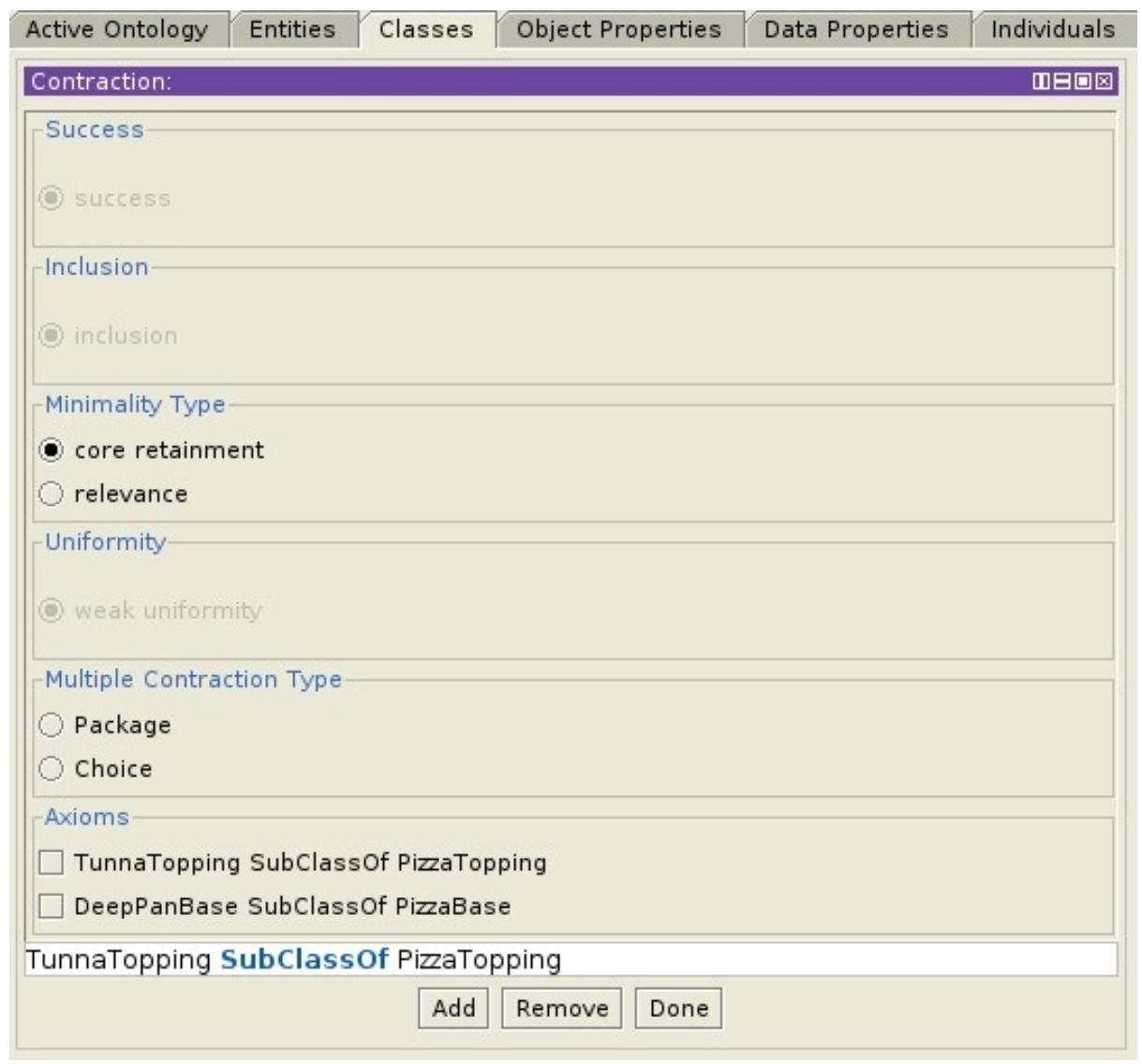

Figura 6.6: Exemplo de adição de 2 axiomas ao conjunto pelo qual queremos contrair

É possível ver que, por último antes do editor da Manchester OWL Syntax, há um espaço entitulado como Axioms, espaço este destinado às sentenças que formarão o conjunto pelo qual contrairemos a ontologia. Antes de dar prosseguimento à operação de contração, o usuário poderá, por meio dos botões $A d d$ e Remove, adicionar e remover, respectivamente, sentenças do conjunto. Suponha que se deseja adicionar duas sentenças: DeepPanBase SubClassOf PizzaBase e TunaTopping SubClassOf PizzaTopping. Podemos ver, na Figura 6.6, ambas as sentenças no espaço Axioms.

Se desejamos desistir de contrair por TunaTopping SubClassOf PizzaTopping, basta selecionar essa sentença e clicar em Remove (Figura 6.7).

Suponha que não desejamos mais ter implícitas duas informações: que DeepPanBase é subclasse de PizzaBase e que JalapenoPepperTopping é um tipo de PizzaTopping. Assim, queremos contrair da nossa base de conhecimento o conjunto formado pelas sentenças DeepPanBase $\sqsubseteq$ PizzaBase e JalapenoPepperTopping $\sqsubseteq$ PizzaTopping. Por meio de contração Kernel package, existem dois subconjuntos minimais da base que implicam algo do conjunto em questão. Esses subconjuntos são:

\section{Elem. Kernel 1:}

- JalapenoPepperTopping $\sqsubseteq$ PepperTopping

- PepperTopping $\sqsubseteq$ VegetableTopping

- VegetableTopping $\sqsubseteq$ PizzaTopping

\section{Elem. Kernel 2:}

- DeepPanBase $\sqsubseteq$ PizzaBase

Logo, se desejamos contrair usando conjuntos kernel, esses são os conjuntos que a aplicação precisa devolver. As sentenças DeepPanBase $\sqsubseteq$ PizzaBase e JalapenoPepperTopping $\sqsubseteq$ 


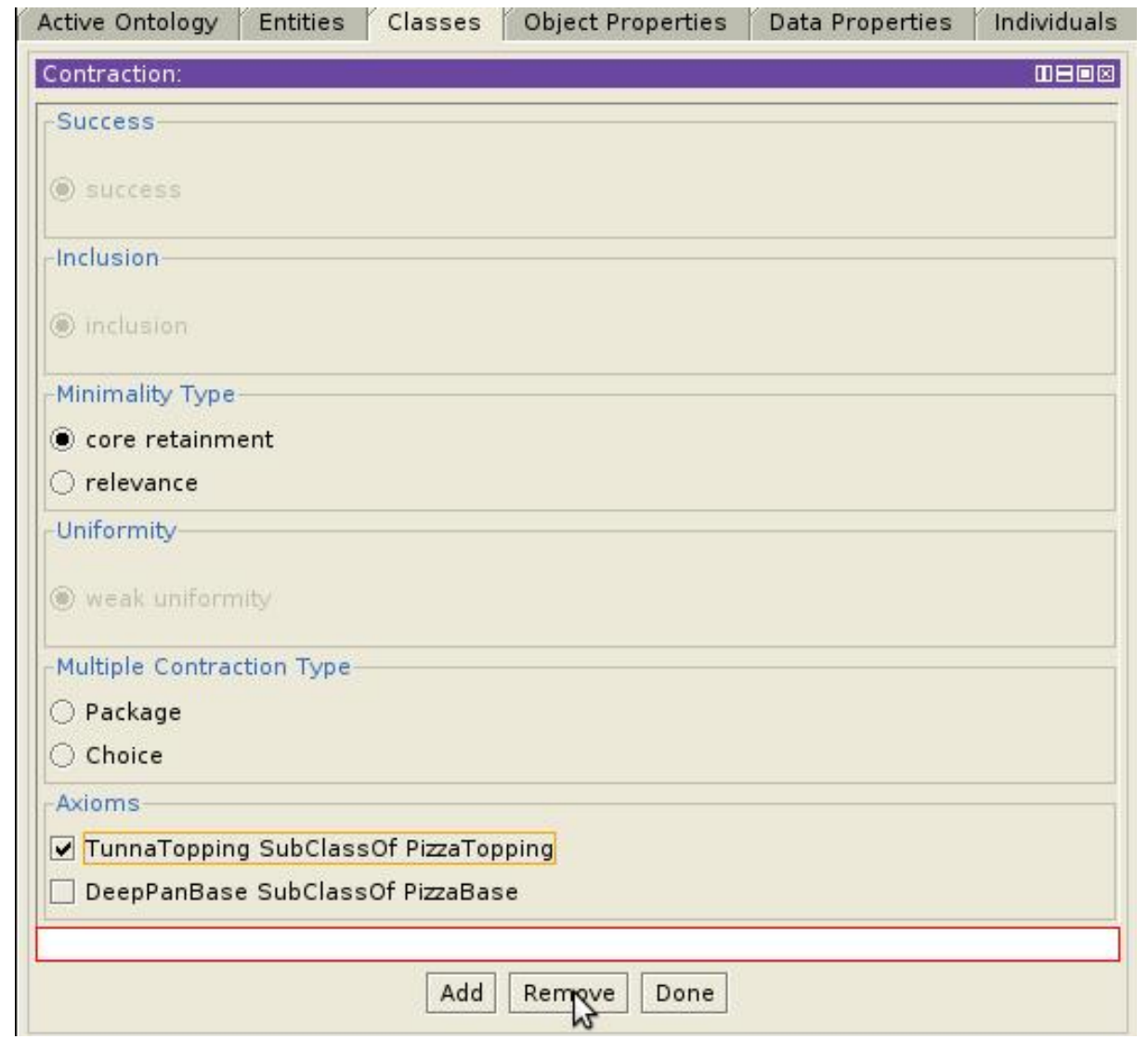

Figura 6.7: Exemplo de remoção de um axioma antes de dar prosseguimento à operação de contração

PizzaTopping na Manchester OWL Syntax são escritas, respectivamente, como JalapenoPepperTopping SubClassOf PizzaTopping e DeepPanBase SubClassOf PizzaBase. No caso agora que estamos trabalhando com contração múltipla, quando o usuário deseja adicionar a última sentença antes de executar a contração, ele não a adiciona ao quadro Axioms mas clica em Done, conforme a Figura 6.8. Antes de fazer isso, ele deve apenas escolher o tipo de contração múltipla que deseja operar por meio das opções presentes no quadro Multiple Contraction Type. No caso aqui apresentado, estamos investigando o funcionamento da contração package, que aparece na figura como a opção selecionada.

Pela Figura 6.9, vemos que o plug-in devolve exatamente os elementos do Kernel calculados acima. Inclusive, como um deles contém apenas uma sentença, é ela que será removida, por isso não foi dada opção ao usuário. Assim como explicado no capítulo anterior, nessa versão com contração múltipla o papel da função de incisão continua sendo delegado ao usuário. Em relação ao Kernel 1, decidimos desistir da crença de que PepperTopping é um VegetableTopping. Na Figura 6.10 temos o estado final da ontologia.

Apresentaremos, agora, um segundo exemplo com uma sentença envolvendo união de conceitos. Considerando a ontologia de volta ao estado original, suponha que não desejamos mais a união dos conceitos MozzarellaTopping e HamTopping seja um subconceito de PizzaTopping (MozzarellaTopping $\sqcup$ HamTopping $\sqsubseteq$ PizzaTopping) e nem que ParmezanTopping seja um subconceito de PizzaTopping (ParmezanTopping $\sqsubseteq$ PizzaTopping). Em Manchester OWL Syntax, essas sentenças são expressas, respectivamente, como MozzarellaTopping or HamTopping SubClassOf PizzaTopping e ParmezanTopping SubClassOf PizzaTopping, como pode ser visto na Figura 6.11 .

Para que a união dos conceitos em questão deixe de ser um subconceito de PizzaTopping, basta que pelo menos um dos conceitos deixe de ser subconceito de PizzaTopping. Assim, temos dois elementos no conjunto Kernel, os quais são devolvidos pelo plug-in (Figura 6.12). 


\begin{tabular}{|c|c|c|c|c|c|c|}
\hline Active Ontology & Entities & Classes & \multicolumn{2}{|c|}{ Object Properties } & Data Properties & Individuals \\
\hline \multicolumn{5}{|l|}{ Contraction: } & & 向日回 \\
\hline \multicolumn{7}{|l|}{ Success } \\
\hline \multicolumn{7}{|l|}{ (9) success } \\
\hline \multicolumn{7}{|l|}{ Inclusion } \\
\hline \multicolumn{7}{|l|}{ (C) inclusion } \\
\hline \multicolumn{7}{|c|}{ Minimality Type } \\
\hline \multicolumn{7}{|c|}{ (- core retainment } \\
\hline \multicolumn{7}{|l|}{ Qrelevance } \\
\hline \multicolumn{7}{|l|}{ Uniformity } \\
\hline \multicolumn{7}{|c|}{ (C) weak uniformity } \\
\hline \multicolumn{7}{|c|}{ Multiple Contraction Type } \\
\hline \multicolumn{7}{|c|}{ - Package } \\
\hline \multicolumn{7}{|l|}{ Choice } \\
\hline \multicolumn{7}{|l|}{ Axioms } \\
\hline \multicolumn{7}{|c|}{$\square$ JalapenoPepperTopping SubClass of PizzaTopping } \\
\hline \multicolumn{7}{|c|}{ DeepPanBase SubClass of PizzaBase } \\
\hline & & Add & Remove & Done & & \\
\hline
\end{tabular}

Figura 6.8: Exemplificação de como adicionar sentenças e finalizar para dar prosseguimento à contração

\begin{tabular}{|c|c|c|c|c|c|c|}
\hline Active Ontology & Entities & Classes & \multicolumn{2}{|c|}{ Object Properties } & Data Properties & Individuals \\
\hline \multicolumn{6}{|l|}{ Contraction: } & Ш曰口回 \\
\hline \multicolumn{7}{|l|}{ Kernel 1} \\
\hline \multicolumn{7}{|c|}{$\checkmark$ SubClassOf(<PepperTopping $><$ VegetableTopping $>$ ) } \\
\hline \multicolumn{7}{|c|}{$\square$ SubClass Of( $<$ VegetableTopping $><$ PizzaTopping $>$ ) } \\
\hline \multicolumn{7}{|c|}{$\square$ SubClassOf( <JalapenoPepperTopping $><$ PepperTopping $>$ ) } \\
\hline \multicolumn{7}{|l|}{ Kernel 2} \\
\hline \multicolumn{7}{|c|}{$\square$ SubClass Of(<DeepPanBase $><$ PizzaBase $>$ ) } \\
\hline & & & vious & Finish & & \\
\hline
\end{tabular}

Figura 6.9: Conjunto Kernel resultante da contração múltipla package pelas sentenças selecionadas 


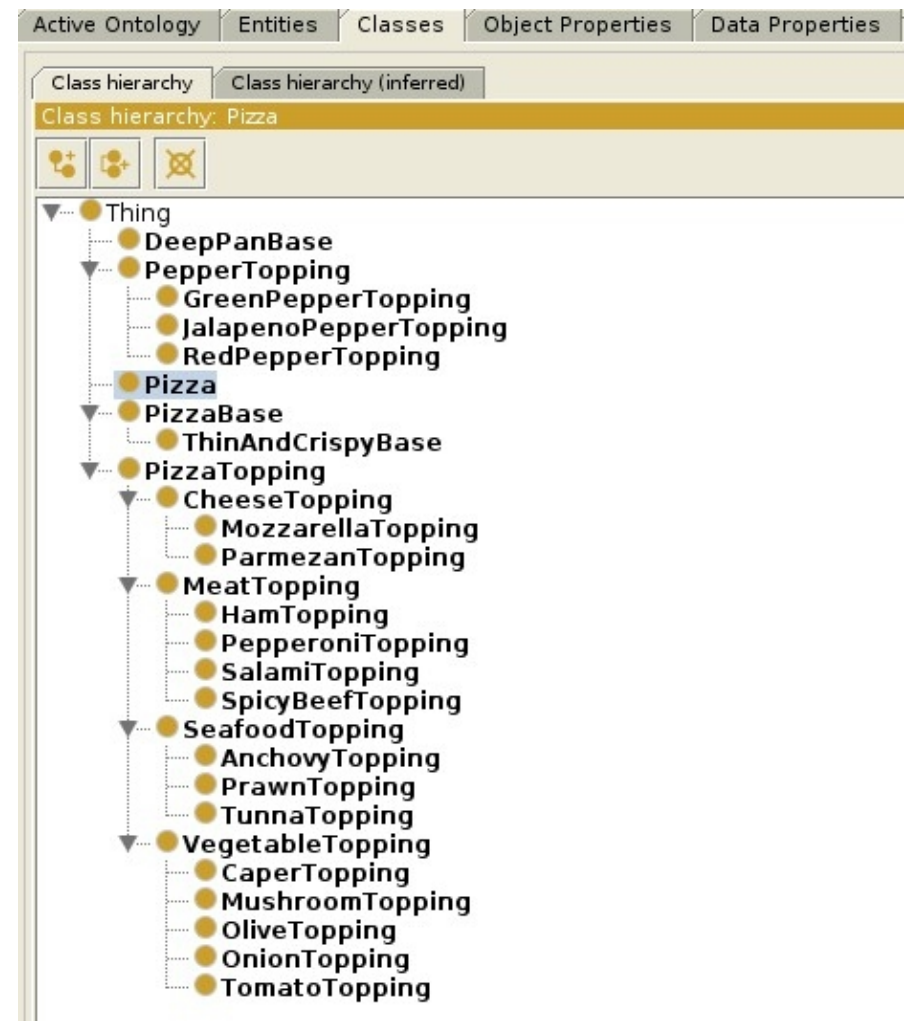

Figura 6.10: Ontologia após ser aplicada contração Kernel package

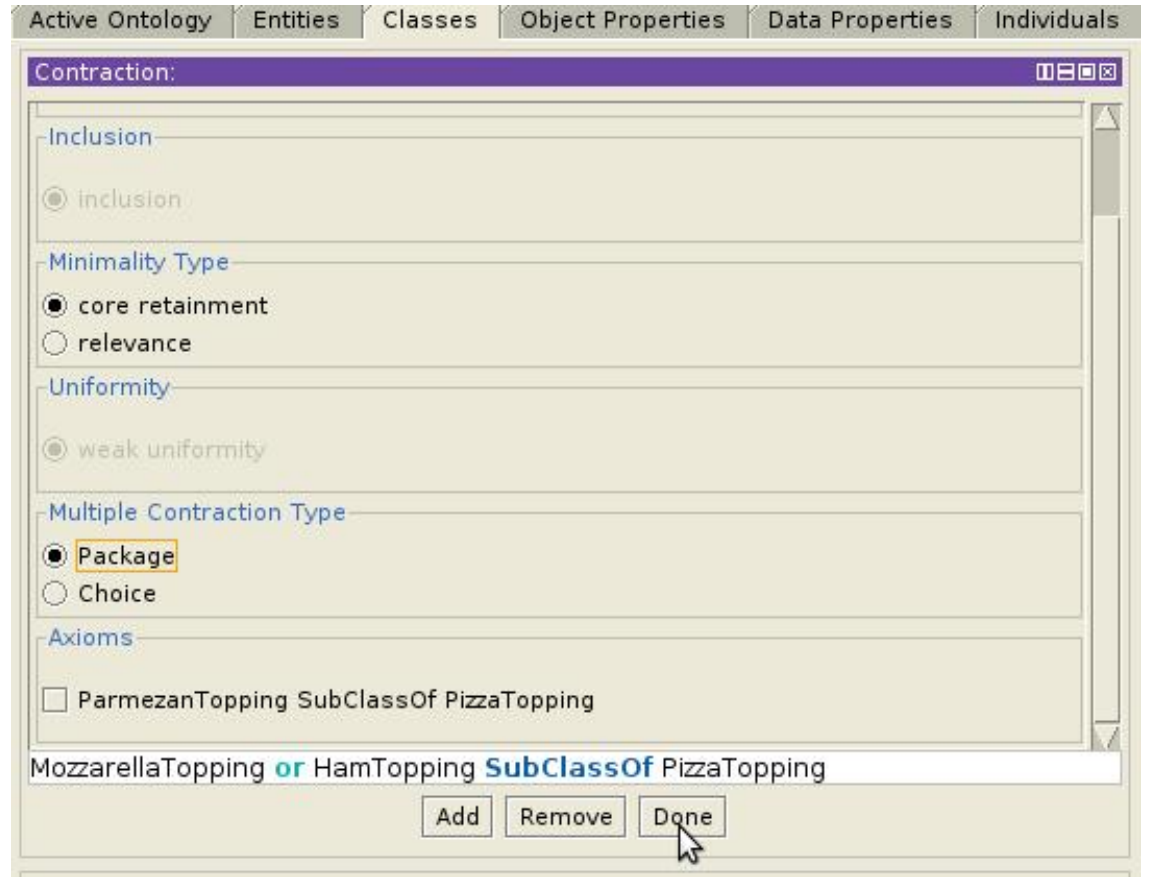

Figura 6.11: Exemplo de contração múltipla usando união de conceitos 


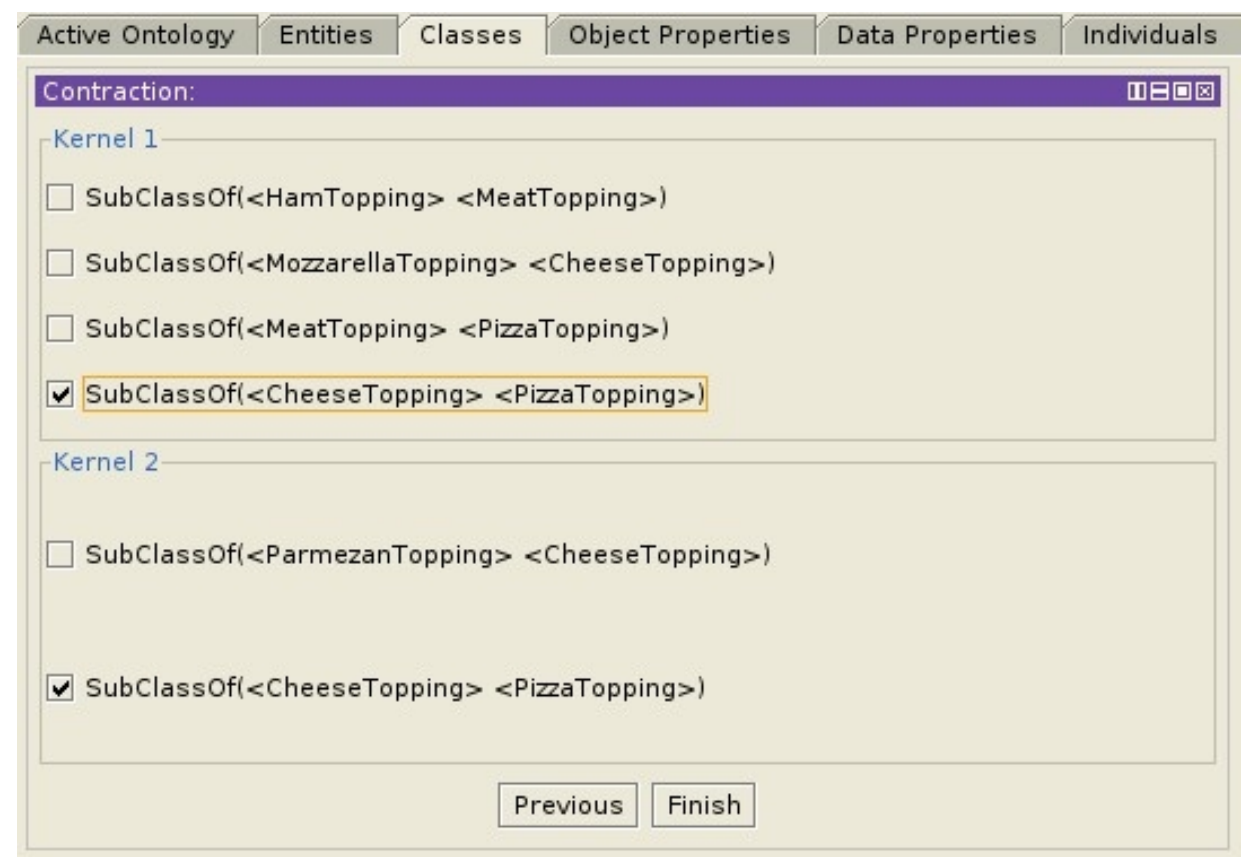

Figura 6.12: Conjunto Kernel resultante da contração múltipla package pelas sentenças selecionadas

Nesse caso, pode-se notar que, como o axioma CheeseTopping SubClassOf PizzaTopping está presente em ambos os elementos, podemos resolver a contração múltipla com a remoção de apenas uma sentença. No caso do plug-in, ao selecionar um axioma desse tipo, ele já automaticamente seleciona as demais ocorrências do mesmo nos outros elementos do Kernel. O resultado podemos ver na Figura 6.13.

\subsubsection{Kernel Choice}

Apresentamos, aqui, os algoritmos para contração Kernel package:

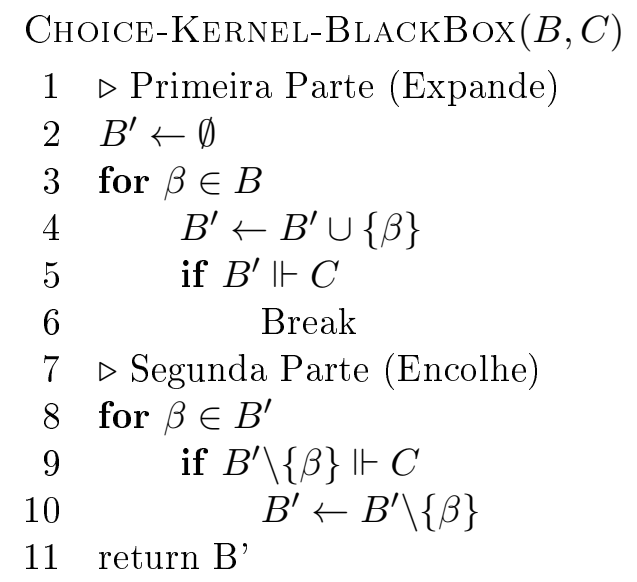

Proposição 5 O algoritmo Cholce-Kernel-BlackBox devolve um elemento de $B \Perp_{C} C$.

Prova: Precisamos provar que o $B^{\prime}$ devolvido pelo algoritmo é tal que $B^{\prime} \in B \Perp_{C} C$.

Suponha, por contradição, que o algoritmo devolve um $B^{\prime}$ tal que $B^{\prime} \notin B \Perp_{C} C$. Assim, ou $B^{\prime} \nVdash C$ ou $\exists K$ tal que $K \subset B^{\prime} \subseteq B$ e $K \Vdash C$ (isto é, $B^{\prime}$ não é minimal).

Suponha que $B^{\prime} \nVdash C$. Como $B^{\prime}$ começa vazio e é construído na linha 4 , a condição da linha 5 junto com o comando de interrupção de laço na linha 6 nos garante um invariante na linha 3 do início laço entre as linhas 3-6: $B^{\prime} \nVdash C$. Assim, esse laço só é interrompido quando $B^{\prime} \Vdash C$. No laço 


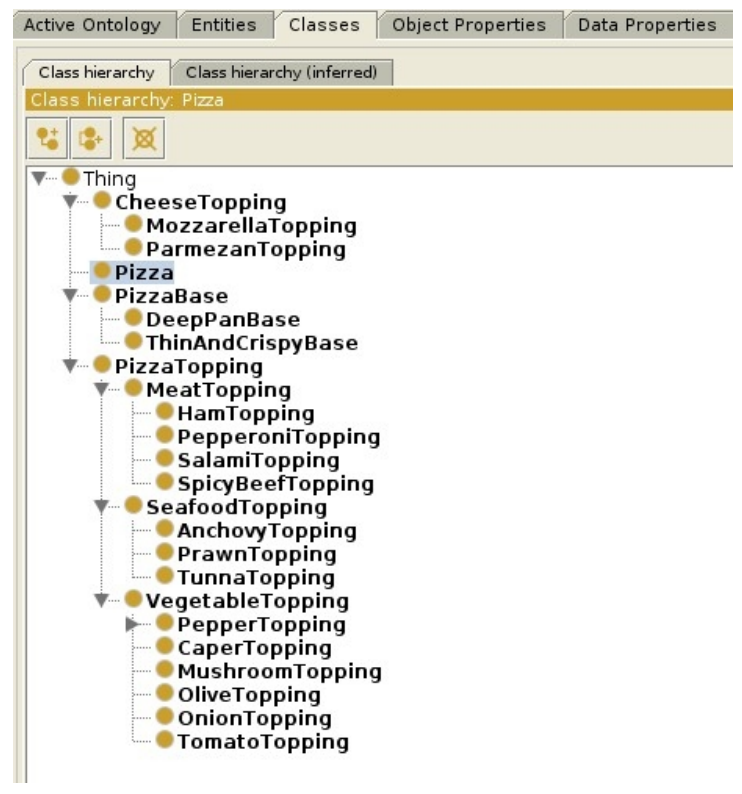

Figura 6.13: Ontologia após ser aplicada contração Kernel package

entre as linhas 8-10, um elemento $\beta \in B^{\prime}$ só é removido de $B^{\prime}$ se $B^{\prime} \backslash\{\beta\} \Vdash C$. Logo, $B^{\prime}$ devolvido pelo algoritmo é tal que $B^{\prime} \Vdash C$. Contradição.

Suponha que $\exists K$ tal que $K \subset B^{\prime} \subseteq B$ e $K \Vdash C$. Então $\exists \beta \in B^{\prime}$ tal que $B^{\prime} \backslash\{\beta\} \Vdash C$. Portanto, $\beta$ foi removido de $B^{\prime}$ devido à condição da linha 9 . Assim, $\beta \notin B^{\prime}$ devolvido pelo algoritmo. Contradição.

Portanto, Choice-Kernel-BlackBox devolve um elemento de $B \Perp_{C} C$.

\section{Choice-Kernel $(B, C)$}

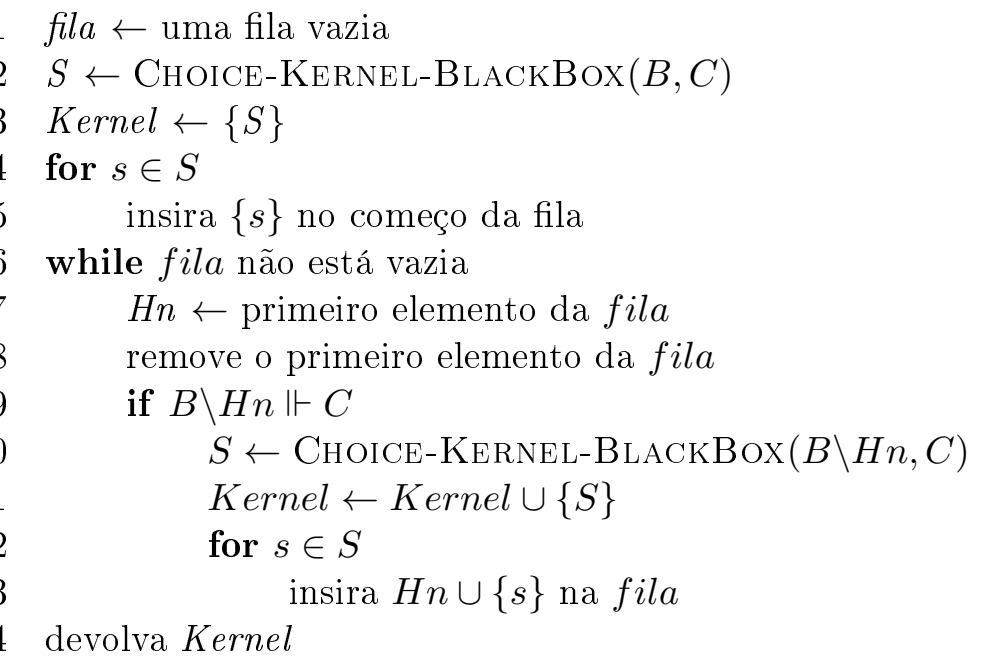

Proposição 6 O algoritmo CHOICEKernel devolve o conjunto kernel de $B$ em relação ao conjunto $C$ por meio de contração choice $\left(B \Perp_{C} C\right)$.

Prova: Análoga à demonstração do algoritmo PACKAGeKernel, dado que a estrutura deles é a mesma.

\section{Implementação}

Aqui, continuaremos a apresentar o funcionamento do plug-in para executar operações de contração múltipla Kernel, mas agora na modalidade choice. 


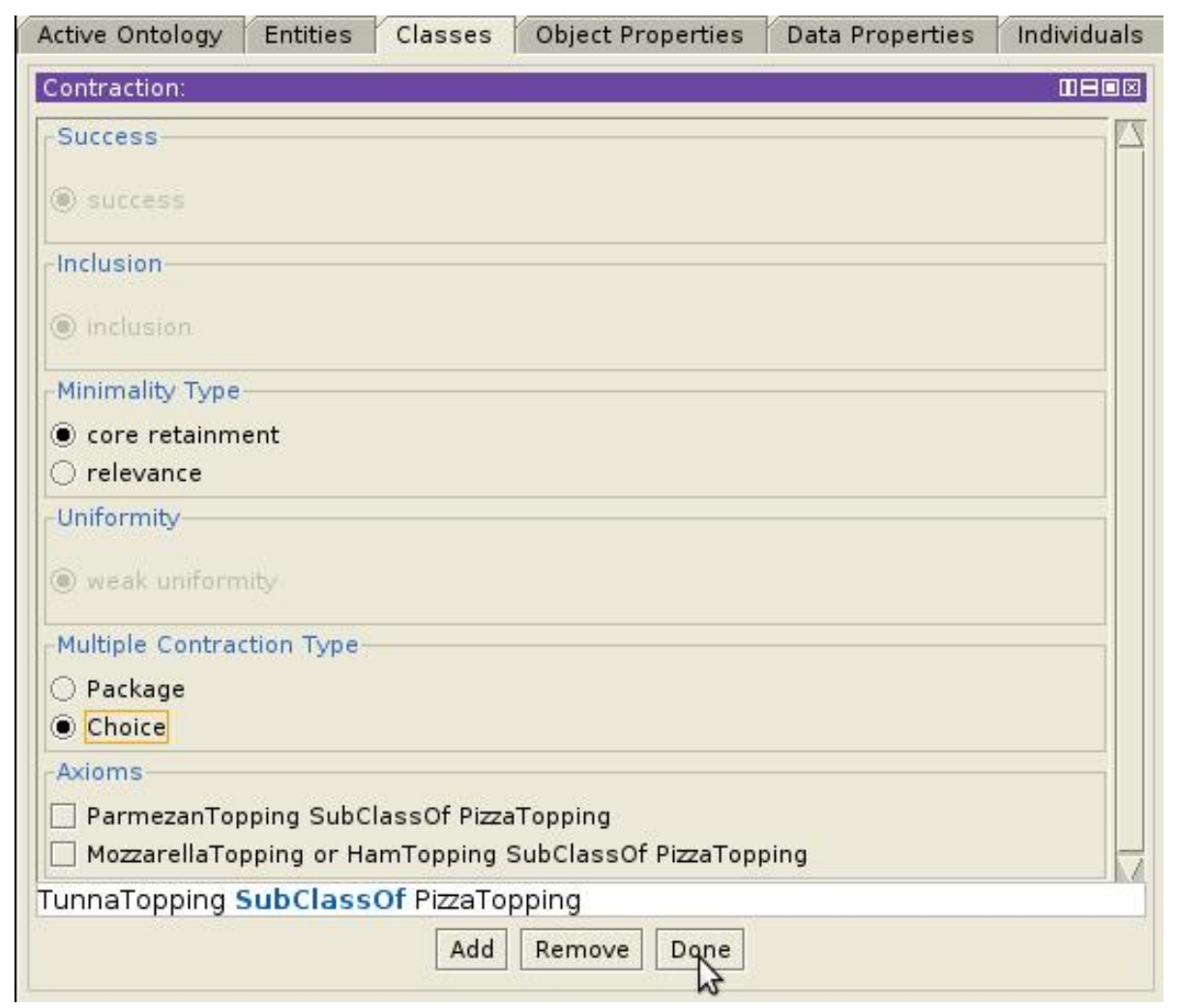

Figura 6.14: Inserção de sentenças para executar uma contração múltipla choice

Ainda considerando o caso da ontologia das pizzas, suponhamos que o conjunto pelo qual desejamos contrair a ontologia seja formado por 3 sentenças:

- MozzarellaTopping $\sqcup$ HamTopping $\sqsubseteq$ PizzaTopping

- ParmezanTopping $\sqsubseteq$ PizzaTopping

- TunnaTopping $\sqsubseteq$ PizzaTopping

De acordo com a definição 16, cada elemento do Kernel implica por completo o conjunto a ser contraído. Logo, o conjunto Kernel possui apenas um elemento:

- MozzarellaTopping $\sqsubseteq$ CheeseTopping

- CheeseTopping $\sqsubseteq$ PizzaTopping

- HamTopping $\sqsubseteq$ MeatTopping

- MeatTopping $\sqsubseteq$ PizzaTopping

- ParmezanTopping $\sqsubseteq$ CheeseTopping

- TunnaTopping $\sqsubseteq$ SeaFoodTopping

- SeaFoodTopping $\sqsubseteq$ PizzaTopping

Pode-se ver, nas Figuras 6.14 e 6.15, respectivamente, a inserção das sentenças a serem contraídas juntamente com a escolha da opção choice como tipo de contração múltipla e o conjunto Kernel resultante devolvido pelo plug-in.

Por sua definição, o conjunto Kernel só terá mais de um elemento se houver mais de uma forma de gerar pelo menos uma das implicações. Suponha, então, a estrutura da seguinte base de conhecimento: 


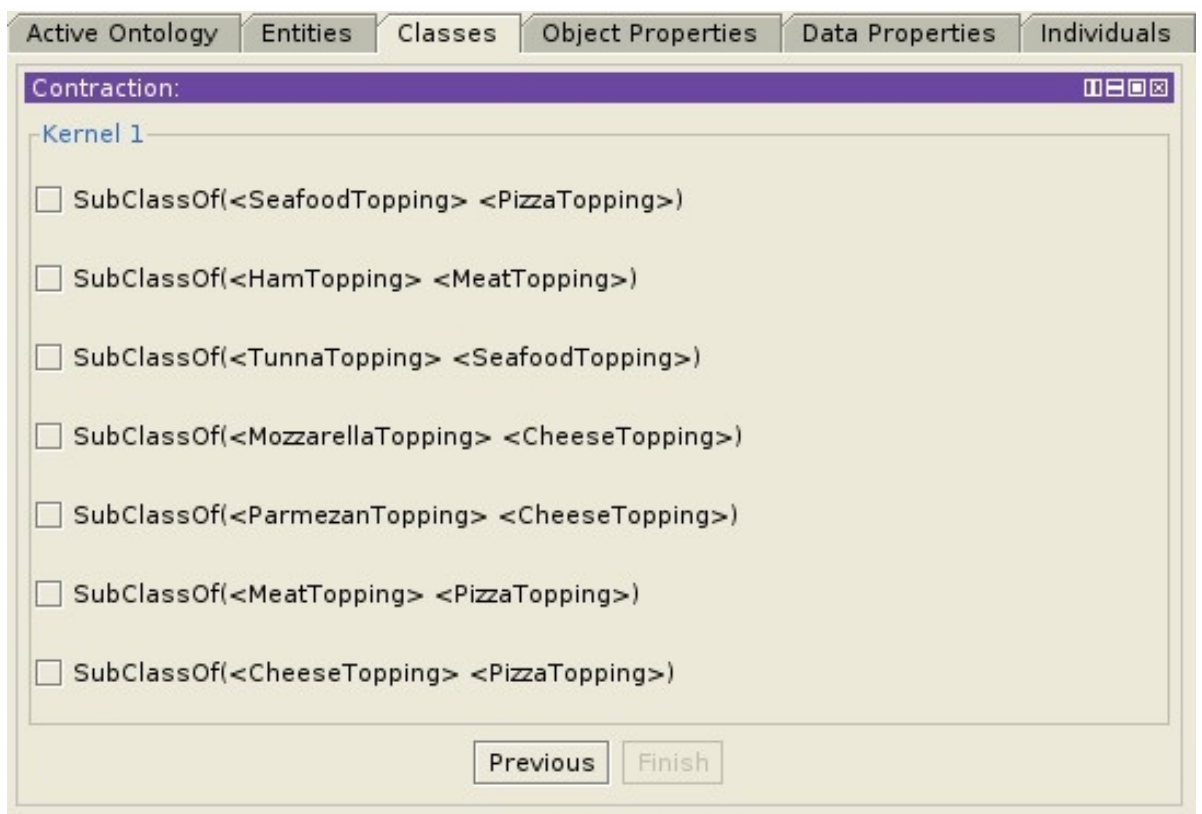

Figura 6.15: Kernel resultante da operação de contração múltipla choice pelas sentenças escolhidas

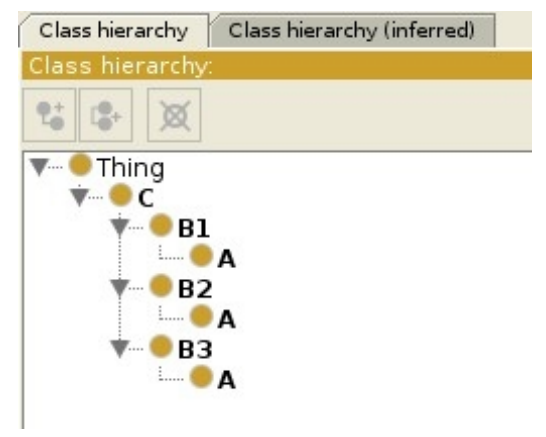

Figura 6.16: Ontologia modelada para testar a execução de contraçâa múltipla choice

- $A \sqsubseteq B 1$

- $A \sqsubseteq B 2$

- $A \sqsubseteq B 3$

- $B 1 \sqsubseteq C$

- $B 2 \sqsubseteq C$

- $B 3 \sqsubseteq C$

Na Figura 6.16, temos a mesma no Protégé. Seja abaixo o conjunto pelo qual desejamos contrair a base:

- $A \sqsubseteq C$

- $B 2 \sqsubseteq C$

Logo, o conjunto Kernel possui 3 elementos:

Elem. Kernel 1:

- $A \sqsubseteq B 1$

- $B 1 \sqsubseteq C$ 


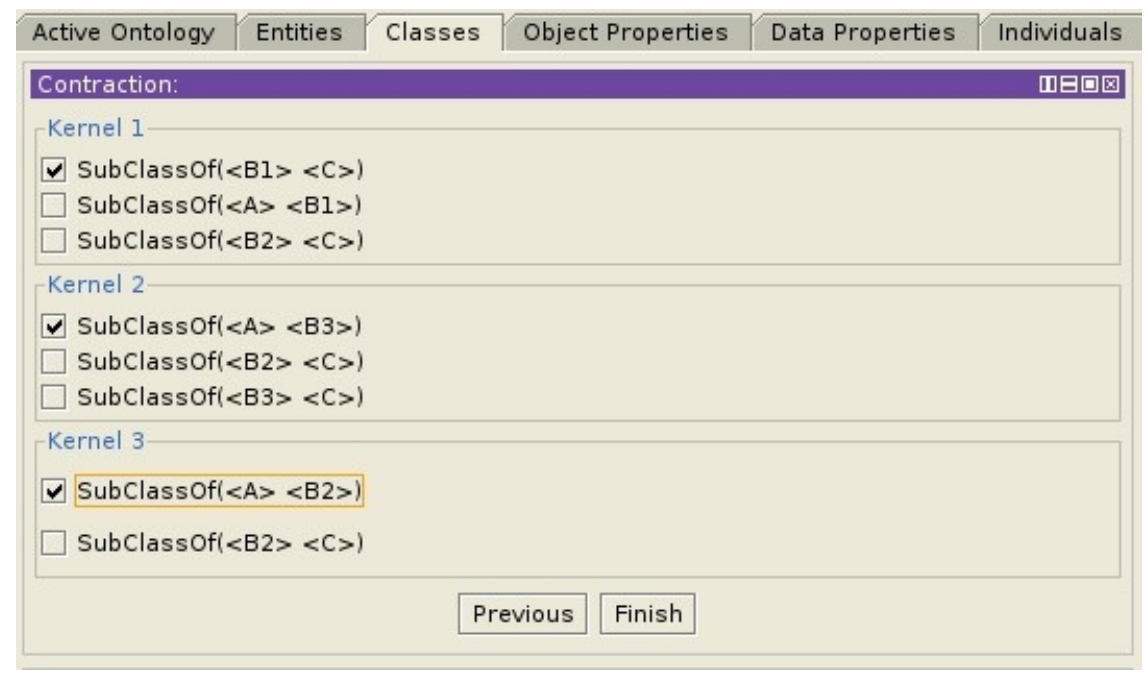

Figura 6.17: Kernel resultante da operação de contração múltipla choice pelas sentenças escolhidas

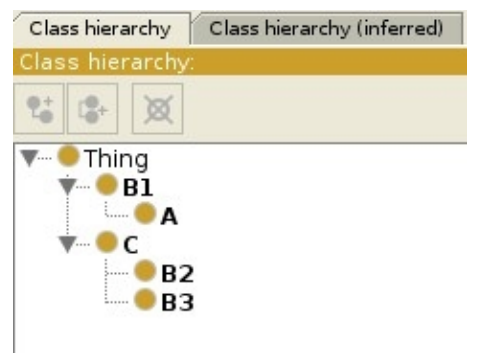

Figura 6.18: Estado final da ontologia após a execução da contração

- $B 2 \sqsubseteq C$

Elem. Kernel 2:

- $A \sqsubseteq B 2$

- $B 2 \sqsubseteq C$

Elem. Kernel 3:

- $A \sqsubseteq B 3$

- $B 3 \sqsubseteq C$

- $B 2 \sqsubseteq C$

A Figura 6.17 mostra o conjunto Kernel devidamente devolvido pelo plug-in, contando também com as sentenças da incisão escolhidas. Na Figura 6.18, vemos o estado da ontologia após a contração.

\subsubsection{Partial Meet Package}

Package-Remainder-BlackBox $(B, C, X)$

$1 \triangleright$ Encontrar um conjunto $X^{\prime}$ tal que $X \subseteq X^{\prime} \in B \perp_{P} C$

$2 \quad X^{\prime} \leftarrow X$

3 for $\beta \in B$

$4 \quad$ if $X^{\prime} \cup\{\beta\} \nvdash C$

$5 \quad X^{\prime} \leftarrow X^{\prime} \cup\{\beta\}$

6 return $X^{\prime}$ 
Proposição 7 O algoritmo PaCKage-Remainder-Black-Box devolve um elemento de $B \perp_{P} C$.

Prova: precisamos provar que $X^{\prime}$ devolvido pelo algoritmo é um elemento do resíduo da contração package de $B$ por $C$ (considerando que o $X$ passado como argumento não implica nada de $C)$.

Suponha, por contradição, que o algoritmo devolve um $X^{\prime}$ tal que $X^{\prime} \notin B \perp_{P} C$. Assim, ou $X^{\prime} \vdash C$ ou $\exists K$ tal que $X^{\prime} \subset K \subseteq B$ e $K \nvdash C$ (isto é, $X^{\prime}$ não é maximal).

Suponha que o algoritmo devolveu $X^{\prime}$ tal que $X^{\prime} \vdash C$. No algoritmo, as sentenças de $B$ são adicionadas a $X^{\prime}$ uma a uma (laço entre as linhas 3 e 5 ) e, toda vez que algum deles vai levar $X^{\prime}$ a implicar algo de $C$, não é adicionado a $X^{\prime}$. Dessa forma, $X^{\prime}$ é composto progressivamente pela linha 4 do algoritmo e apenas se a nova sentença a ser adicionada, junto com as sentenças possivelmente já presentes em $X^{\prime}$, não implica $C$ (condição checada na linha 3). Então, há um invariante na linha 2 (início do laço): $X^{\prime} \nvdash C$. Contradição.

Suponha que $\exists K$ tal que $X^{\prime} \subset K \subseteq B$ e $K \nvdash C$. Então, $\exists \beta \in K$ tal que $\beta \notin X^{\prime}$. Se $\beta$ não foi adicionado a $X^{\prime}$, ele fez com que a condição da linha 3 falhasse. Assim, $X^{\prime} \cup\{\beta\} \vdash C$. Contradição, porque $\left(X^{\prime} \cup\{\beta\}\right) \subseteq K$ e $K \nvdash C$.

Portanto, Package-Remainder-Black-Box devolve um elemento de $B \perp_{P} C$.

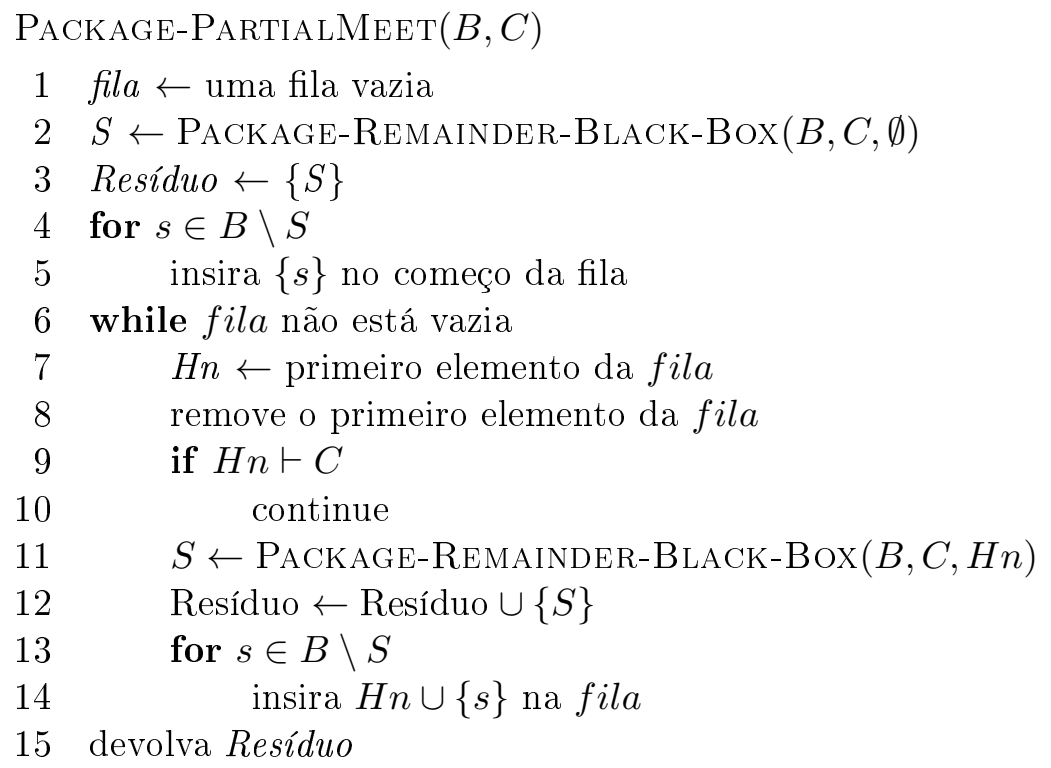

Proposição 8 O algoritmo Package-PARtialMeet devolve o conjunto resíduo da contração package de $B$ pelo conjunto $C\left(B \perp_{P} C\right)$.

Prova: Em relação a esse algoritmo principal que busca encontrar todos os elementos de $B \perp_{P} C$, nós precisamos de uma prova em dois passos:

1 - Provar que S na linha 11 é um elemento de $B \perp_{P} C$.

2 - Provar que, se $X \in B \perp_{P} C$, então $X$ será computado como $S$ na linha 11.

Parte 1:

A primeira parte é mais simples pois, como $H n$ não implica nada de $C$, é uma consequência direta do fato de PaCKage-Remainder-Black-Box devolver um elemento de $B \perp_{P} C$.

Suponha por contradição que há algum $S$ gerado na linha 11 tal que $S \notin B \perp_{P} C$. Então, ou $S \vdash C$ ou $\exists S^{\prime}$ tal que $S \subset S^{\prime} \subseteq B$ e $S^{\prime} \nvdash C$.

Suponha que $S \vdash C$. Então, ou $H n \vdash C$ (o que não é possível por causa da condição na linha 9) ou Package-Remainder-Black-Box devolveu um $S$ tal que $S \vdash C$, o que não é possível como vimos na demonstração acima. Contradição. 
Suponha que $\exists S^{\prime}$ tal que $S \subset S^{\prime} \subseteq B$ e $S^{\prime} \nvdash C$. Então Package-Remainder-Black-Box devolveu um $S$ que não é maximal (e, portanto, não é um elemento de $B \perp_{P} C$ ). Contradição (de acordo com a prova anterior).

Portanto, $S$ na linha 11 é um elemento de $B \perp_{P} C$.

Parte 2:

Para demonstrar essa parte, observaremos o invariante da fila válido na linha 6 do laço entre as linhas 6-14. Temos que, $\forall X \in B \perp_{P} C$, ou $X \in$ Resíduo ou então $\exists A \in$ fila tal que $A \subseteq X$. No raciocínio a seguir, verificaremos a validade desse invariante.

Seja $X$ um elemento de $B \perp_{P} C$. Se $X$ não for o primeiro elemento de $B \perp_{P} C$ obtido na linha 2, então $\exists a \in B \backslash S$ tal que $a \in X$ e, portanto, $\{a\}$ será colocado na fila (linhas 4-5). Vale o invariante.

Agora, vamos considerar o laço entre as linhas 6 e 14. Hn recebe os elementos da fila. Toda vez que $H n \subset X$, há a possibilidade de Package-Remainder-Black-Box devolver $X$ (linha 11), já que o $H n$ da iteração em questão é subconjunto do conjunto $S$ obtido na linha 11 naquela mesma iteração. Consideremos o caso quando isso ocorre $(H n \subseteq X)$. Se Package-Remainder-BlackBox devolve $X$, então esse $C$-resíduo é encontrado e computado em Resíduo. Caso contrário, $\exists a \in B \backslash S$ tal que $a \in X$, e $H n \cup\{a\}$ é colocado na fila (linhas 13-14). Assim, o invariante continua valendo.

Como na linha 15 a fila está vazia, temos que Resíduo $=B \perp_{P} C$. Logo, se $X \in B \perp_{P} C$, então $X$ será computado como $S$ na linha 11 .

\subsubsection{Partial Meet Choice}

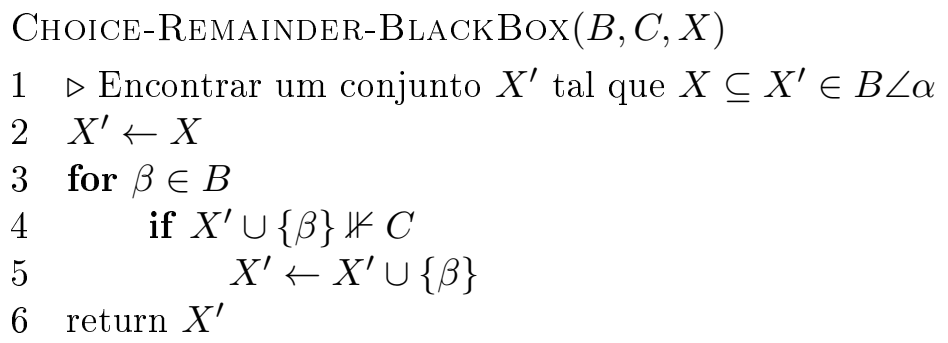

Proposição 9 O algoritmo Choice-Remainder-Black-Box devolve um elemento de $B \perp_{C} C$.

Prova: Precisamos provar que $X^{\prime}$ devolvido pelo algoritmo é um elemento do resíduo da contração choice de $B$ por $C$ (considerando que o $X$ passado como argumento não implica todo o $C)$.

Suponha, por contradição, que o algoritmo devolve um $X^{\prime}$ tal que $X^{\prime} \notin B \perp_{P} C$. Assim, ou $B^{\prime} \Vdash C$ ou $\exists K$ tal que $B^{\prime} \subset K \subseteq B$ e $K \nVdash C$ (isto é, $B^{\prime}$ não é maximal).

Suponha que o algoritmo devolveu $X^{\prime}$ tal que $X^{\prime} \Vdash C$. No algoritmo, as sentenças de $B$ são adicionadas a $X^{\prime}$ uma a uma (laço entre as linhas 3 e 5 ) e, toda vez que algum deles vai levar $X^{\prime}$ a implicar todo o $C$, não é adicionado a $X^{\prime}$. Dessa forma, $X^{\prime}$ é composto progressivamente pela linha 4 do algoritmo e apenas se a nova sentença a ser adicionada, junto com as sentenças possivelmente já presentes em $X^{\prime}$, não implica todo o $C$ (condição checada na linha 3 ). Então, há um invariante na linha 2 (início do laço): $X^{\prime} \nVdash C$. Contradição.

Suponha que $\exists K$ tal que $X^{\prime} \subset K \subseteq B$ e $K \nVdash C$. Então, $\exists \beta \in K$ tal que $\beta \notin X^{\prime}$. Se $\beta$ não foi adicionado a $X^{\prime}$, ele fez com que a condição da linha 3 falhasse. Assim, $X^{\prime} \cup\{\beta\} \Vdash C$. Contradição, porque $\left(X^{\prime} \cup\{\beta\}\right) \subseteq K$ e $K \nVdash C$.

Portanto, Choice-Remainder-Black-Box devolve um elemento de $B \perp_{C} C$. 


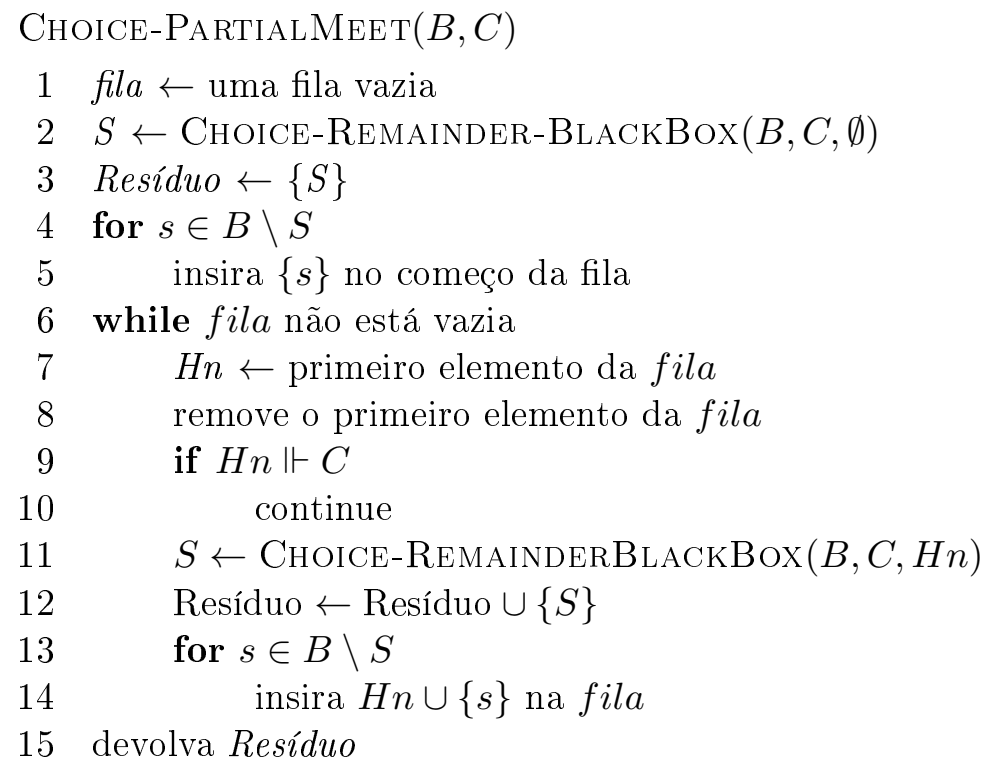

Proposição 10 O algoritmo Choice-PARTIALMeet devolve o conjunto resíduo da contração choice de $B$ pelo conjunto $C\left(B \perp_{C} C\right)$.

Prova: Análoga à demonstração do algoritmo PackagePartialMeet, dado que a estrutura deles é a mesma.

\subsection{Testes}

Nesta seção, iremos apresentar alguns testes comparativos que realizamos entre os algoritmos Kernel e Partial Meet (em contrações simples). Primeiramente, observemos o teorema a seguir:

Teorema 1 [Rib10] Seja $\mathcal{L}$ uma lógica tarskiana e compacta, $B \subseteq \mathcal{L}$ e $\alpha \in \mathcal{L}:$

1. $X \in\{B \backslash Y: Y \in B \perp \alpha\}$ se e somente se $X$ é um corte minimo de $B \Perp \alpha$

2. $X \in B \Perp \alpha$ se e somente se $X$ é um corte minimo de $\{B \backslash X: X \in B \perp \alpha\}$

Esse teorema pode trazer a ideia que os dois problemas (calcular os conjuntos Kernel e Resíduo) têm características parecidas. Porém, por meio de alguns exemplos é possível constatar que, dependendo do caso, pode ser menos computacionalmente custoso calcular um ou o outro. Esta diferença pode chegar a ser exponencial, o que explicita ainda mais a necessidade da abordagem e exploração de ambos os problemas.

Veja a seguir dois exemplos apresentados em [Rib10] em Lógica Proposicional, os quais serão apresentados de forma análoga na LD $\mathcal{A L C}$. Ambos os exemplos em Lógicas de Descrição foram testados com os algoritmos apresentados neste trabalho. Consideramos "|." como a cardinalidade de um conjunto.

\subsubsection{Kernel pequeno e Resíduo grande}

Primeiramente, vejamos um exemplo no qual o conjunto Kernel para a contração é pequeno mas o tamanho do conjunto resíduo obtido por Partial Meet é grande. Em Lógica Proposicional Clássica:

$$
\mathscr{B}=\left\{\begin{array}{c}
b_{1}, b_{1} \rightarrow a, \\
b_{2}, b_{2} \rightarrow a, \\
\vdots \\
b_{n}, b_{n} \rightarrow a
\end{array}\right\}
$$


Temos que $|\mathscr{B} \Perp a|=n$ e $|\mathscr{B} \perp a|=2^{n}$.

Para $n=3$, por exemplo, teríamos:

$$
\begin{aligned}
& \mathscr{B} \Perp a=\left\{\begin{array}{c}
\left\{b_{1}, b_{1} \rightarrow a\right\}, \\
\left\{b_{2}, b_{2} \rightarrow a\right\}, \\
\left\{b_{3}, b_{3} \rightarrow a\right\}
\end{array}\right\} \\
& \mathscr{B} \perp a=\left\{\begin{array}{c}
\left\{b_{1}, b_{2}, b_{3}\right\}, \\
\left\{b_{1}, b_{2} \rightarrow a, b_{3}\right\}, \\
\left\{b_{1}, b_{2}, b_{3} \rightarrow a\right\}, \\
\left\{b_{1}, b_{2} \rightarrow a, b_{3} \rightarrow a\right\}, \\
\left\{b_{1} \rightarrow a, b_{2}, b_{3}\right\}, \\
\left\{b_{1} \rightarrow a, b_{2} \rightarrow a, b_{3}\right\}, \\
\left\{b_{1} \rightarrow a, b_{2}, b_{3} \rightarrow a\right\}, \\
\left\{b_{1} \rightarrow a, b_{2} \rightarrow a, b_{3} \rightarrow a\right\},
\end{array}\right\}
\end{aligned}
$$

O exemplo análogo para as Lógicas de Descrição:

$$
\mathscr{B}=\left\{\begin{array}{c}
A \sqsubseteq B_{1}, B_{1} \sqsubseteq C, \\
A \sqsubseteq B_{2}, B_{2} \sqsubseteq C, \\
\vdots \\
A \sqsubseteq B_{n}, B_{n} \sqsubseteq C
\end{array}\right\}
$$

Temos que $|\mathscr{B} \Perp A \sqsubseteq C|=n$ e $|\mathscr{B} \perp A \sqsubseteq C|=2^{n}$.

Para $n=3$, por exemplo, teríamos:

$$
\begin{gathered}
\mathscr{B} \Perp a=\left\{\begin{array}{c}
\left\{A \sqsubseteq B_{1}, B_{1} \sqsubseteq C\right\}, \\
\left\{A \sqsubseteq B_{2}, B_{2} \sqsubseteq C\right\}, \\
\left\{A \sqsubseteq B_{3}, B_{3} \sqsubseteq C\right\}
\end{array}\right\} \\
\mathscr{B} \perp a=\left\{\begin{array}{c}
\left\{A \sqsubseteq B_{1}, A \sqsubseteq B_{2}, A \sqsubseteq B_{3}\right\}, \\
\left\{A \sqsubseteq B_{1}, B_{2} \sqsubseteq C, A \sqsubseteq B_{3}\right\}, \\
\left\{A \sqsubseteq B_{1}, A \sqsubseteq B_{2}, B_{3} \sqsubseteq C\right\}, \\
\left\{A \sqsubseteq B_{1}, B_{2} \sqsubseteq C, B_{3} \sqsubseteq C\right\}, \\
\left\{B_{1} \sqsubseteq C, A \sqsubseteq B_{2}, A \sqsubseteq B_{3}\right\}, \\
\left\{B_{1} \sqsubseteq C, B_{2} \sqsubseteq C, A \sqsubseteq B_{3}\right\}, \\
\left\{B_{1} \sqsubseteq C, A \sqsubseteq B_{2}, B_{3} \sqsubseteq C\right\}, \\
\left\{B_{1} \sqsubseteq C, B_{2} \sqsubseteq C, B_{3} \sqsubseteq C\right\},
\end{array}\right\}
\end{gathered}
$$

Os resultados do teste do tempo de execução para cada algoritmo calcular seu conjunto correspondente (kernel ou resíduo) estão na tabela abaixo:

\begin{tabular}{|c|c|c|}
\hline $\mathrm{n}$ & Kernel $(\mathrm{s})$ & Partial Meet $(\mathrm{s})$ \\
\hline 2 & 0,455 & 0,041 \\
\hline 3 & 0,082 & 0,163 \\
\hline 4 & 0,167 & 0,572 \\
\hline 5 & 0,246 & 1,461 \\
\hline 6 & 0,186 & 4,203 \\
\hline 7 & 0,252 & 32,693 \\
\hline 8 & 0,619 & 302,454 \\
\hline 9 & 0,929 & 2888,412 \\
\hline 10 & 1,886 & 32432,381 \\
\hline
\end{tabular}

Tabela 6.1: Tempos de execução do teste com exemplo de kernel pequeno e resíduo grande 
A diferença no tamanho dos conjuntos é visível na diferença do tempo de execução no cálculo dos mesmos. Enquanto pelo algoritmo Kernel a execução passou a durar mais de 1 segundo somente com $\mathrm{n}=10$, com Partial Meet já durava mais de 1 segundo para $\mathrm{n}=5$, sendo que com $\mathrm{n}=10$ o algoritmo Partial Meet levou mais de 9 horas para concluir sua execução.

\subsubsection{Resíduo pequeno e Kernel grande}

Vejamos, agora, um exemplo oposto, no qual o conjunto Kernel para a contração é grande mas o tamanho do conjunto resíduo obtido por Partial Meet é pequeno. Em Lógica Proposicional

\section{Clássica:}

$$
\mathscr{B}=\left\{\begin{array}{c}
b_{1}, b_{1}^{\prime}, \\
\left(b_{1} \vee b_{1}^{\prime}\right) \rightarrow b_{2},\left(b_{1} \vee b_{1}^{\prime}\right) \rightarrow b_{2}^{\prime}, \\
\left(b_{2} \vee b_{2}^{\prime}\right) \rightarrow b_{3},\left(b_{2} \vee b_{2}^{\prime}\right) \rightarrow b_{3}^{\prime}, \\
\vdots \\
\left(b_{n} \vee b_{n}^{\prime}\right) \rightarrow a
\end{array}\right\}
$$

Temos que $|\mathscr{B} \perp a|=n+1$ e $|\mathscr{B} \Perp a|=2^{n}$.

Para $n=3$, por exemplo, teríamos:

$$
\begin{gathered}
\left\{\begin{array}{l}
\left\{b_{1},\left(b_{1} \vee b_{1}^{\prime}\right) \rightarrow b_{2},\left(b_{2} \vee b_{2}^{\prime}\right) \rightarrow b_{3},\left(b_{3}, b_{3}^{\prime}\right) \rightarrow a\right\}, \\
\left\{b_{1},\left(b_{1} \vee b_{1}^{\prime}\right) \rightarrow b_{2},\left(b_{2} \vee b_{2}^{\prime}\right) \rightarrow b_{3}^{\prime},\left(b_{3}, b_{3}^{\prime}\right) \rightarrow a\right\}, \\
\left\{b_{1},\left(b_{1} \vee b_{1}^{\prime}\right) \rightarrow b_{2}^{\prime},\left(b_{2} \vee b_{2}^{\prime}\right) \rightarrow b_{3},\left(b_{3}, b_{3}^{\prime}\right) \rightarrow a\right\}, \\
\left\{b_{1},\left(b_{1} \vee b_{1}^{\prime}\right) \rightarrow b_{2}^{\prime},\left(b_{2} \vee b_{2}^{\prime}\right) \rightarrow b_{3}^{\prime},\left(b_{3}, b_{3}^{\prime}\right) \rightarrow a\right\}, \\
\left\{b_{1}^{\prime},\left(b_{1} \vee b_{1}^{\prime}\right) \rightarrow b_{2},\left(b_{2} \vee b_{2}^{\prime}\right) \rightarrow b_{3},\left(b_{3}, b_{3}^{\prime}\right) \rightarrow a\right\}, \\
\left\{b_{1}^{\prime},\left(b_{1} \vee b_{1}^{\prime}\right) \rightarrow b_{2},\left(b_{2} \vee b_{2}^{\prime}\right) \rightarrow b_{3}^{\prime},\left(b_{3}, b_{3}^{\prime}\right) \rightarrow a\right\}, \\
\left\{b_{1}^{\prime},\left(b_{1} \vee b_{1}^{\prime}\right) \rightarrow b_{2}^{\prime},\left(b_{2} \vee b_{2}^{\prime}\right) \rightarrow b_{3},\left(b_{3}, b_{3}^{\prime}\right) \rightarrow a\right\}, \\
\left\{b_{1}^{\prime},\left(b_{1} \vee b_{1}^{\prime}\right) \rightarrow b_{2}^{\prime},\left(b_{2} \vee b_{2}^{\prime}\right) \rightarrow b_{3}^{\prime},\left(b_{3}, b_{3}^{\prime}\right) \rightarrow a\right\},
\end{array}\right\} \\
\mathscr{B} \perp a=\left\{\begin{array}{c}
\mathscr{B} \backslash\left\{b_{1}, b_{1}^{\prime}\right\}, \\
\mathscr{B} \backslash\left\{\left(b_{1} \vee b_{1}^{\prime}\right) \rightarrow b_{2},\left(b_{1} \vee b_{1}^{\prime}\right) \rightarrow b_{2}^{\prime}\right\}, \\
\mathscr{B} \backslash\left\{\left(b_{2} \vee b_{2}^{\prime}\right) \rightarrow b_{3},\left(b_{2} \vee b_{2}^{\prime}\right) \rightarrow b_{3}^{\prime}\right\}, \\
\left.\mathscr{B} \backslash\left\{\left(b_{3} \vee b_{3}^{\prime}\right) \rightarrow a\right\}\right\}
\end{array}\right\}
\end{gathered}
$$

O exemplo análogo para as Lógicas de Descrição:

$$
\mathscr{B}=\left\{\begin{array}{c}
\left(B \sqcup B^{\prime}\right)(a) \\
B \sqcup B^{\prime} \sqsubseteq B_{1}, B \sqcup B^{\prime} \sqsubseteq B_{1}^{\prime}, \\
B_{1} \sqcup B_{1}^{\prime} \sqsubseteq B_{2}, B_{1} \sqcup B_{1}^{\prime} \sqsubseteq B_{2}^{\prime}, \\
\vdots \\
B_{n-1} \sqcup B_{n-1}^{\prime} \sqsubseteq B_{n}, B_{n-1} \sqcup B_{n-1}^{\prime} \sqsubseteq B_{n}^{\prime}
\end{array}\right\}
$$

Temos que $\left|\mathscr{B} \Perp\left(B_{3} \sqcup B_{3}^{\prime}\right)(a)\right|=n+1$ e $\left|\mathscr{B} \perp\left(B_{3} \sqcup B_{3}^{\prime}\right)(a)\right|=2^{n}$.

Para $n=3$, por exemplo, teríamos: 


$$
\begin{gathered}
\mathscr{B} \Perp\left(B_{3} \sqcup B_{3}^{\prime}\right)(a)=\left\{\begin{array}{c}
\left\{\left(B \sqcup B^{\prime}\right)(a), B \sqcup B^{\prime} \sqsubseteq B_{1}, B_{1} \sqcup B_{1}^{\prime} \sqsubseteq B_{2}, B_{2} \sqcup B_{2}^{\prime} \sqsubseteq B_{3}\right\} \\
\left\{\left(B \sqcup B^{\prime}\right)(a), B \sqcup B^{\prime} \sqsubseteq B_{1}^{\prime}, B_{1} \sqcup B_{1}^{\prime} \sqsubseteq B_{2}, B_{2} \sqcup B_{2}^{\prime} \sqsubseteq B_{3}\right\} \\
\left\{\left(B \sqcup B^{\prime}\right)(a), B \sqcup B^{\prime} \sqsubseteq B_{1}, B_{1} \sqcup B_{1}^{\prime} \sqsubseteq B_{2}^{\prime}, B_{2} \sqcup B_{2}^{\prime} \sqsubseteq B_{3}\right\} \\
\left\{\left(B \sqcup B^{\prime}\right)(a), B \sqcup B^{\prime} \sqsubseteq B_{1}^{\prime}, B_{1} \sqcup B_{1}^{\prime} \sqsubseteq B_{2}^{\prime}, B_{2} \sqcup B_{2}^{\prime} \sqsubseteq B_{3}\right\} \\
\left\{\left(B \sqcup B^{\prime}\right)(a), B \sqcup B^{\prime} \sqsubseteq B_{1}, B_{1} \sqcup B_{1}^{\prime} \sqsubseteq B_{2}, B_{2} \sqcup B_{2}^{\prime} \sqsubseteq B_{3}^{\prime}\right\} \\
\left\{\left(B \sqcup B^{\prime}\right)(a), B \sqcup B^{\prime} \sqsubseteq B_{1}^{\prime}, B_{1} \sqcup B_{1}^{\prime} \sqsubseteq B_{2}, B_{2} \sqcup B_{2}^{\prime} \sqsubseteq B_{3}^{\prime}\right\} \\
\left\{\left(B \sqcup B^{\prime}\right)(a), B \sqcup B^{\prime} \sqsubseteq B_{1}, B_{1} \sqcup B_{1}^{\prime} \sqsubseteq B_{2}^{\prime}, B_{2} \sqcup B_{2}^{\prime} \sqsubseteq B_{3}^{\prime}\right\} \\
\left\{\left(B \sqcup B^{\prime}\right)(a), B \sqcup B^{\prime} \sqsubseteq B_{1}^{\prime}, B_{1} \sqcup B_{1}^{\prime} \sqsubseteq B_{2}^{\prime}, B_{2} \sqcup B_{2}^{\prime} \sqsubseteq B_{3}^{\prime}\right\}
\end{array}\right\} \\
\mathscr{B} \perp\left(B_{3} \sqcup B_{3}^{\prime}\right)(a)=\left\{\begin{array}{c}
\mathscr{B} \backslash\left\{B \sqcup B^{\prime} \sqsubseteq B_{1}, B \sqcup B^{\prime} \sqsubseteq B_{1}^{\prime}\right\}, \\
\mathscr{B} \backslash\left\{B_{1} \sqcup B_{1}^{\prime} \sqsubseteq B_{2}, B_{1} \sqcup B_{1}^{\prime} \sqsubseteq B_{2}^{\prime}\right\}, \\
\mathscr{B} \backslash\left\{B_{2} \sqcup B_{2}^{\prime} \sqsubseteq B_{3}, B_{2} \sqcup B_{2}^{\prime} \sqsubseteq B_{3}^{\prime}\right\},
\end{array}\right\}
\end{gathered}
$$

Os resultados do teste do tempo de execução para cada algoritmo calcular seu conjunto correspondente (kernel ou resíduo) estão na tabela abaixo:

\begin{tabular}{|c|c|c|}
\hline $\mathrm{n}$ & Kernel $(\mathrm{s})$ & Partial Meet $(\mathrm{s})$ \\
\hline 2 & 0,671 & 0,066 \\
\hline 3 & 0,579 & 0,091 \\
\hline 4 & 1,627 & 0,223 \\
\hline 5 & 4,592 & 0,152 \\
\hline 6 & 22,243 & 0,268 \\
\hline 7 & 193,929 & 0,676 \\
\hline 8 & 1898,887 & 1,353 \\
\hline 9 & 12029,633 & 1,791 \\
\hline 10 & 93826,732 & 2,264 \\
\hline
\end{tabular}

Tabela 6.2: Tempos de execução do teste com exemplo de kernel grande e resíduo pequeno

Novamente, a diferença no tamanho dos conjuntos é visível na diferença do tempo de execução no cálculo dos mesmos. Enquanto pelo algoritmo Partial Meet a execução passou a durar mais de 1 segundo somente com $\mathrm{n}=8$, com Kernel já durava mais de 1 segundo para $\mathrm{n}=4$, sendo que com n=10 o algoritmo Kernel levou mais de 26 horas para concluir sua execução.

\subsubsection{Comparação entre implementações}

Outro teste que efetuamos foi comparar a nossa implementação com outras implementações já disponíveis. As duas implementações escolhidas foram o BContractor [LRW12] e o Explanation Plugin [Hor11].

O BContractor ${ }^{1}$ é um arcabouço flexível desenvolvido para realizar operações de revisão de crenças. De acordo com a própria definição do autor, "BContractor é uma interface simples, mas poderosa, desenvolvidada para operações sobre bases de crenças. Simples devido a uma interface facilmente implementável; poderosa porque é extensível e pode ser facilmente adaptada." Já o Explanation Plugin ${ }^{2}$ é uma ferramenta para o Protégé que pode calcular justificativas, as quais são um tipo de explicação para uma inferência, ou seja, um subconjunto minimal da ontologia que é suficiente para implicar uma inferência.

\footnotetext{
${ }^{1}$ https://bitbucket.org/renatolundberg/bcontractor

${ }^{2}$ http://owl.cs.manchester.ac.uk/research/explanation/
} 
Nosso trabalho difere-se de ambos devido a alguns aspectos importantes, como, por exemplo, o fato da ferramenta desenvolvida não ser de aplicação genérica mas específica para o Protégé (ontologias e Lógicas de Descrição). Por outro lado, os algoritmos desenvolvidos são independentes da lógica. Além disso, trabalhamos não somente com subconjuntos minimais que justificam uma inferência (Kernel) mas também subconjuntos maximais que não implicam a inferência desejada (Partial Meet), juntamente com o trabalho de contração múltipla. Por isso, consideramos interessante comparar estes diferentes projetos.

Para estender o BContractor a fim de utilizá-lo com Lógicas de Descrição, aplicamos o que foi desenvolvido em [CRW13]. O teste foi realizado utilizando o exemplo de kernel pequeno dado acima, calculando quanto tempo cada uma leva para realizar a contração. Considerando nossa implementação representada pela linha tracejada, o Explanation Plugin pela linha tradicional e o BContractor pela linha com os pontos indicados por meio de círculos, temos a seguir um gráfico com a indicação do tempo gasto por cada uma das três implementações de acordo com o tamanho do conjunto kernel:

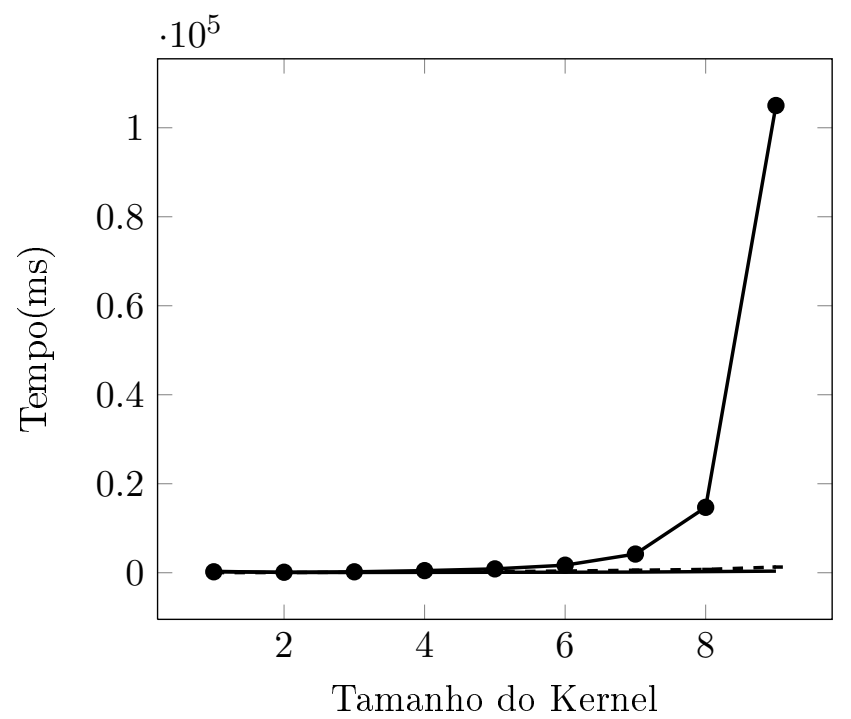

Por meio do gráfico, é possível constatar que a ferramenta mais eficiente no cálculo proposto é o Explantion Plug-in, o que se deve, também, à aplicação de heurísticas especiais para melhoria de performance, vantagem esta obtida devido à aplicabilidade específica da ferramenta. No entanto, vê-se que o plug-in desenvolvido neste trabalho teve um desempenho bem semelhante a ele, ou seja, uma performance próxima a de uma ferramenta já consolidada, o que é positivo. Além disso, o desempenho foi muitas vezes superior ao do BContractor, o que pode indicar a necessidade de melhorias de performance nesta última e/ou um trade-off entre generalização e desempenho.

\subsection{Contribuições}

Neste capítulo, nossas contribuições abrangeram dois alvos principais. Primeiramente, desenvolvemos e demonstramos um algoritmo genérico que implementa a operação de contração por Partial Meet. Também o implementamos no plug-in, conforme demonstrado anteriormente. Depois, também desenvolvemos e demonstramos quatro algoritmos para contração múltipla, sendo eles referentes às operações Kernel e Partial Meet, cada uma nas modalidades package e choice. O plug-in foi refatorado de forma a implementar essas operações e também estar preparado para receber mais de uma sentença como entrada.

É importante ressaltar que as operações por uma única sentença exibidas no capítulo anterior continuam a ser operadas pelo plug-in. Neste caso, o usuário coloca a sentença desejada no editor do plug-in e clica diretamente em Done. Lembrando que a parte de revisão continua implementada apenas para uma única sentença. 


\section{Capítulo 7}

\section{Conclusões e Trabalhos Futuros}

\subsection{Conclusões}

Neste trabalho, desenvolvemos um algoritmo para a operação de contração Partial Meet e também algoritmos para operações de contração múltipla, tanto via Kernel quanto via Partial Meet. Juntamente com outros já existentes na literatura, aplicamos esses algoritmos na implementação de um plug-in para o editor de ontologias Protégé, plug-in este disponível gratuitamente e capaz de realizar operações de revisão de crenças sobre as ontologias desenvolvidas, editadas ou visualizadas no programa em questão.

Além disso, apesar deste trabalho estar focado em Lógicas de Descrição, os algoritmos desenvolvidos são independentes da linguagem, uma vez que os mesmos não dependem do motor de inferências.

Parte da implementação foi aproveitada para a ferramenta de combinação de ontologias (merging) apresentada na sexta edição do Seminário de Pesquisa em Ontologias do Brasil (ONTOBRAS 2013): [CRW13].

\subsection{Trabalhos futuros}

Como possíveis trabalhos a serem realizados para a continuação da pesquisa exposta nesta dissertação, podemos citar:

1. Testes com diferentes lógicas $(\mathcal{E} \mathcal{L}$, DL-Lite, etc).

2. Testes com TBoxes e ABoxes grandes.

3. Testes maiores com ontologias utilizadas no mundo real, como as do NCBO BioPortal ${ }^{1}$, por exemplo.

4. Testes mais específicos e detalhados sobre a diferença no custo computacional de usar, em um problema, o algoritmo Kernel ou Partial Meet, buscando chegar a um meio de determinar previamente qual deles é mais eficiente.

5. Desenvolvimento algorítmico e implementação do estudo de modularidade em Lógicas de Descrição que, no trabalho de revisão de crenças em bases de crenças grandes, visa extrair, primeiramente, o subconjunto dessa base que é relavante para a operação desejada, com o intuito de ganhar eficiência ao evitar um possível trabalho desnecessário.

6. Desenvolvimento da parte de Revisão Múltipla.

\footnotetext{
${ }^{1}$ https://bioportal.bioontology.org/
} 


\section{Referências Bibliográficas}

[AGM85] Carlos Alchourrón, Peter Gärdenfors, and David Makinson. On the logic of theory change. Journal of Symbolic Logic, 50(02):510-530, 1985.

[AM82] Carlos Alchourrón and David Makinson. On the logic of theory change: Contraction functions and their associated revision functions. Theoria, 48(01):14-37, 1982.

[BBL05] Franz Baader, Sebastian Brandt, and Carsten Lutz. Pushing the el envelope. In IJCAI, volume 5, pages 364-369, 2005.

$\left[\mathrm{BCM}^{+}\right.$03] F. Baader, D. Calvanese, D.L. McGuinness, D. Nardi, and P.F. Patel-Schneider, editors. The Description Logic Handbook. Cambridge University Press, New York, NY, USA, 2003.

[BP07] Franz Baader and Rafael Peñaloza. Axiom pinpointing in general tableaux. In Nicola Olivetti, editor, Automated Reasoning with Analytic Tableaux and Related Methods, volume 4548 of Lecture Notes in Computer Science, pages 11-27. Springer Berlin Heidelberg, 2007.

[CRW13] Raphael Cóbe, Fillipe Resina, and Renata Wassermann. Merging ontologies via kernel contraction. In Ontobras, 2013.

[DP97] Adnan Darwiche and Judea Pearl. On the logic of iterated belief revision. Artificial Intelligence, 89(1-2):1-29, 1997.

[FH94] André Fuhrmann and Sven Ove Hansson. A survey of multiple contractions. Journal of Logic, Language and Information, 3(1):39-75, 1994.

[Flo06] Giorgos Flouris. On Belief Change and Ontology Evolution. PhD thesis, University of Crete, 2006.

[FR13] Eduardo Fermé and Maurício Reis. Epistemic entrenchment-based multiple contractions. The Review of Symbolic Logic, 6:460-487, 2013.

[FSS03] Eduardo Fermé, Karina Saez, and Pablo Sanz. Multiple kernel contraction. Studia Logica, 73(2):183-195, 2003.

[Fuh88] André Fuhrmann. Relevant Logics, Modal Logics and Theory Change. PhD thesis, Australian National University, Camberra, 1988.

[Gar88] Peter Gardenfors. Knowledge in Flux - Modeling the Dynamics of Epstemic States. MIT Press, 1988.

[GM88] Peter Gärdenfors and David Makinson. Revisions of knowledge systems using epistemic entrenchment. In Proceedings of the 2Nd Conference on Theoretical Aspects of Reasoning About Knowledge, pages 83-95, San Francisco, CA, USA, 1988. Morgan Kaufmann Publishers Inc. 
[Gru95] Thomas R. Gruber. Toward principles for the design of ontologies used for knowledge sharing? International Journal of Human-Computer Studies, 43(5-6):907-928, 1995.

[Han91a] Sven Ove Hansson. Belief Base Dynamics. PhD thesis, Uppsala University, Uppsala, Suécia, 1991.

[Han91b] Sven Ove Hansson. Belief contraction without recovery. Studia Logica, 50(2):251-260, 1991.

[Han92] Sven Ove Hansson. A dyatic representation of belief. In Peter Gärdenfors, editor, Belief Revision, volume 29 of Lecture Notes in Cambridge Tracts in Theoretical Computer Science, pages 89-121. Cambridge University Press, New York, 1992.

[Han93] SvenOve Hansson. Reversing the levi identity. Journal of Philosophical Logic, 22(6):637669, 1993.

[Han94] Sven Ove Hansson. Kernel contraction. Journal of Symbolic Logic, 59(3):845-859, 1994.

[Han99] Sven Ove Hansson. A Textbook of Belief Dynamics. Kluwer Academic Publishers, Norwell, MA, USA, 1999.

[Hay85] P. J. Hayes. The second naive physics manifesto. In J. R. Hobbs and R. C. Moore, editors, Formal Theories of the Commonsense World, pages 1-36. Ablex, Norwood, NJ, 1985.

$\left[\mathrm{HDG}^{+}\right.$06] Matthew Horridge, Nick Drummond, John Goodwin, Alan L. Rector, Robert Stevens, and Hai Wang. The manchester owl syntax. In OWLed, volume 216, 2006.

[Hor11] Matthew Horridge. Justification based explanation in ontologies. PhD thesis, the University of Manchester, 2011.

[HPS03] I. Horrocks and P. Patel-Schneider. Reducing owl entailment to description logic satisfiability. In Proceedings of the 2nd International Semantic Web Conference (ISWC), pages 17-29, New York, USA, 2003. Springer.

[JMY04] Igor Jurisica, John Mylopoulos, and Eric Yu. Ontologies for knowledge management: An information systems perspective. Knowledge and Information Systems, 6(4):380401, 2004.

[Kal06] Aditya Kalyanpur. Debugging and repair of owl ontologies. PhD thesis, University of Maryland, College Park, MD, USA, 2006.

[KV11] Diana Kalibatiene and Olegas Vasilecas. Survey on ontology languages. In Janis Grabis and Marite Kirikova, editors, Perspectives in Business Informatics Research, volume 90 of Lecture Notes in Business Information Processing, pages 124-141. Springer Berlin Heidelberg, 2011.

[Lev77] Isaac Levi. Subjunctives, dispositions and chances. Synthese, 34(4):423-455, 1977.

[LRW12] Renato Lundberg, Márcio Ribeiro, and Renata Wassermann. A framework for empirical evaluation of belief change operators. In Leliane Barros, Marcelo Finger, Aurora Pozo, Gustavo Gimenénez-Lugo, and Marcos Castilho, editors, Advances in Artificial Intelligence - SBIA 2012, Lecture Notes in Computer Science, pages 12-21. Springer Berlin Heidelberg, 2012.

[Mak87] David Makinson. On the status of the postulate of recovery in the logic of theory change. Journal of Philosophical Logic, 16(4):383-394, 1987. 
[Nie91] Reinhard Niederée. Multiple contraction: a further case against gärdenfors' principle of recovery. In André Fuhrmann and Michael Morreau, editors, The Logic of Theory Change, volume 465 of Lecture Notes in Computer Science, pages 322-334. Springer Berlin Heidelberg, 1991.

[Rei87] Raymond Reiter. A theory of diagnosis from first principles. Artificial Intelligence, 32(1):57-95, 1987.

[Res10] Fillipe Resina. Revisão de crenças em lógicas de descrição e o plug-in para o protégé. Trabalho de Conclusão de Curso disponível em http://www.ime.usp.br/〜cef/ mac499-10/monografias/fillipe/Monografia.pdf, 2010.

[Rib10] Márcio Ribeiro. Revisão de Crenças em Lógicas de Descrição e em Outras Lógicas não Clássicas. PhD thesis, Universidade de São Paulo (USP), 2010.

[RW08] M. Ribeiro and R. Wassermann. The ontology revisor plug-in for protégé. In Proceedings of the Third Workshop on Ontologies and their Applications (WONTO), 2008.

[RW09] M. Ribeiro and R. Wassermann. Base revision for ontology debugging. Journal of Logic and Computation, 19(5):721-743, 2009.

[Was00] Renata Wassermann. An algorithm for belief revision. In Proceedings of the rth International Conference on Principles of Knowledge Representation and Reasoning (KR'00), pages 345-352, Breckenridge, Colorado, USA, abril 2000. 